\title{
AVO analysis of a weak BSR on the Hikurangi margin, New Zealand
}

Srinivasan Navalpakam Roopa

A thesis submitted for the degree of Masters in Science

at Victoria University of Wellington 



\begin{abstract}
Gas hydrates occur in deep, cold areas on the Hikurangi margin, New Zealand, generally at water depths of $\geq 600 \mathrm{~m}$ and $\leq 8^{\circ} \mathrm{C}$ temperature. In these areas elevated hydrostatic pressures and low temperatures create stable conditions for hydrate formation. The occurrence of Bottom-Simulating Reflections (BSRs) is known to indicate the Base of the Gas Hydrate Stability (BGHS) zone, below which solid hydrates cannot exist due to increasing temperatures of sediments. BSRs in most settings worldwide are thought to be largely caused by free gas at the base of the gas hydrate stability zone. They are characterized by a large negative reflection coefficient due to significant decrease in $\mathrm{P}$-wave velocity attributed to the presence of gas below the BSR.
\end{abstract}

On the Hikurangi margin however, many BSRs appear relatively weak. This study presents the results of Amplitude Variation with Offset (AVO) analysis of a weak BSR beneath Puke Ridge, a thrust ridge on the accretionary wedge east of Gisborne, North Island. Rock-physics modelling is used to interpret the findings.

The 05CM04 seismic line has been processed by preserving the amplitude and care has been taken to not bias the variation of reflectivity coefficient with offset. The zero-offset reflection coefficient or AVO intercept (A) is in the range of -0.008 to -0.015 and the AVO gradient $(\mathrm{B})$ is between -0.015 and -0.03 .

Rock-physics modelling was employed to determine the possible concentrations of gas and hydrate that can yield the observed reflection coefficients. Negligible hydrate saturation above with a patchy gas distribution of $3 \%$ saturation beneath the BSR might explain this pattern. An alternative end-member estimation of $13 \%$ saturation of hydrate in a framesupporting model with no gas beneath it could generate the observed reflection coefficient but it is geologically unlikely. Synthetic modelling reveals that the low reflectivity of the BSR could also be due to the presence of thin layers of more concentrated or evenly distributed gas but this scenario is considered to be geologically unlikely.

BSRs beneath some thrust ridges in the southern Hikurangi margin, appear as a series of clearly separated bright spots, which indicate free gas accumulations which when connected mimic the geometry of the seafloor. The most likely lithologic explanation for these high amplitude patches within weak BSRs, is the concept of segmented BSRs which is also seen in the Gulf of Mexico. The bright "gas" anomalies are inferred to correlate with sand-rich high permeability layers while the weak BSR could be due to low saturations of gas in clay-rich low permeability layers. The weak BSR beneath the Puke Ridge is indicative of low and 
patchy gas saturations in low-permeability reservoir rocks while high amplitude patches found in this area may indicate high-permeability sands that may be attractive reservoir rocks for future gas hydrate production. 


\section{Acknowledgements}

Throughout the course of this research, I have had the pleasure of knowing a number of people whose contribution in assorted ways to the research and the making of the thesis deserve special mention. It is a pleasure to convey my gratitude to them all in my humble acknowledgment.

It is difficult to overstate my gratitude to my two supervisors, Dr. Ingo Pecher and Prof. Tim Stern. I would especially like to thank Dr. Ingo Pecher for his quality supervision, advice and guidance throughout the course of my thesis. Above all, he has been very patient and understanding when the progress of my thesis was slow as I had to support myself financially by working part-time. He has provided me unflinching encouragement and support in various ways and I am indebted to him more than he knows. I gratefully acknowledge Prof. Tim Stern for his advice and valuable comments during the drafting of this thesis.

I wish to express my warm and sincere thanks to Dr. John Haines, Dunedin Research Centre, GNS Science, for taking out the time to help me with synthetic modelling.

Many thanks go in particular to Suzannah Toulmin, for her valuable advice and time in introducing me to GLOBE Claritas ${ }^{\mathrm{TM}}$. She has patiently explained and answered some unintelligent questions about seismic processing.

My special thanks go to Guy Maslen of GLOBE Claritas ${ }^{\mathrm{TM}}$ team at GNS Science, for not just answering and resolving my doubts but for also being mentor and advisor. Guy, I am grateful in every possible way for the sound advice and encouragement you gave me for my job hunt.

I would also acknowledge Damon Clarke, Dhiresh Hansaraj and Chris Town for their advice, support and providing me an opportunity to learn more about seismic data processing.

Furthermore, I would also like to thank GLOBE Claritas ${ }^{\mathrm{TM}}$ team, IT support and the librarians at GNS Science for their help and trouble-shooting some technical problems I encountered.

Where would I be without my family? My parents deserve special mention for their support and prayers. My Father, N.R.Srinivasan, is the person who has given me the courage and strength to not just be independent but be successful and achieve my dreams. He has showed me the joy of intellectual pursuit ever since I was a child. My Mother, Anuradha, is the one who raised me with her caring and gentle love. It is all your prayers that have made 
me who I am Mum. Govindan, thanks for being a supportive and caring elder brother and best friend. And also a big thanks to my lovely sister-in-law, Kavitha.

Words fail me to express my gratitude to my best friend Saurabh Jain, whose persistent confidence in me, has helped me get over extremely tough situations. I owe him for keeping me amused and sane. He has also been very helpful and has patently formatted this thesis.

I would also like to thank my friends Margaret Slessor and Jane Upton for their support and love during some tough times I have gone through this past year.

I also wish to express my gratitude to my Reiki teacher Anne Campbell for helping me learn and grow spiritually and as a person.

Finally, this thesis would not have been possible without the help provided by Syndicate Bank, India in supporting and funding my studies here in New Zealand. 


\section{Table of Contents}

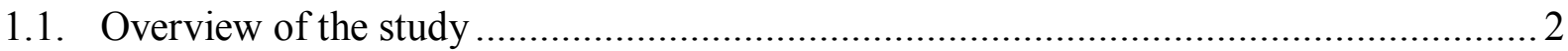

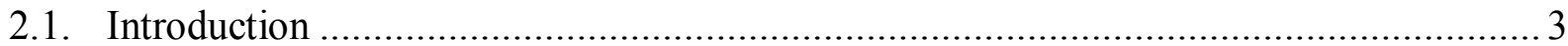

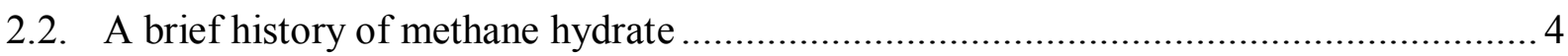

2.3. The science of methane hydrate ...................................................................... 6

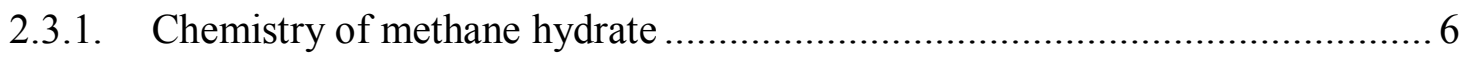

2.3.2. Necessary conditions for the formation of methane.................................. 7

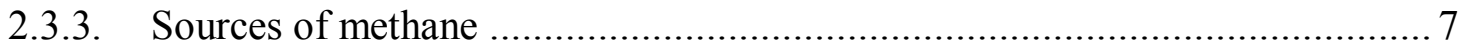

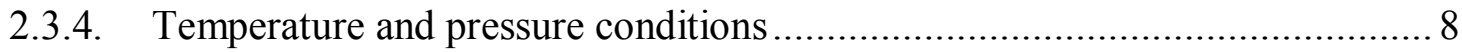

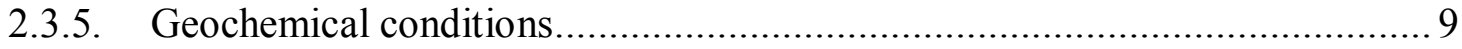

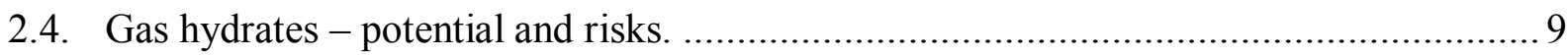

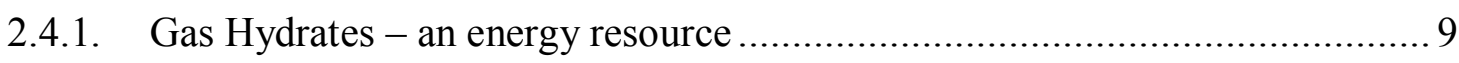

2.4.2. Gas hydrates - climate change .......................................................... 11

2.4.3. Gas Hydrates - continental slope stability and drilling hazard.................... 12

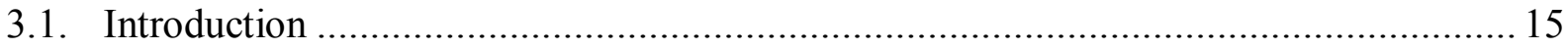

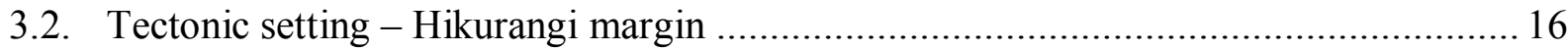

3.3. Tectonic-sediment interactions across the Hikurangi margin ................................... 18

3.3.1. The Waipaoa sediment source .................................................................. 19

3.3.2. The Waipaoa sedimentary sink: The Poverty shelf and slope ...................... 20

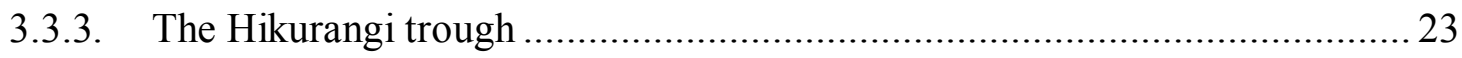

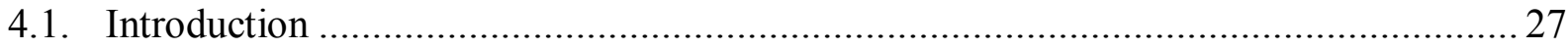

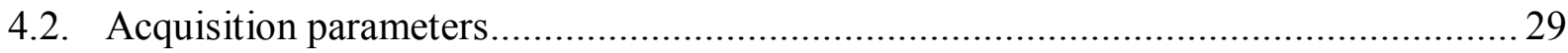

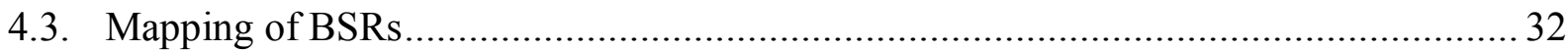

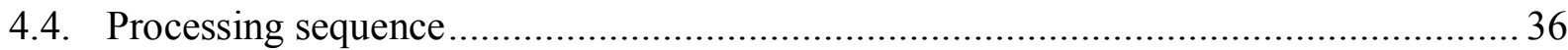

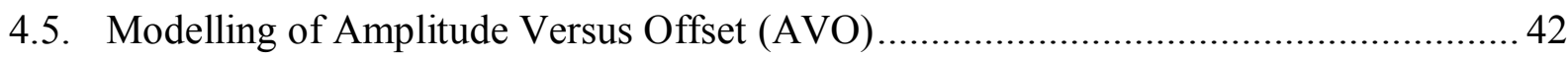

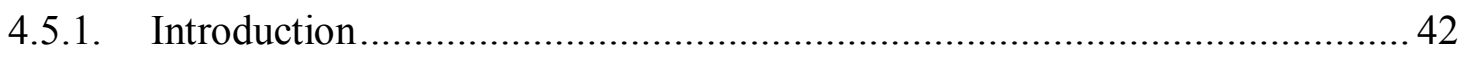

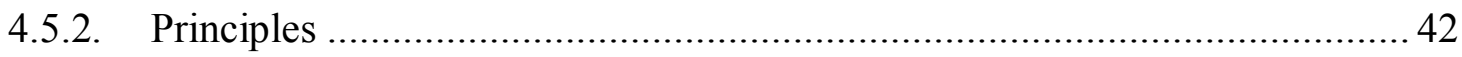

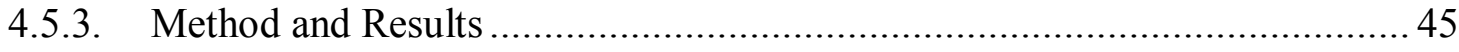

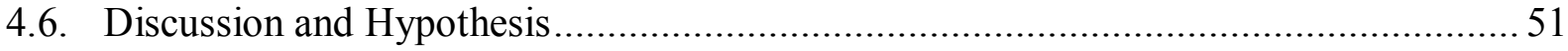

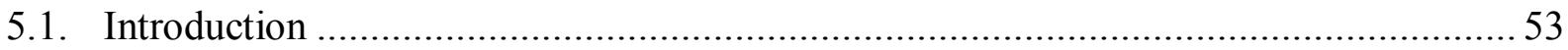

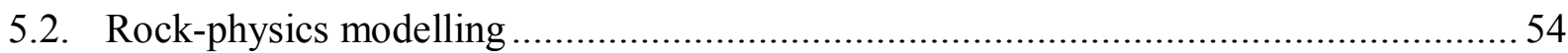

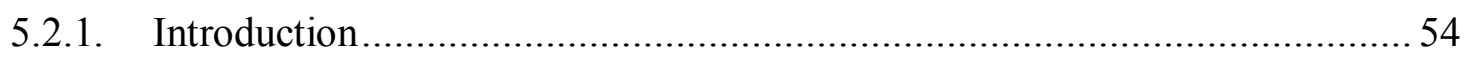

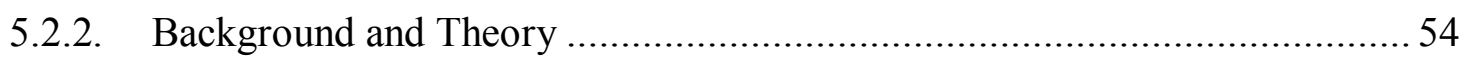




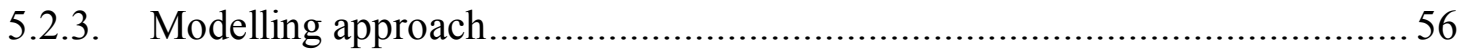

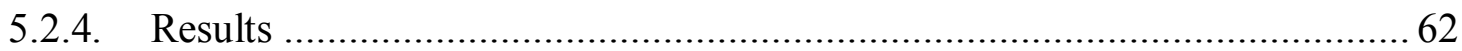

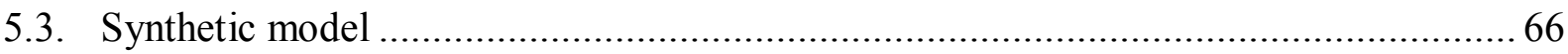

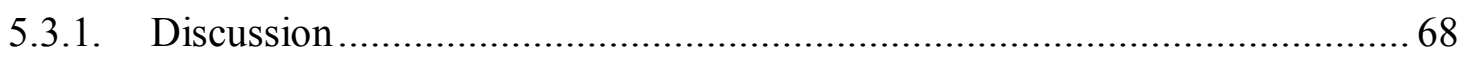

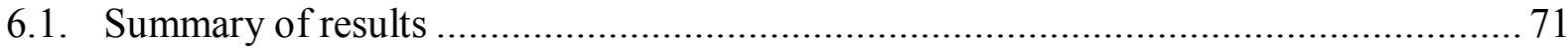

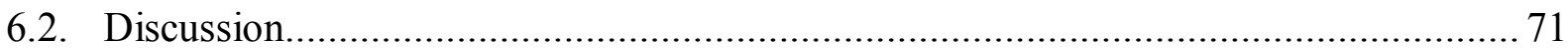

6.2.1. Effects of uncertainties in data analysis ............................................... 73

7.1. Ray tracing method to relate offset to angle of incidence ......................................... 75

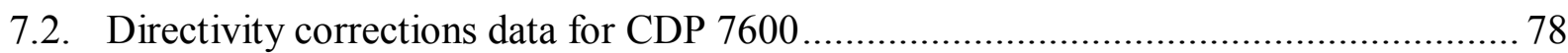

7.3. Seafloor reflection coefficients as a function of angle of incidence for CDP $7600 \ldots . . .80$

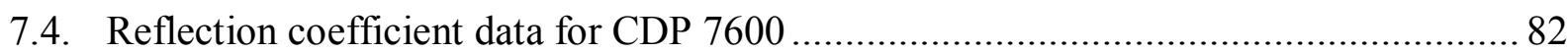

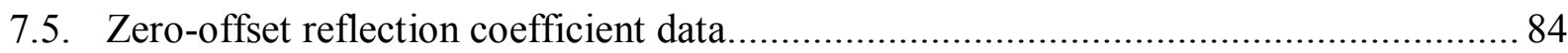

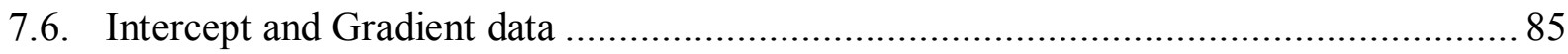

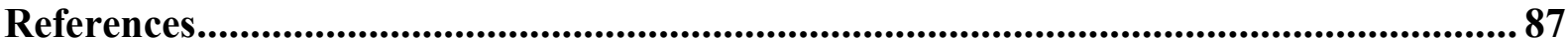




\section{List of Tables}

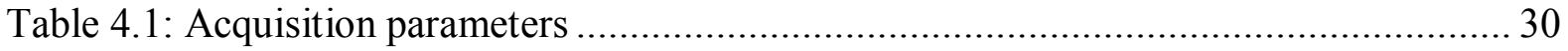

Table 5.1: Parameters used in theoretical calculations from Lee, (2002) ........................... 56

Table 5.2: Interval velocities calculated from RMS velocities for CDP's 7595-7620 …...... 62

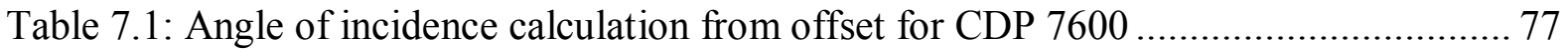

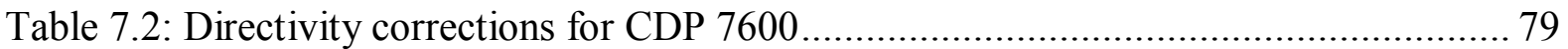

Table 7.3: Seafloor reflection coefficients calculated as a function of angle of incidence for

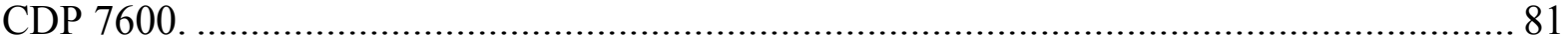

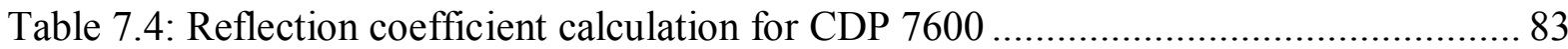

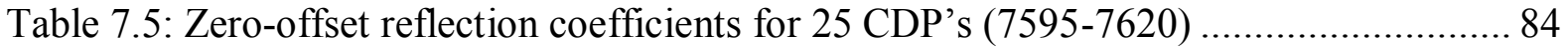

Table 7.6: Intercept, Gradient and Zero-offset reflection coefficients for 25 CDP's (75957620) 



\section{List of Figures}

Figure 2.1: A large gas hydrate plug formed in subsea hydrocarbon pipeline. Photo from Petrobras (Brazil). 5

Figure 2.2: Typical structure I of gas hydrate with water molecules linked together to form a cage trapping a gas molecule such as methane within. Image reproduced from (Suess et al., 1999)......

Figure 2.3: Phase boundary diagram showing the combination of temperature and pressure that marks the transition from a system of co-existing free methane gas to a water/ice solid methane hydrate.

Figure 2.4: Distribution of known methane hydrate accumulations (courtesy of Council of Canadian Academies (2008), based on data from Kvenvolden and Rogers (2005)).

Figure 2.5: The gas hydrate resource pyramid: The various components the total gas hydrate resource is arranged with the most readily recoverable at the top. Image reproduced from Boswell and Collett, 2006. 11

Figure 2.6: Illustration of slope failure processes and their potential to contribute to the release of large quantities of gas. Reproduced from (Maslin et al., 2010)..... 13

Figure 3.1: Plate tectonic setting of New Zealand showing relative plate motion of Pacific plate with respect to the Australian plate (Julien Bailleul et al., 2007). Bold black arrows show the relative plate motion.

Figure 3.2: Sediment plume during storm event, Waipaoa River, 7 August 2002. (Photo: D.Peacock, 2002).

Figure 3.3: Detailed bathymetric map of the Poverty margin collected during GeodyNZ project after (Collot et al., 1996b). The boxed area represents the Poverty indentation.......... 21

Figure 3.4: A: Location map of the Hikurangi margin and the Poverty Bay indentation, with major geomorphic features. The Hikurangi margin is divided into the Southern, central and Northern sectors. The Poverty bay indentation is located north of the transition from the Central to the Northern sector. Plate motion vectors (relative to the Australian Plate) are indicated by heavy black arrows from Beavan et al., 2002. GK= Gisborne Knolls, RDA = Ruotoria Debris Avalanche, NIDFB $=$ North island Dextral Fault Belt, TVZ = Taupo Volcanic Zone are names shown in all three sub-figures. B: Schematic cross-section A-B, not in scale, but shows the relationship between the subducting Pacific Plate and large scale deformation features observed in the over-riding Australian Plate. C: Swath bathymetry generated digital elevation model (DEM) and seismic lines for Poverty indentation, offshore Poverty Bay. Bold black numbers indicate modelled convergence rates $(\mathrm{mm} / \mathrm{yr}$ ) (Wallace et al., 2004). Bathymetry contours $250 \mathrm{~m}$, Grey area is a background hillshade archived SIMRAD EM 12 Dual multibeam data acquired by RV L'ATLANTE and coastal echosoundings. The red line shows the current research line in this thesis shown as figure 3.7. Image reproduced from (Pedley et al., 2010)

Figure 3.5: A) Seismic profile 05CM04. Interpretation of the profile from Pedley et al., 2010, B) Weak BSR analysed in this study, C) Enlargement of Hikurangi Trough. 25

Figure 4.1: Location map showing seismic reflection data coverage of the 05CM survey across the Hikurangi margin. Inset: Hikurangi Plateau subducts beneath the east coast of North Island, New Zealand (Australian Plate). Bathymetry is 1 minute resolution redicted bathymetry (Smith and Sandwell, 1997) with higher resolution swath bathymetry 
superimposed where available. Red vectors show the long-term estimate of convergence between the rotating east coast margin relative to the Pacific Plate in $\mathrm{mm} / \mathrm{yr}$ (Wallace et al., 2004). The bold blue line is the 05CM04 seismic line discussed in this chapter. Figure reproduced from Barker et al. (2009).

Figure 4.2: BSR distribution in the northern part of the Hikurangi margin. The BSRs mapped are shown in red.

Figure 4.3: Example of termination of gas charged layers forming a BSR as seen on line 05CM19. The solid green line marked as BSR1 is the termination of gas charged layers, while the solid blue line represents BSR2 is the residual of BSR1. 33

Figure 4.4: Example of termination of gas charged layers forming a BSR as seen on line $05 \mathrm{~cm} 23$. BSR is marked in green.

Figure 4.5: Example of termination of gas charged layers forming a BSR as seen on line $05 \mathrm{~cm} 31$. BSR is marked in green.

Figure 4.6: Example of termination of gas charged layers forming a BSR as seen on line $05 \mathrm{~cm} 04$ is represented by the thick blue line, BSR 1 . The residual BSR is represented by the thick green line, BSR2. 34

Figure 4.7: Example of a deep BSR as seen on line $05 \mathrm{~cm} 44$. 36

Figure 4.8: Variable area wiggle display of shot 2000. A) Part of raw shot gather without the Butterworth filter and B) Same part of raw shot gather with the Butterworth filter. ............ 37

Figure 4.9: Variable area wiggle plot of CDP 7400 with offsets increasing to the right....... 38

Figure 4.10: Variable density display of CDP 5000. A) Before NMO correction and B) After NMO correction with an automatic stretch mute of $80 \%$............................................... 39

Figure 4.11: RMS Velocities for CDPs in the range 2200-2400 ..................................... 40

Figure 4.12: Interval velocity converted from RMS velocities for CDPs from 2200-2400 ... 41

Figure 4.13: Variable density display of migrated stacked section of the line 05CM04 between CDPs 7300-8600. The western side of the Puke ridge has a weaker BSR in comparison to the eastern side.

Figure 4.14: Reflection and transmission at an interface between two infinite elastic half

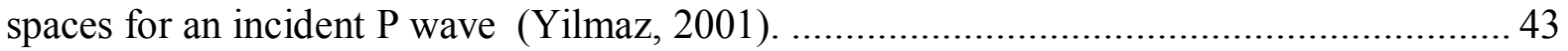

Figure 4.15: A portion of CDP 7600 showing the peak BSR amplitudes picked in red........ 45

Figure 4.16: A) Amplitude versus offset plot of CDP 7600 across the BSR. Here the amplitudes are multiplied by -1, B) Amplitude versus angle of incidence plot of CDP 7600 across the BSR. Here the amplitudes are multiplied by -1 . Offsets are converted to angle of incidence by ray tracing method.

Figure 4.17: Plot of sea floor amplitude versus angle of incidence for CDP 7600. 48

Figure 4.18: Reflection coefficient of BSR across the CDP 7600 plotted against angle of incidence. Offsets were converted to angle of incidence by tray tracing method

Figure 4.19: Plot of zero-offset or near vertical BSR reflection coefficients for CDP's 75957620 .

Figure 4.20: Plot of Intercept, Gradient and Zero-offset reflection coefficient of 25 CDP's across the BSR 
Figure 4.21: Example of a weak BSR with low reflectivity beneath Porangahau ridge on the line $05 \mathrm{~cm} 38$. Image after Pecher et al., 2010.

Figure 5.1: Distribution of gas hydrates in sediments. A) Modeling of gas hydrate free host sediment where the sediments are modeled as spheres (Hertz-Mindlin theory). Water is present in the pore space and gas hydrates are added floating in the pores, B) Gas hydrates can be disseminated in the pores without any interaction with the sediment frame, C) Gas hydrates being part of the frame and D) Gas hydrates acting as a cementing agent between grains. Image reproduced after Winters et al.,2004. 59

Figure 5.2: A) Even saturation and B) Patchy saturation. 60

Figure 5.3: Variation of P-wave velocity with increasing hydrate saturations. 62

Figure 5.4: Variation of P-wave velocity with patchy gas saturations. 63

Figure 5.5: Variation of P-wave velocity with even gas saturations. 63

Figure 5.6: Reflection coefficient versus sine square of the angle of incidence for $3 \%$ patchy gas saturation. 64

Figure 5.7: Reflection coefficient versus sine square of the angle of incidence for 5\% hydrate saturation and $2 \%$ patchy gas saturation. 65

Figure 5.8: Reflection coefficient versus sine square of the angle of incidence for $13 \%$ hydrate saturation and $0 \%$ gas saturation. 65

Figure 5.9: Illustration of a uniform layer of gas with patchy distribution of 3\% saturation. . 67 Figure 5.10: Illustration of layered gas model of patchy distribution with saturations up to $8 \%$. 68

Figure 7.1: Multilayer geometry -complex relationship with $\theta$ and offset 76 



\section{Acronyms used in this thesis}

BSR - Bottom-Simulating Reflector

BGHS - Base of Gas Hydrate Stability

AVO - Amplitude Versus Offset / Amplitude Variation with Offset

TCF - Trillion Cubic Feet

MHZ - Methane Hydrate Zone

STP - Standard Temperature and Pressure

ODP - Ocean Drilling Program

IODP - Integrated Ocean Drilling Program

NGHP - Indian National Gas Hydrate Program

NMO - Normal Move-Out

UKOOA - United Kingdom Offshore Operations Association

CDP - Common Depth Point

RMS - Root Mean Square

AVA - Amplitude Variation with Angle

CREWES - Consortium for Research in Elastic Wave Exploration Seismology

RVO - Reflection coefficient Versus Offset

EMT - Effective-Medium Theory

TWT - Two Way Travel time 


\section{CHAPTER 1}

\section{INTRODUCTION}

1.1. Overview of the study

Methane hydrate, often called fiery ice, is an ice-like clathrate substance, whereby methane molecules are held in a matrix of water molecules. This substance is stable at low temperature and high pressure conditions. $1 \mathrm{~m}^{3}$ of methane hydrate can contain up to $164 \mathrm{~m}^{3}$ of methane gas at standard temperature and pressure conditions (Kvenvolden, 1993, 1998; Sloan, 1998b). Interest in natural methane hydrate as a potential energy resource has increased steadily since the 1960s, when gas hydrate deposits were discovered in the Soviet Union (Krason, 2000). The more recent government-supported methane hydrates program in Japan (now called MH21; Tsuji et al., 2009) is expected to give helpful insights into the formation and occurrence of gas hydrates.

Methane is a greenhouse gas that has a global warming potential 20 times larger than an equivalent weight of carbon dioxide (Shine, 1991). Methane hydrates may be destabilized by changing temperature and pressure conditions due to climate change, thus resulting in positive carbon-climate feedback (Kennett et al., 2002). The dissociation of gas hydrates into gas and water also decreases seafloor stability, potentially leading to submarine slides (Dillon et al., 1998; Pecher et al., 2005).

There is no current offshore commercial production of methane hydrates, but countries including Japan, South Korea, China, India and United States have exploration programmes that expect to start in the near future (Fischer, 1999). New Zealand has gas hydrate accumulations in the Hikurangi margin offshore of the East Coast (Henrys et al., 2009; Katz, 1982; Townend, 1997). The gas hydrate province extends from about water depths of approximately $600 \mathrm{~m}$ to the Hikurangi trench (Pecher and Henrys, 2003).

The nature and width of the Hikurangi margin varies from the north to the south, with the northern end having thin trench-fill and rapid subduction of numerous seamounts resulting in little or no frontal accretion and tectonic erosion (Jean-Yves Collot et al., 1996). The majority of the historical seep sites (Lewis and Marshall, 1996) as well as the new seep sites recently detected linked to the three research cruises in 2006 and 2007, occur in the central zone of the Hikurangi margin. This part of the margin exhibits slower convergence with few seamounts, thick trench sediments and tapering frontal accretion (Greinert et al., 2010). 
The occurrence of gas hydrates is interpreted from the occurrence of Bottom Simulating Reflections (BSRs) which are negative-polarity seismic reflections that are roughly parallel to the seafloor but diverge from it as depth increases (Henrys et al., 2009; Kvenvolden, 1998). They represent the base of the gas-hydrate bearing zone and are underlain by free gas (Kvenvolden, 1998). Henrys et al., (2009) analyzed BSR strength in grids of seismic data on a large area on the Hikurangi margin and showed that BSR reflectivity is stronger (generally $<-0.2$ ) beneath structures focusing fluid flow, such as anticlines, than beneath areas of relatively flat sea floor (generally $>-0.1$ ). Crutchley, G. (2009) detected a weak BSR reflectivity (in the range of -0.02 to -0.1 ) beneath the Eastern Porangahau anticline in the southern Hikurangi margin. Wu et al., 2007 analysed a weak or a low-amplitude BSR in South China Sea and hypothesized that the although the gas hydrate saturation is high in the hydrate stability zone, the low amplitude BSR was probably caused by the scarcity of free gas below it.

This study attempts to analyse the northern portion of the central Hikurangi margin where weak BSRs are known to exist beneath anticlines and to suggest a few possible explanations for the low reflectivity of the BSR found in the study area.

\subsection{Overview of the study}

Chapter 2 describes the chemical structure of methane hydrates. It also explains the conditions required for their formation and describes the geographic environments where hydrates accumulate. Lastly, the chapter explores the role of methane hydrates as an energy resource, their role as a geohazard in submarine systems and in global climate change.

Chapter 3 outlines the tectonic setting of the Hikurangi margin and describes the tectonic and sedimentary processes that shape the landscape across the Hikurangi margin. It also describes the geology and sedimentation that might be found in the study area.

Chapter 4 describes the seismic processing techniques used to identify and characterize areas of gas hydrate provinces via BSRs. One study area is selected where the BSR is weak for developing and testing the research method. Additionally, analysis of the methane hydrate related reflections or BSRs is done in greater detail through Amplitude Versus Offset (AVO) analysis to determine reservoir characteristics and possible causes of reflections.

Chapter 5 describes some simple rock-physics models used to estimate the amount of methane gas and methane hydrate concentrations made from the observations in Chapter 4.

Chapter 6 provides a discussion of the results. 


\section{HISTORY AND SCIENCE OF NATURAL METHANE HYDRATE}

2.1. Introduction 3

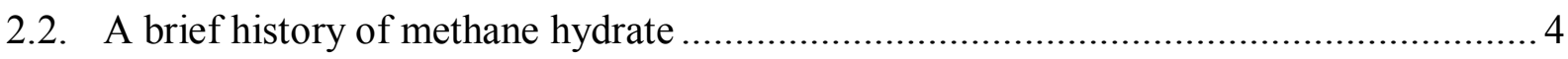

2.3. The science of methane hydrate ...................................................................... 6

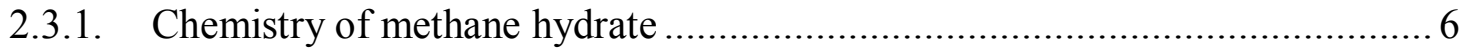

2.3.2. Necessary conditions for the formation of methane................................... 7

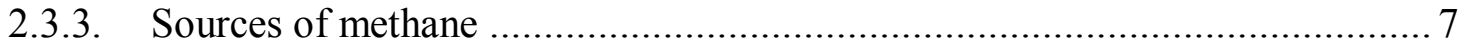

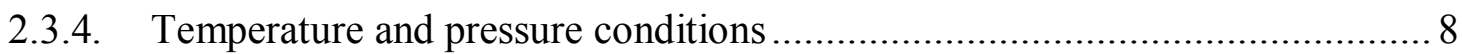

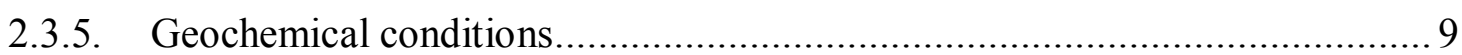

2.4. Gas hydrates - potential and risks. ................................................................. 9

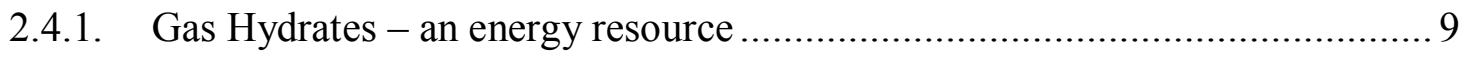

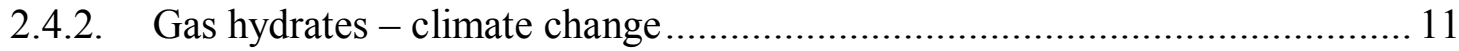

2.4.3. Gas Hydrates - continental slope stability and drilling hazard.................... 12

\subsection{Introduction}

A crystalline solid consisting of water with gas molecules in an ice-like cage structure. Water molecules form a lattice structure into which many types of gas molecules can fit.

Most gases, except hydrogen and helium, can form hydrates. $\mathrm{C}_{1}$ to $\mathrm{nC}_{5}$ hydrocarbons, $\mathrm{H}_{2} \mathrm{~S}$ and $\mathrm{CO}_{2}$ readily form hydrates at low temperature and high pressure. Heavier hydrocarbons may also enter the structure but do not form hydrates by themselves (http://www.glossary.oilfield.slb.com/Display.cfm?Term=gashydrate, last updated 12 June 2006). Hydrocarbons captured in gas hydrates come from various sources. Methane hydrates are the most abundant type in the earth's ocean. Methane is a colourless odourless gas and the simplest member of the alkane series of hydrocarbons. It is the main constituent of natural gas and a useful source of energy. Methane has been found to occur naturally in a state whereby its molecules are trapped in a cage of ice. It occurs in this state in oceans worldwide. This type of methane is called methane hydrate or "fiery ice".

Volume estimates of methane in natural gas hydrates ranges from 100,000 to 1,000,000 Trillion Cubic Feet (TCF). Keith Kvenvolden (1998) has estimated that the amount of carbon worldwide bound in gas hydrates is twice the amount of carbon found in fossil fuels. Dissociation of methane hydrate into water and methane due to shifts in climatic conditions may contribute to global warming (Kennett et al., 2002; Kvenvolden and Lorenson, 2008). 
Hence, understanding the nature, environmental role and resource potential of methane hydrates is useful.

In this chapter, section 2.2 outlines a brief history of how methane hydrates were discovered. Section 2.3 describes the chemistry of methane hydrates. It also highlights the conditions under which methane hydrates are formed and section 2.4, explores the potential and risks of methane hydrate exploration.

\subsection{A brief history of methane hydrate}

The history of gas hydrates can be traced back to Sir Humphrey Davy, who identified chlorine as an element in 1810 (Sloan,1998a). During the course of his experiment with chlorine-water mixtures, Davy and his assistant, Michael Faraday found a solid substance forming above the normal freezing point of water. Davy found that, unstable water molecules became stable with the inclusion of a guest molecule in the cavities of its structure (Sloan, 1998a). This substance was called chlorine clathrate hydrate. Throughout the 18th century, other types of clathrates with different guest molecules were discovered (Sloan, 1998a). This remained largely an academic curiosity as natural occurrences of hydrates were unknown.

Throughout the 19th century, researchers were interested in the components that formed hydrates and the conditions under which they were formed. In the 1930s Hammerschmidt discovered that hydrate-formation was responsible for clogging of high-pressure pipelines (Sloan, 1998a). Since then petroleum companies have found ways to inhibit the formation of methane in natural gas pipelines. 


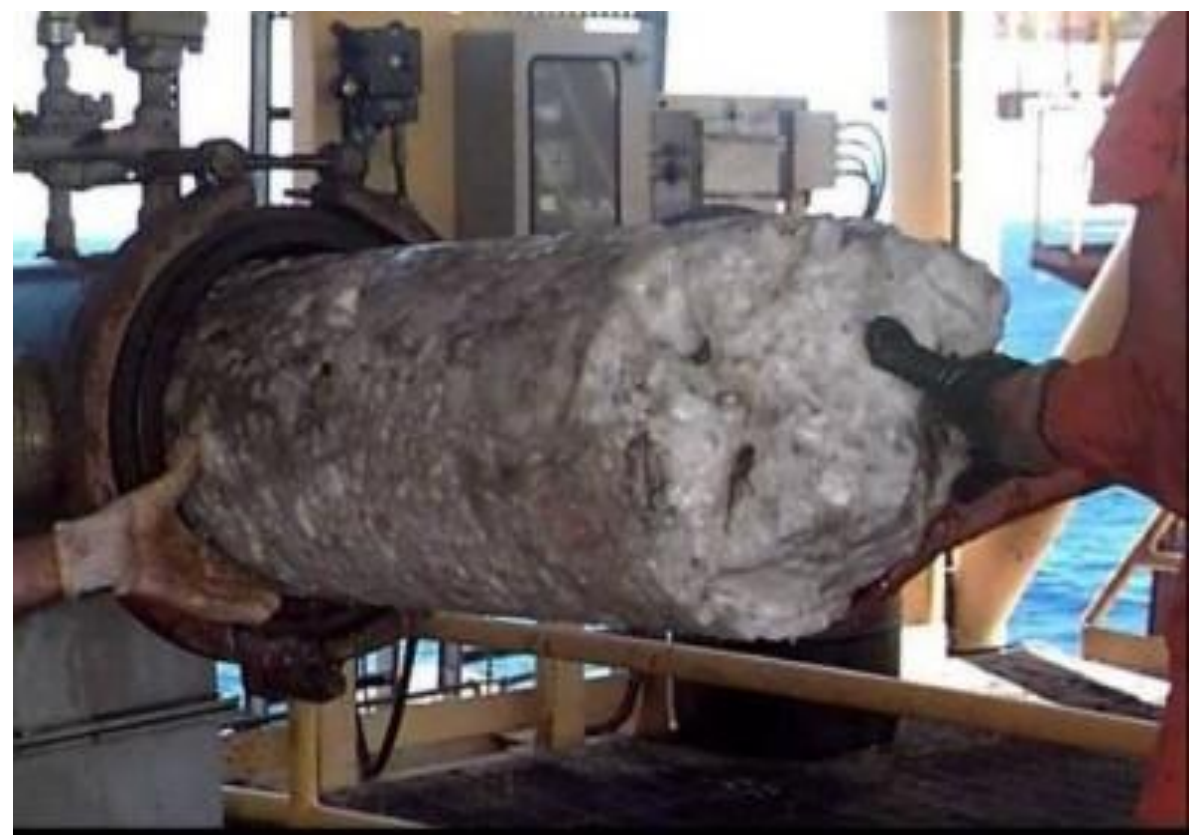

Figure 2.1: A large gas hydrate plug formed in subsea hydrocarbon pipeline. Photo from Petrobras (Brazil).

However, hydrates also occur naturally wherever there are high pressures, low temperatures and sufficient concentrations of gas and water. These conditions prevail in permafrost regions and marine sediments on continental slopes. In the 1960s, methane hydrates where discovered in sub-permafrost sediments on the north slope of Alaska (Krason, 2000).

Gas hydrate in sediments poses both new opportunities and new hazards. An enormous quantity of natural gas, likely far exceeding the global inventory of conventional fossil fuels, is locked up worldwide in hydrates (Holbrook et al., 2002). Suddenly, what had once been a curiosity and an industrial nuisance looked like it might be a significant resource. In the mid1990s, Japan and United States of America took the lead in methane hydrate research, with the goal of finding more deposits and developing ways to extract the trapped methane economically (Collett, 2009).

The standard method for determining where hydrate occurs at depth is by identifying a bottom-simulating reflection (BSR) on a seismogram. The BSR represents a reflection from the hydrate-gas phase boundary, which generates an impedance contrast because hydratebearing sediments have a higher P-wave velocity than gas-bearing sediments. The essential characteristic of the BSR is its cross-cutting relationship to strata, which identifies it as a chemical phase boundary rather than a stratigraphic reflection (Holbrook et al., 2002).

The first hydrate region globally for which the presence of gas hydrates was inferred from bottom-simulating reflections was the Hikurangi margin, east of the North island of New 
Zealand (Katz, 1981). Since then, scientists have been developing the technology required to commercially exploit large hydrate deposits around the world.

\subsection{The science of methane hydrate}

\subsubsection{Chemistry of methane hydrate}

Methane hydrate is a clathrate, a chemical substance made of one compound nested inside another. The proper name 'clathrate' was given to the class by Powell (1948) from the Latin 'clathratus' meaning to encage (Sloan, 1998b). One compound serves as a host, the other as a guest (figure 2.2). Gas hydrates generally form one of two basic crystal structures: Structure I and Structure II.

A unit cell of Structure I gas hydrate includes 46 water molecules that form two small dodecahedral voids and six large tetradecahedral voids. Structure I gas hydrates can only hold gas molecules whose diameters do not exceed 5.2 angstroms, such as methane and ethane (Sloan, 1998a). Most of the naturally occurring natural gas hydrate formations are Structure I and Structure II hydrates (Sloan, 1998a). Structure II gas hydrate unit cells consist of 16 small dodecahedral and eight large hexakaidecahedral voids formed by 136 water molecules. Structure II gas hydrates may contain gases with molecular dimensions ranging from 5.9-6.9 angstroms, such as propane and isobutane (Collett and Kuuskraa, 1998).

In a fully saturated structure I methane hydrate, one molecule of methane is present for every 5.75 molecules of water. Thus when appropriate hydrate expansion factors are considered, $1 \mathrm{~m}^{3}$ of methane hydrate can contain up to $164 \mathrm{~m}^{3}$ of methane gas at standard conditions (Hunt, 1979). 


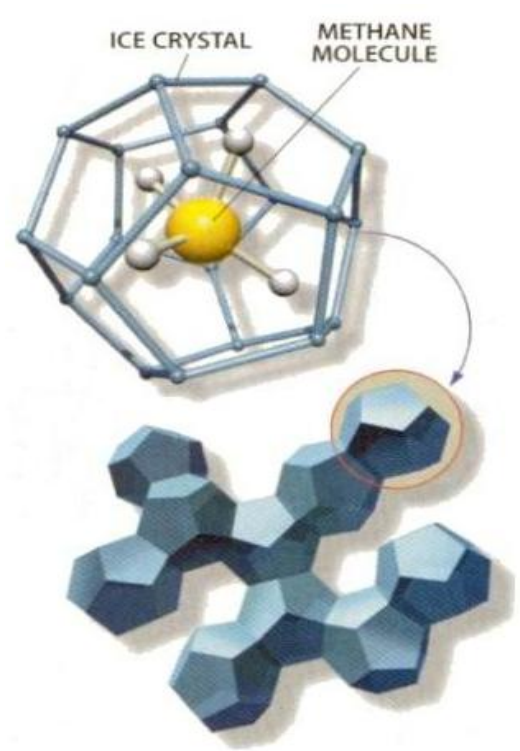

Figure 2.2: Typical structure I of gas hydrate with water molecules linked together to form a cage trapping a gas molecule such as methane within. Image reproduced from (Suess et al., 1999).

In 1987, a new hydrate structure was discovered and called structure $\mathrm{H}(\mathrm{sH})$. This structure contains 34 water molecules in its unit cell, forming a hexagonal lattice. Structure $\mathrm{H}$ hydrates are rare, but are known to exist in the Gulf of Mexico, where supplies of thermogenically-produced heavy hydrocarbons are common (Sassen, R., and MacDonald, I.R., 1994).

\subsubsection{Necessary conditions for the formation of methane}

Methane hydrates require specific conditions to form and to be stable. A precise knowledge of the conditions is necessary to predict the areas where they are formed and to also know their response to climatic conditions. The three main controls on methane hydrate formation are: a) adequate supply of water and methane, b) suitable temperature and pressure conditions and c) geochemical conditions like water salinity and presence of other gases (Sloan, 1998b).

\subsubsection{Sources of methane}

Methane is a simple molecule made up of one atom of carbon and four atoms of hydrogen $\left(\mathrm{CH}_{4}\right)$. Two distinct processes produce methane gas: biogenic and thermogenic degradation of organic matter (Sloan, 1998b).

Thermogenic methane is formed when organic matter (such as remains of plants and animals) is compressed under the earth at very high pressures for long time periods. This compression and the high temperatures within the earth break down the carbon bonds in the organic matter. At lower temperatures (shallower depths), this produces more oil relative to natural gas. At higher temperatures more natural gas is created relative to oil. 
Biogenic methane is formed when micro-organisms chemically break down organic matter (Sloan, 1998a).They are usually formed in areas which are devoid of oxygen. Formation of methane in this manner usually takes place close to the surface of the earth, and the methane produced is often lost into the atmosphere. In certain circumstances, however, this methane can be trapped underground, recoverable as natural gas.

\subsubsection{Temperature and pressure conditions}

The temperature and pressure conditions required for the formation of methane hydrates is given by the phase diagram shown in figure 2.3 .

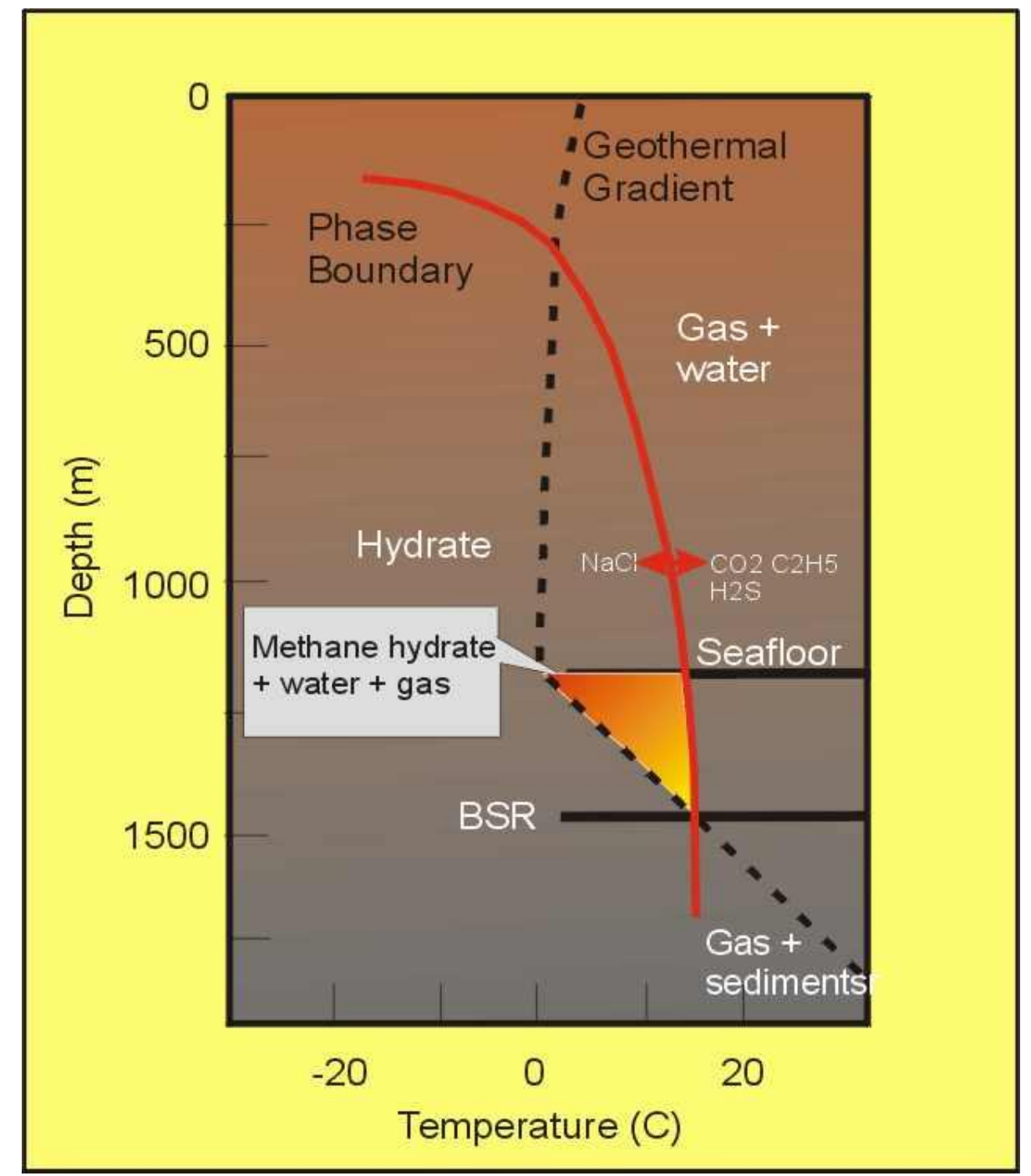

Figure 2.3: Phase boundary diagram showing the combination of temperature and pressure that marks the transition from a system of co-existing free methane gas to a water/ice solid methane hydrate.

When conditions move to the left across the hydrate-gas/water boundary, hydrate formation will occur. Moving to the right across the boundary results in the dissociation (akin 
to melting) of the hydrate structure and the release of free water and methane. The phaseboundary information suggests that the upper depth limit for methane hydrates is about $200 \mathrm{~m}$ in the continental polar regions, where surface temperatures are below $0^{0} \mathrm{C}$. In oceanic sediment, gas hydrates occur where the bottom-water temperatures approach $0^{0} \mathrm{C}$. Depth depends on water temperature, which is highly variable. Methane hydrates form in waters of about $8^{\circ} \mathrm{C}$ and $600 \mathrm{~m}$ depth on the Hikurangi Margin off New Zealand's East Coast (Pecher, I.A. and Henrys, S.A., 2003).

\subsubsection{Geochemical conditions}

In addition to temperature and pressure, the composition of water and gas also plays an important role in the formation and stability of hydrates. The methane hydrate zone (MHZ) thickness becomes thinner with increasing salinity and the stability is lowered while other gases such as carbon dioxide $\left(\mathrm{CO}_{2}\right)$ and hydrogen sulphide $\left(\mathrm{H}_{2} \mathrm{~S}\right)$ will increase the stability of the hydrate, shifting the curve to the right (http://www.netl.doe.gov/technologies/oilgas/FutureSupply/MethaneHydrates/about-hydrates/conditions.htm, last updated May 2011).

\subsection{Gas hydrates - potential and risks.}

\subsubsection{Gas Hydrates - an energy resource}

With the discovery of the Messoyakha gas field in 1970 in western Siberia, researchers began to understand the conditions required for the natural formation of gas hydrates. Because of the temperature-pressure and gas volume requirements, methane hydrates are restricted to two regions: polar and deep oceanic (Kvenvolden, 1993). Figure 2.4 displays the known and inferred occurrences of gas hydrates globally.

The early estimates of global gas hydrate resources by Trofimuk et al. (1973) were very high, of the order of $10^{17}$ to $10^{18} \mathrm{~m}^{3}$ of methane. The estimates produced in the late $1980 \mathrm{~s}$ and 1990s were based on the assumption that gas hydrates occurred along continental margins (Kvenvolden and Claypool, 1988) with the criteria that a certain amount of carbon is required for the formation of methane in hydrates (Kvenvolden and Barnard, 1983). The growing knowledge of gas hydrate distribution in sediments lead to an estimatie of $21 \times 10^{15} \mathrm{~m}^{3}$ of methane at Standard Temperature and Pressure (STP) or 10,000 Gt of methane carbon (Kvenvolden, 1999). More recent estimates (Milkov, 2004) are about 1-5 x $10^{15} \mathrm{~m}^{3}$ or 500$2500 \mathrm{Gt}$ of methane carbon. Archer et al., (2009) predict a combined total of methane hydrate and bubbles in the ocean today of between 1600 and $2000 \mathrm{Gt}$ of carbon. They found that most 
of the hydrate is concentrated in the Pacific Ocean owing to its low oxygen levels which enhance the preservation of organic carbon.

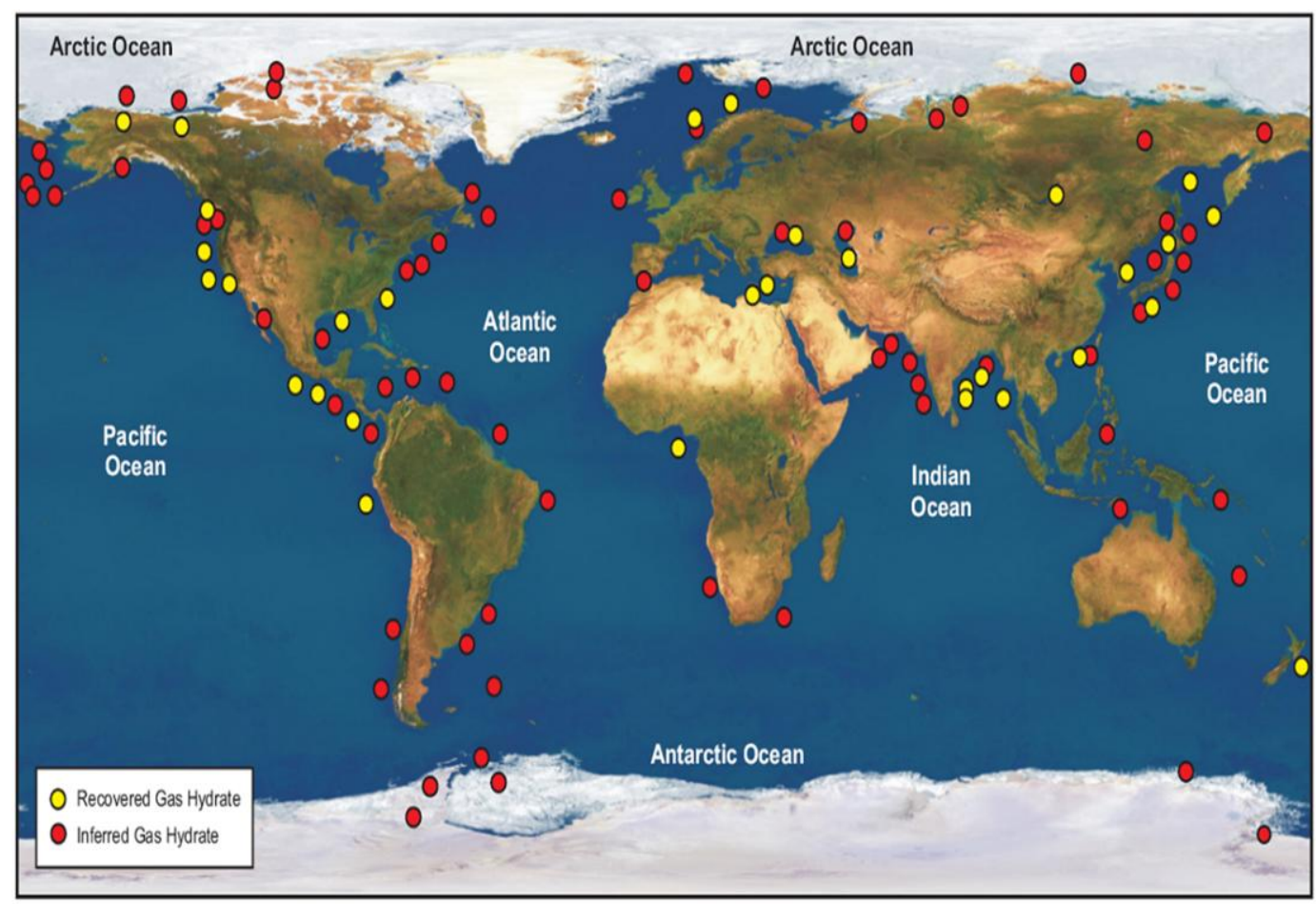

Figure 2.4: Distribution of known methane hydrate accumulations (courtesy of Council of Canadian Academies (2008), based on data from Kvenvolden and Rogers (2005)).

None of the estimates of natural gas hydrates is precise, and therefore they are all speculative to a certain extent. Finely-disseminated accumulations, typified by the Blake Ridge accumulation offshore of eastern USA (Borowski, 2004), in which large volumes of gas hydrate are relatively evenly distributed through vast volumes of fine-grained and relatively undeformed sediment at low saturations. Such resources may represent the bulk of the world's global gas hydrate in-place resource in the hundreds of tcf gas-in-place (Boswell and Collett, 2006).

One way to depict the potential size and producibility of global gas hydrate resources is by using a resource pyramid as shown in figure 2.5. The most promising gas hydrate reservoirs are arctic and marine sands. Sand reservoirs are attractive because of their permeability. Since gas hydrates form in the pore space of materials, this high permeability enables hydrates to accumulate in high concentrations. Unlike the vast but highly dispersed marine gas hydrates in mud, the sand bodies contain discrete and isolated reservoirs that are richly concentrated. Furthermore, these reservoirs are commonly buried many hundreds of meters below the sea floor and enclosed in a matrix of impermeable sediments that help to prevent 
the escape of released methane. Therefore, the most prospective gas hydrate deposits are also those that are most effectively buffered from environmental change (Boswell and Collet, 2006).

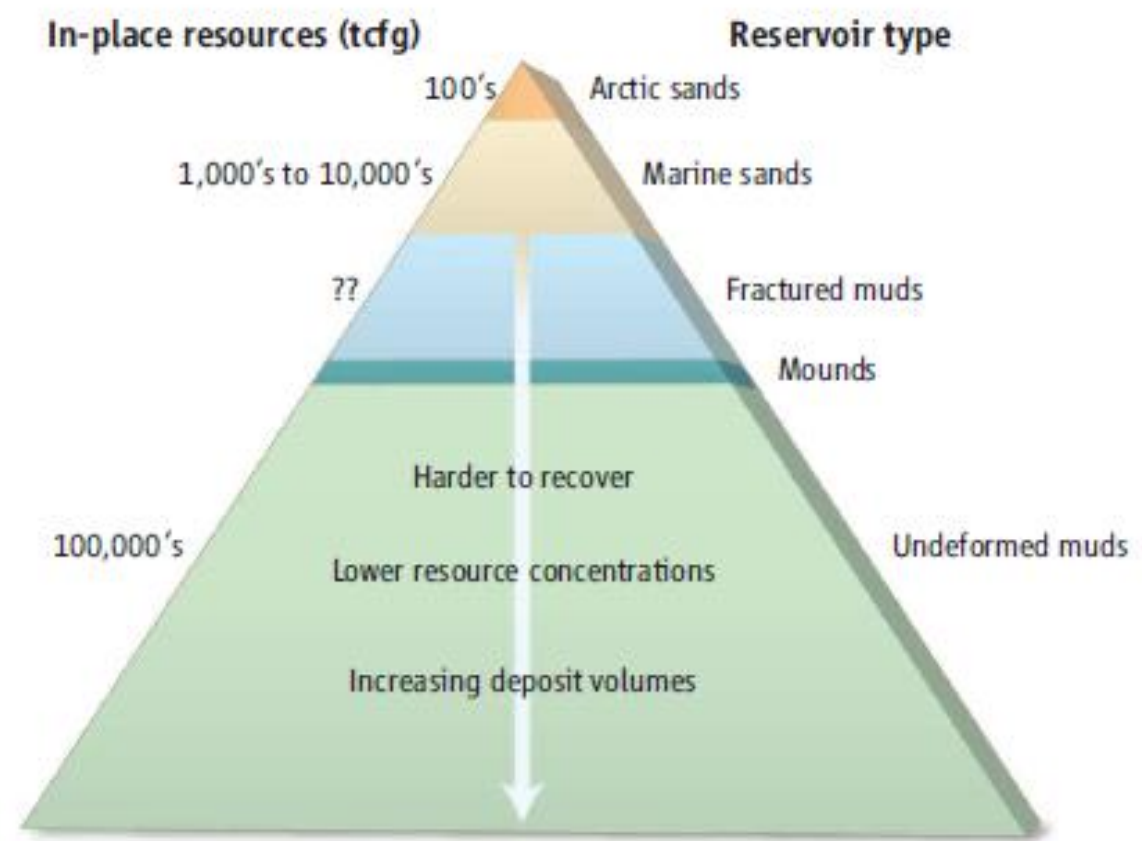

Figure 2.5: The gas hydrate resource pyramid: The various components the total gas hydrate resource is arranged with the most readily recoverable at the top. Image reproduced from Boswell and Collett, 2006.

As in the case of conventional hydrocarbon production, it is logical that gas recovery from hydrate resources will occur when there is relatively easy site access and the gas hydrate is concentrated (Collett, 2007). The 2008 U.S Geological Survey (USGS) oil and gas assessment had identified gas hydrate resources on the North Slope of Alaska as a producible resource occurring in discrete carbon traps and structures. This assessment indicates the existence of technically recoverable gas hydrate resources, that is, resources that can be discovered, developed, and produced using current technology (Collett et al., 2009).

New Zealand's methane hydrates endowment comprises of a commercially promising area of deposits - the Hikurangi margin, off the east coast of North Island. The area has a similar geologic setting as the Eastern Nankai trough in Japan, where resource assessments suggest 20 tcf of gas to be present (Fujii et al., 2008). Even if only a small part of this volume is economically recoverable, hydrates could provide the main source of gas for New Zealand for several decades (Pecher, I.A and the GHR working group, 2011).

\subsubsection{Gas hydrates - climate change}

The temperature-pressure relationship required for the stability of gas hydrates means that any major change in either of the controlling factors will tend to alter the zone of stability. 
Methane is a greenhouse gas, and discharge of large amounts of methane into the atmosphere could cause global warming. It has been well documented that methane levels in the atmosphere were lower during glacial periods than during interglacial periods (Blunier et al., 1995; Brook et al., 1996; Chapellaz et al., 1993).

Dillion \& Paull (1983) suggested that a sea level drop of 120m during the last glacial maximum reduced hydrostatic pressure and raised the lower limit of gas hydrates by $20 \mathrm{~m}$. The dissociation of gas hydrates during deglaciation has therefore been linked to the ending of ice ages during the last few millions of years (Haq, 1998; MacDonald, 1990b; Nisbet, 1990; Paull et al., 1991; Raynaud et al., 1998).

Paull et al. (1991) suggested that the occurrence of large oceanic gas hydrate reservoirs has played a role in limiting the severity of ice ages. They suggested that outer continental margin gas-hydrate deposits release methane during a falling sea level, that is, during global cooling. This decrease in pressure, causes the hydrates to dissociate. The released methane enhances global warming and triggers deglaciation (Kennett et al., 2002).

Both these scenarios are speculative because the amount of methane that can actually reach the atmosphere to affect global climate change is uncertain.

\subsubsection{Gas Hydrates - continental slope stability and drilling hazard}

When gas hydrates are present in the pore space of sedimentary structures, they tend to act as a cementing material and stabilize the seafloor. The degree of strengthening depends on the temperature, strain rate, particle size, density and cage occupancy (Winters et al., 2004).

The Rock garden ridge, east of New Zealand's North island exhibits a remarkably flat top when compared to other deformations ridges worldwide (Pecher et al., 2005). This anomalous morphology is hypothesized to be due to the presence of high concentrated deposits of gas hydrates close the sea floor of the Rock garden ridge, reducing the bulk permeability of sediments and partially trapping fluids (Ellis et al., 2009). The partial trapping of fluids can cause significant overpressuring, reducing the mechanical strength of the sediments close to the sea floor.

Changes in the temperature, pressure or salinity conditions may dissociate the hydrate into gas and water, consequently weakening the sediment strength and increasing the pore pressure. The compactness of the seafloor decreases, resulting in submarine slope failures (figure 2.6). Slides may also occur due to the melting of the top of a hydrate layer that is covered with sediment. As hydrates melt producing water and methane, they could disturb 
the sediment and promote shifting. This process can occur as a result of sea-level fall during glacial periods (Maslin et al., 2010).

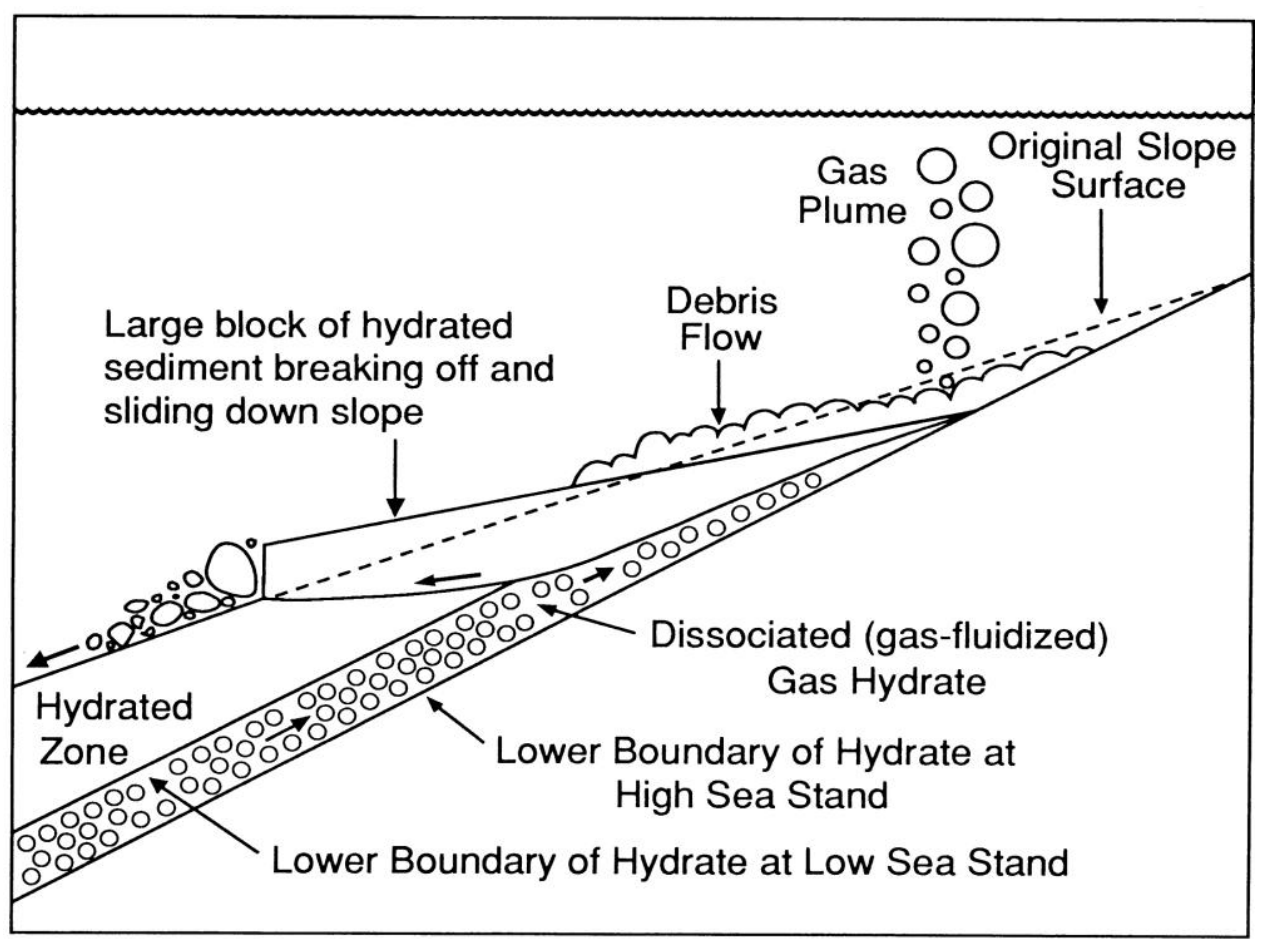

Figure 2.6: Illustration of slope failure processes and their potential to contribute to the release of large quantities of gas. Reproduced from (Maslin et al., 2010)

In addition, gas hydrates can represent a significant hazard to conventional oil and gas drilling and production operations. If the solid gas hydrates dissociate suddenly and release expanded gas during offshore drilling, they could disrupt the marine sediments and compromise pipelines and production equipment on the seafloor (Moridis and Kowalsky, 2006).

The tendency of gas hydrates to dissociate and release methane, which can be a hazard, is the same characteristic that research and development efforts strive to enhance so that methane can be produced and recovered in commercial quantities. 

CHAPTER 3

\section{TECTONIC AND SEDIMENTARY PROCESSES OPERATING ACROSS THE HIKURANGI MARGIN}

3.1. Introduction

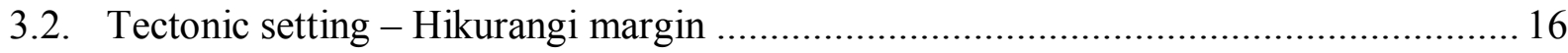

3.3. Tectonic-sediment interactions across the Hikurangi margin ................................. 18

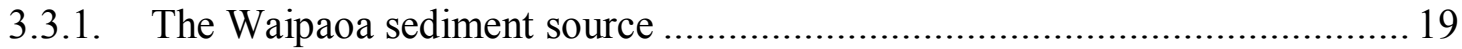

3.3.2. The Waipaoa sedimentary sink: The Poverty shelf and slope ..................... 20

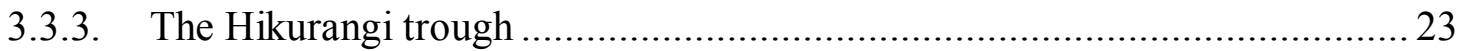

\subsection{Introduction}

Methane hydrate naturally occurs as disseminated grains and in a variety of other forms such as veins in fractures, cementing material binding sedimentary grains together and even as massive layers of pure hydrate (Tréhu et al., 2006). Although the factors controlling the type, distribution and amount of hydrate are poorly understood, porosity, permeability and degree of lithification of the enclosing medium are thought to play a primary role (Middleton, 2003). These factors are determined by the geologic environment in which the sediments occur.

Active tectonic regions provide improved prospects for marine methane hydrate accumulation. They reflect the migration of fluids and gas towards the seabed as a result of tectonic deformation, compaction, porosity reduction and dewatering of sedimentary sequences (Kvenvolden, 1993). Such tectonically active continental margins are also often characterized by small mountainous rivers carrying large sediment loads to narrow shelves (Milliman and Syvitski, 1992). The combination of high sediment yields and the prevalence of tectonically controlled accommodation on active continental margins such as that existing across the Hikurangi margin, makes it an ideal candidate to study its tectonic and sedimentary processes.

The northern part of the Hikurangi margin is characteristic of non-accretionary and tectonically eroding continental margins due to the presence of multiple seamounts (Pedley et al., 2010). The origin of the Poverty indentation, extending from the trench floor almost to the shelf edge across the entire forearc slope is attributed to a seamount impact, accompanied by canyon incision, multiple debris flows and avalanche deposits (figure 3.3).

The Waipaoa river empties into the sea south of Gisborne on the north-eastern coast of the North Island (figure 3.2). The Poverty Bay Indentation represents a section of the Hikurangi 
Margin north of the boundary between the central and northern segments and contains a large canyon system, thought to be the main pathway for sediment from the Waipaoa River to the abyssal plain.

Section 3.2 outlines the tectonic setting of the Hikurangi margin. Section 3.3 describes the tectonic and sedimentary processes that shape the landscape from the mountains to the deep ocean and outlining a brief interpretation of the current research location.

\subsection{Tectonic setting - Hikurangi margin}

The Hikurangi margin, off eastern New Zealand, is at the southern end of the TongaKermadec-Hikurangi subduction system, where convergence between the Pacific Plate and the overriding Australian Plate decreases and becomes progressively more oblique towards the south. It is notable for the lack of a bathymetric trench, its elevated accretionary prism and the shallow dip of the subducting slab (Barnes et al., 2010). The rate of convergence between the forearc and the subducting plate increases towards the north of the Hikurangi margin from about $20 \mathrm{~mm} / \mathrm{yr}$ off southern Wairarapa to nearly $47 \mathrm{~mm} / \mathrm{yr}$ off the Raukumara Peninsula (Barnes et al., 2010; Wallace et al., 2004). 


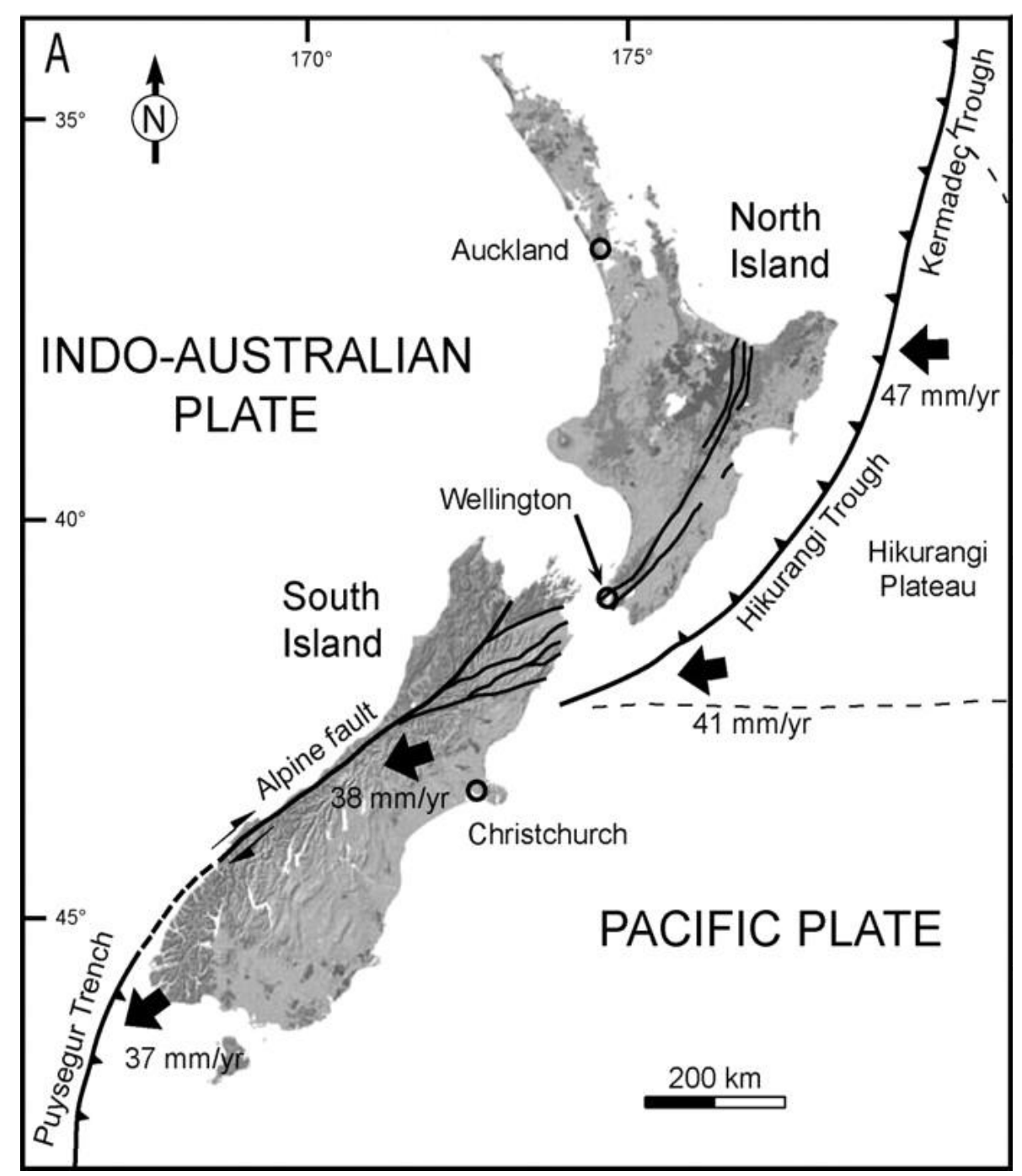

Figure 3.1: Plate tectonic setting of New Zealand showing relative plate motion of Pacific plate with respect to the Australian plate (Julien Bailleul et al., 2007). Bold black arrows show the relative plate motion. 
The Hikurangi margin is represented by a deformation zone ranging from the offshore Hikurangi trench to the back arc opening in the Taupo Volcanic Zone (TVZ) and Havre Trough. In the tectonically active forearc along the Raukumara Range, subduction-related underplating is uplifting the axial ranges at an estimated rate of $3 \mathrm{~mm} / \mathrm{yr}$ (Carter et al., 2010; Orpin, 2004; Berryman et al., 2000; Reyners and McGinty, 1999 ).

The Hikurangi trench is shallow (c. 3000m) compared to the Karmadec trench $(>9000 \mathrm{~m})$ and has a flat floor of about $720 \mathrm{~km}$ in length and less than $70 \mathrm{~km}$ wide (Lewis et al., 1998). The flat plain of the Hikurangi trench is characterised by an active turbidite channel, known as the Hikurangi channel. It funnels density currents from the south, before turning at rightangles out of the trough into the Hikurangi Plateau.

Along the Hikurangi margin, the Hikurangi Plateau on the Pacific Plate is subducted beneath thinning continental crust on the feather edge of the Australian Plate (Collot et al., 2001; Lewis and Pettinga, 1993; Walcott, 1978). Gravity models of the Hikurangi Plateau, by Davy \& Wood (1994) indicate that the crust thickens from about $10 \mathrm{~km}$ in the north to about $15 \mathrm{~km}$ adjacent to the Chatham Rise.

The northern part of the Hikurangi margin off Raukumara Peninsula is characterised by non-accretion and is a site of tectonic erosion by a seamount-studded subducting plate, whereas the central part of the margin off the Wairarapa coast is an imbricate thrust wedge dominated by accretion (Collot et al., 1996b; Davey et al., 1986; Lewis and Barnes, 1999; Lewis and Pettinga, 1993). The southern end of the margin lies in the transition zone from oblique subduction to continental strike-slip deformation (Barnes et al., 2010; Holt and Haines, 1995). The tectonic and geomorphic transition between the sediment-flooded central part of the margin and subducting seamounts in the northern part of the margin has been recently located south of the Rock Garden bank off southern Hawke Bay (Barnes et al., 2010). As a result of seamount subduction in the northern part of the margin, major collapse of the margin has been evidenced offshore Poverty Bay and offshore East Cape known as the Poverty indentation and Ruatoria indentation respectively.

\subsection{Tectonic-sediment interactions across the Hikurangi margin}

The collision margin between the Pacific Plate and the Australian Plate, offshore eastern New Zealand shows complex large scale tectonic-sediment interactions. It is characterised by high terrigenous sediment flux and uplift of Mesozoic and Tertiary sediments. The following sections describe the tectonic and sedimentary processes that shape the landscape from the mountains to the deep ocean. 


\subsubsection{The Waipaoa sediment source}

The Poverty Bay continental shelf and slope lies on the active deformation front, where the Pacific Plate is subducted obliquely beneath the Raukumara Peninsula and its eastern margin (figure 3.1). Subduction-related underplating is elevating the North Island axial ranges, including the catchment of the Waipaoa River, at an estimated rate of $3 \mathrm{~mm} / \mathrm{yr}$ (Carter et al., 2010; Orpin, 2004; Berryman et al., 2000; Reyners and McGinty, 1999). Despite a small catchment of $2205 \mathrm{~km}^{2}$, the Waipaoa River delivers $\sim 15 \mathrm{Tg}$ of sediment to the marine environment, with a bedload yield of $\sim 1 \%$ of the suspended load. The Waipaoa River contributes $7 \%$ of New Zealand's total suspended sediment yield to the Pacific Ocean (Hicks and Shankar, 2003).

The rock and sediment in the catchment range from Cretaceous to Recent with dominant lithologies being sandstone, argillite and mudstone (Mazengarb and Speden, 2000). The strongly jointed and clay-rich lithology results in highly unstable landforms, manifest as slumps, landslides and gully erosion (Berryman et al., 2000; Orpin, 2004). This leads to the high sediment yields of the Waipaoa River catchment. In addition, large floods $\left(>1900 \mathrm{~m}^{3} / \mathrm{s}\right)$ are frequent and can occur throughout the year (Reid, 1999), which can increase the annual sediment load (Brackley, 2006; Page et al., 1994a). The Waipaoa River enters Poverty Bay (figure 3.2) via hyperpycnal flow during intense weather storm events with a recurrence interval in the order of 40 years (Foster and Carter, 1997; Hicks et al., 2000).

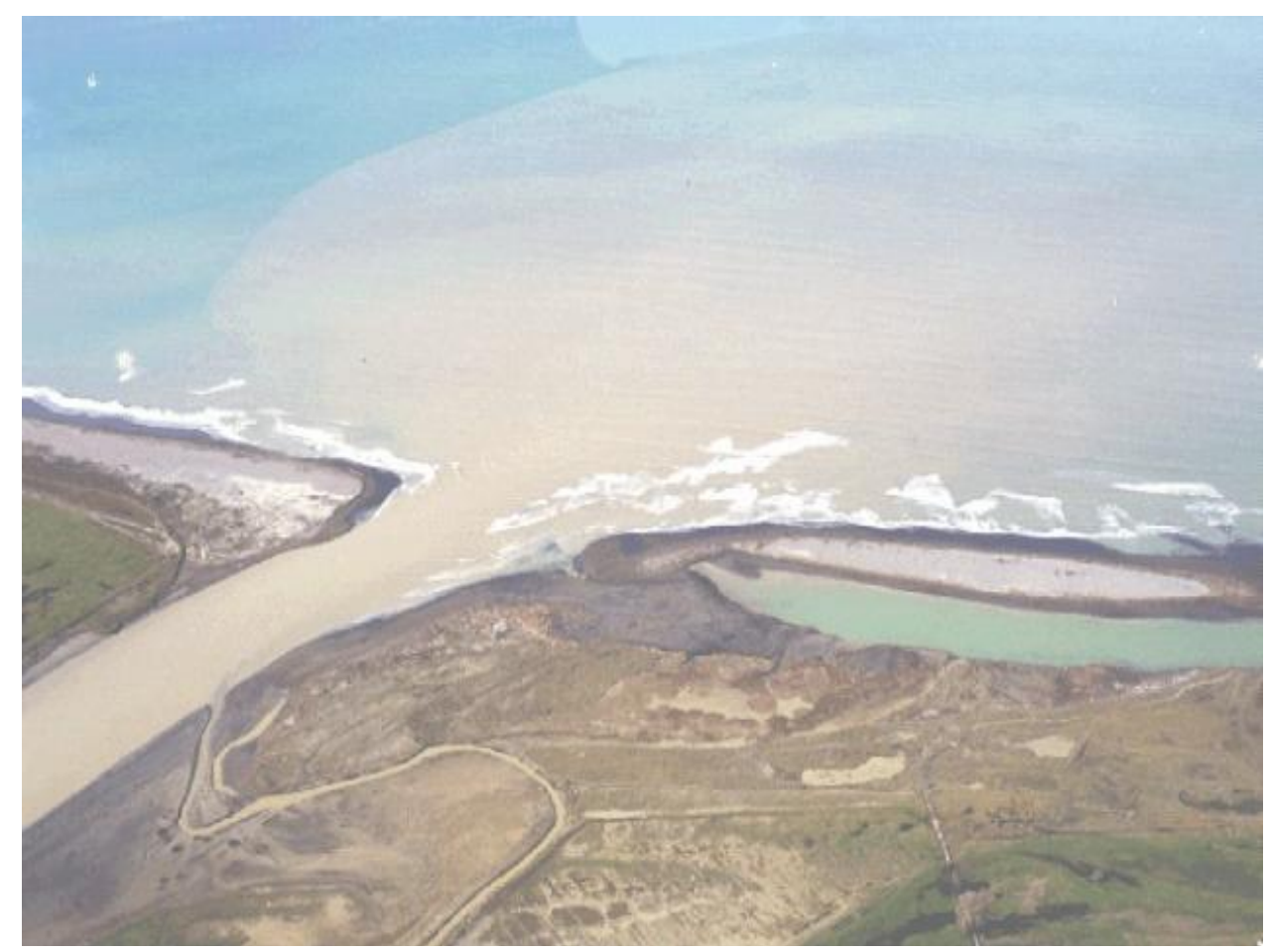

Figure 3.2: Sediment plume during storm event, Waipaoa River, 7 August 2002. (Photo: D.Peacock, 2002). 


\subsubsection{The Waipaoa sedimentary sink: The Poverty shelf and slope}

The Waipaoa continental shelf and slope lie immediately inboard of the Hikurangi subduction zone (figure 3.3). The regional structure along the northern part of the Hikurangi margin has been affected by subducting seamounts and massive avalanche deposits that collapse the margin in their wake (Lewis et al., 1998). Tectonic erosion manifest as scars, indentations and structural re-entrants and these features are observed on the Poverty margin. Imbricate thrust and folded Neogene sediments form the backstop and a narrow accretionary prism forms locally in places at the toe of the slope (Collot et al., 1996b; Lewis and Pettinga, 1993) due to accretionary tectonics and plate convergence. The over-riding long term control of the geometry of shelf deposits is tectonic shortening associated with offshore plate boundary (Gerber et al., 2010; Lewis and Pettinga, 1993; Pedley et al., 2010). Hence, two prominent subsiding depocentres have developed midshelf where $>50 \mathrm{~m}$ thickness of sediments have accumulated since the Last Glacial Maximum (Carter et al., 2010). These features rise from depths of $70 \mathrm{~m}$ to break the surface at Ariel and Penguin Rocks which collectively comprise the Ariel Bank (Foster and Carter, 1997). Ariel Bank and Lachlan Ridge are separated by the Poverty gap which has allowed sediments to escape and deposit a thick mud lobe at the head of Lachlan Ridge (Gerber et al., 2010; Orpin et al., 2006; Walsh et al., 2007).

The distribution of sediments from Poverty Bay follows the pattern of a wave-graded open shelf, where sand dominates the inner shelf and fines seaward to be predominantly muddy at $40 \mathrm{~m}$ depth (Orpin, 2004). The modern mud blanket extends to the shelf edge, except in the vicinity of the anticlines on the outer shelf where exposures of Neogene sedimentary rocks (Katz, 1975; Lewis, 1973) are surrounded by aprons of relict gravel and sand (Foster and Carter, 1997; Orpin, 2004). High modern accumulation rates ( $>0.5 \mathrm{~cm} / \mathrm{yr})$ occur on the outer shelf and in canyon heads (Alexander et al., 2006; Walsh et al., 2007). 


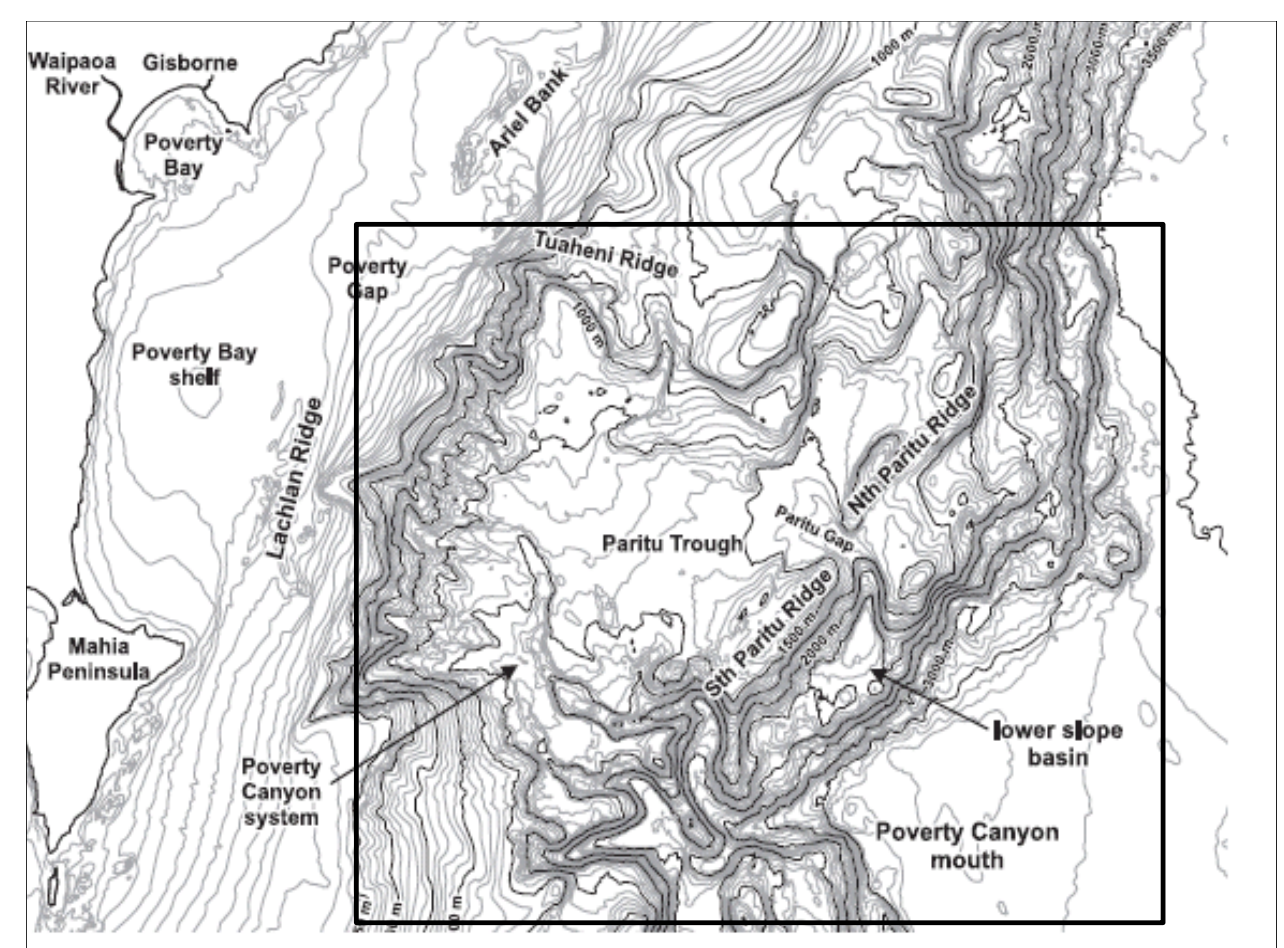

Figure 3.3: Detailed bathymetric map of the Poverty margin collected during GeodyNZ project after (Collot et al., 1996b).The boxed area represents the Poverty indentation.

The $1500 \mathrm{~km}^{2}$ Poverty indentation is a major continental margin depression extending from a re-entrant in the deformation front at the Hikurangi trough to the continental shelf (Collot et al., 1996b). The origin of the Poverty Bay Indentation is inferred to be related to multiple seamount impacts (Collot et al., 1996b; Collot et al., 2001; Davy and Wood, 1994; Lewis, 1997, 2001; Lewis et al., 1998; Lewis and Pettinga, 1993), which initiated numerous large-scale gravitational collapse structures, and multiple debris flow and avalanche deposits ranging in down-slope length from a few hundred metres to more than $40 \mathrm{~km}$. The Indentation has been simultaneously eroded by canyon systems that exhibit many of the features of incised river systems onshore, as well as capture and slump dams. The bathymetry of the Poverty indentation comprises of six basic components (in order of increasing depth) that are (i) a heavily gullied upper slope; (ii) a gently sloping mid-slope trough (Paritu trough); (iii) the Poverty Canyon system; (iv) margin parallel lower slope ridges (North and South Paritu ridges); and (vi) the largely flat expanse of the Hikurangi Trough, seamounts (e.g. Gisborne Knolls) and the Hikurangi channel seawards of the deformation front (Lewis et al., 1998; Orpin, 2004). 


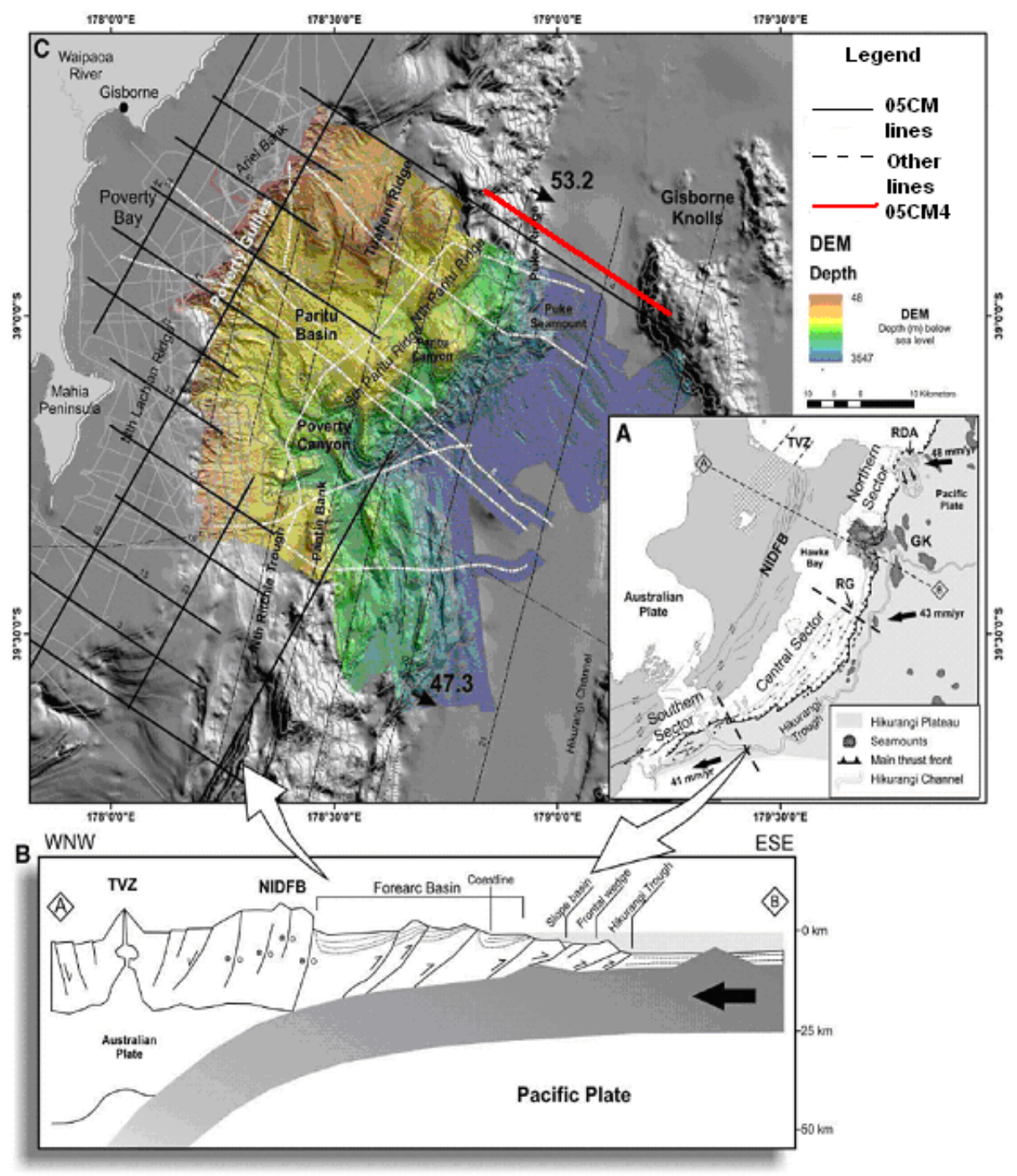

Figure 3.4: A: Location map of the Hikurangi margin and the Poverty Bay indentation, with major geomorphic features. The Hikurangi margin is divided into the Southern, central and Northern sectors. The Poverty bay indentation is located north of the transition from the Central to the Northern sector. Plate motion vectors (relative to the Australian Plate) are indicated by heavy black arrows from Beavan et al., 2002. GK= Gisborne Knolls, RDA = Ruotoria Debris Avalanche, NIDFB = North island Dextral Fault Belt, TVZ = Taupo Volcanic Zone are names shown in all three sub-figures. B: Schematic cross-section A-B, not in scale, but shows the relationship between the subducting Pacific Plate and large scale deformation features observed in the over-riding Australian Plate. C: Swath bathymetry generated digital elevation model (DEM) and seismic lines for Poverty indentation, offshore Poverty Bay. Bold black numbers indicate modelled convergence rates $(\mathrm{mm} / \mathrm{yr})$ (Wallace et al., 2004). Bathymetry contours $250 \mathrm{~m}$, Grey area is a background hillshade archived SIMRAD EM 12 Dual multibeam data acquired by RV L'ATLANTE and coastal echo-soundings. The red line shows the current research line in this thesis shown as figure 3.7. Image reproduced from (Pedley et al., 2010) 
Alexander et al., (2010) used short-lived radionuclides to show that sedimentary material is reaching the Poverty outer shelf to the upper slope and mid-slope plateau on monthly to seasonal time scales. On reaching the upper slope, mud accumulates preferentially in the heads of self-indenting canyons and in upper slope gullies at $3 \mathrm{~mm} / \mathrm{yr}$ (Carter et al., 2010). Alexander et al (2010), provide a sediment budget which indicates that $\sim 11-15 \%$ of the Waipaoa annual discharge accumulates on the continental slope. Orpin (2004) estimated from tephrostratigraphy that the average Holocene sediment mass accumulation rate in the Paritu trough is $\sim 0.05 \mathrm{~g} \mathrm{~cm}^{-2} \mathrm{yr}^{-1}$ and by applying this rate over a $450 \mathrm{~km}^{2}$ area of the slope, identified areas of hemipelagic sedimentation from echo character and speculated that the total mass accumulation on the slope is $0.2 \mathrm{Mt} / \mathrm{yr}$.

Sediment reaching the lower slope basins by mass wasting and hemipelagic settling appears to be retained in a developing frontal wedge (Orpin, 2004; Pedley et al., 2010). No vestige of a sediment fan occurs at the mouth of the Poverty canyon. Rather the seafloor is eroded and has only a thin cover of hemipelagic mud. The seaward barrier provided by the Lachlan Ridge could shut down the direct dispersal of the Waipaoa sediments into the upper slope tributaries of the Poverty canyon, indicating that the main canyon system has probably been inactive since mid-Holocene highstand (Orpin, 2004).

\subsubsection{The Hikurangi trough}

The incoming Pacific Plate east of the Poverty indentation consists of the Hikurangi Plateau and Hikurangi trough (Pedley et al., 2010) as shown in figure 3.4. Sediments from the Poverty canyon are either deposited into a significant trench floor proximal to the toe of the slope, or are conveyed away from the margin, along the Hikurangi channel (Lewis and Pantin, 2002).

The Hikurangi Plateau is dotted with numerous seamounts of Mesozoic age. Some seamounts are approaching the deformation front due to plate convergence while some others such as the Puke seamount (figure 3.4) is in the process of being subducted as identified by Pedley et al. (2010). The Gisborne Knolls is the most proximal seamount lying within $20 \mathrm{~km}$ of the deformation front it is $1500 \mathrm{~m}$ high.

Multi-channel seismic profiles of the trough in the vicinity of these seamounts reveal substantial basement relief ( 200 to $1000 \mathrm{~m}$ ) buried beneath the overlying sediments (figure 3.5). The basin depocentre consists of a horizontal succession of volcanoclastic sediments of Mesozoic age and a condensed Paleogene sequence (Davy and Wood, 1994; Pedley et al., 2010). This in turn is covered by about $1.0 \mathrm{~km}$ (1s two-way travel time) of mainly parallel- 
bedded turbidite fill that includes a conspicuous reflector free layer (Lew is et al., 1998). This reflection-free layer is interpreted as a debris flow deposit and is the southern-most extent of the Ruatoria debris avalanche deposit (Collot et al., 2001; Lewis, 1997; Lewis et al., 1998; Pedley et al., 2010). Other reflection free layers occur on the flanks of seamounts and are interpreted as debris locally derived from the steep Gisborne seamount (Pedley et al., 2010).

High sediment deposition and tectonically controlled accommodation prevail more in the central part of the Hikurangi margin than further north near the study area. Hence, the scarcity of sands coupled with fine-grained reservoir rocks with low permeability similar to indurated mudstones dredged from a submarine outcrop close to the study area may contribute to a weak BSR.

A weak bottom-simulating reflection (BSR) present beneath the Puke Ridge, a thrust ridge in the accretionary wedge (figure 3.5), is analysed for amplitude variations with offset (AVO). The weak continuous BSR beneath this ridge may be due to the focusing of rising fluids carrying methane towards the centre of the structure. Towards the western part of the seismic line, bright high amplitude patches are present which mimic the shape of the seafloor. This could be due to the presence of gas charged sands. The analysis of the weak continuous BSR beneath Puke Ridge is explained in more detail in the next chapter. 


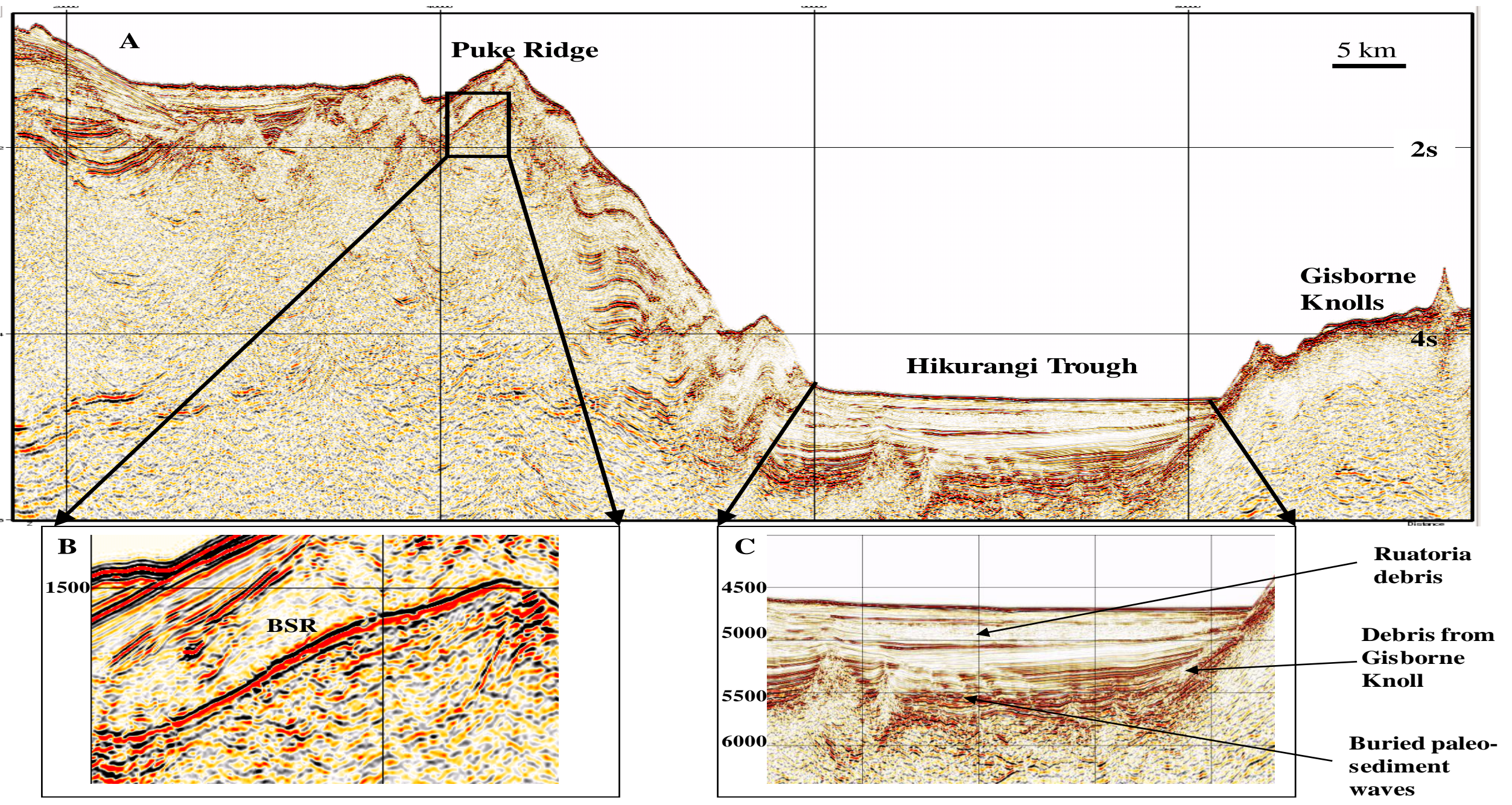

Figure 3.5: A) Seismic profile 05CM04. Interpretation of the profile from Pedley et al., 2010, B) Weak BSR analysed in this study, C) Enlargement of Hikurangi Trough. 

SEISMIC REFLECTION STUDY OF BOTTOM SIMULATING REFLECTIONS (BSRS) IN THE NORTHERN PART OF THE CENTRAL HIKURANGI MARGIN

4.1. Introduction

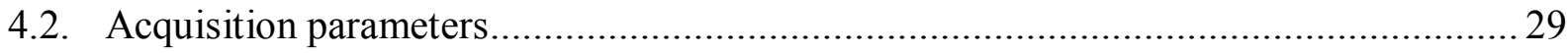

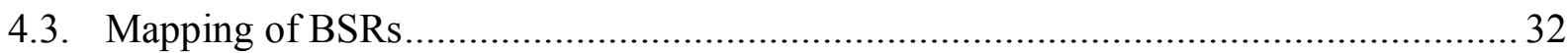

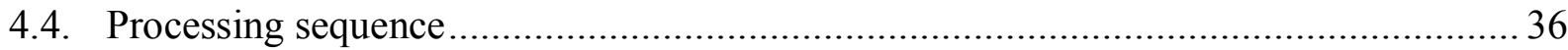

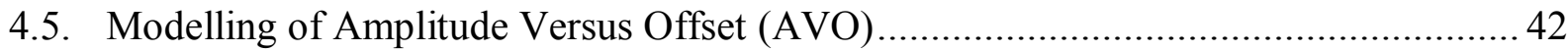

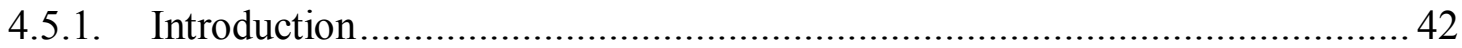

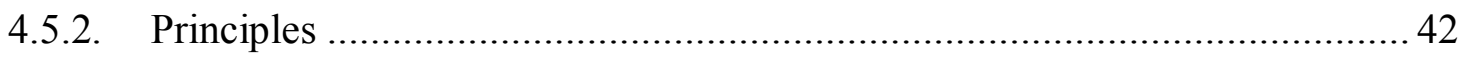

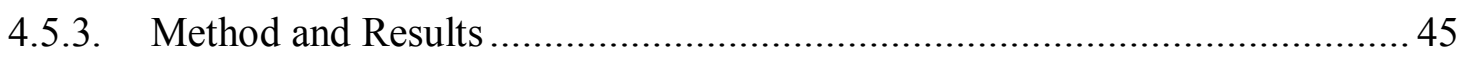

4.6. Discussion and Hypothesis ................................................................................ 51

\subsection{Introduction}

Seismic reflections that are parallel to the seafloor at sub-bottom depths of several hundred metres appear to be associated with the base of the stability field for methane hydrate (Hyndman and Spence, 1992). Such seismic reflections, called Bottom Simulating Reflections (BSRs) are perhaps the most robust geophysical marker to identify gas hydrates. BSRs are observed worldwide on seismic reflection data and are most common in accretionary sediment prisms of convergent continental margins (eg: Blake Ridge, South Carolina, Gulf of Mexico etc). Seismic investigations (Hyndman and Spence, 1992; Shipley et al., 1979) indicate that BSRs are characterized by large negative reflection coefficient and increasing sub-bottom depth with increasing water depth.

In recent years, a number of deep-sea drilling expeditions has been conducted for exploration of gas hydrates. The Ocean Drilling Program (ODP) and the Integrated Ocean Drilling Program (IODP) including ODP legs 164 (Paull et al., 1996) and 204 (Trehu et al., 2004) and IODP Expedition 311 (Riedel et al., 2006) have been conducted. Several recent industry-focused and government-led gas hydrate drilling projects such as the Japanese $\mathrm{MH}$ 21 programme (http:/www.mh21japan.gr.jp/english/, last modified March 2011), the Gulf of Mexico Joint Industry Program (http://gomhydratejip.ucsd.edu/, last modified March 2011) and the India National Gas Hydrate Program (NGHP) Expedition 01 are contributing the understanding of gas hydrates. Recent drilling projects in the offshore of China (Zhang et al., 
2007a, b; Wu et al., 2008; Yang et al., 2008) and South Korea (Park, 2008; Park et al., 2008) have also helped in understanding gas hydrate environments.

Where sediments have been sampled directly, gas hydrates have been identified from other characteristics such as positive resistivity (Pearson et al., 1986), negative thermal conductivity (Stoll and Bryan, 1979) and negative pore water chlorinity (Hesse, 2003). Although remote identification of hydrates using resistivity methods is promising, 3D seismic observations and reflectivity methods provide the main constraint on gas hydrate formation and distribution (Dai et al., 2004).

The exact formation of the hydrate and its distribution are still unknown and different models have been proposed to explain the origin of BSRs. Rice \& Claypool (1981) suggested that methane in most hydrates is generated microbially in situ. Other theories include upward methane transport with hydrate formed either from bubbles driven by buoyancy into the Gas Hydrate Stability Zone (GHSZ) (Minshull et al., 1994; Brewer et al., 1997; Liu and Flemmings, 2007), and methane carried in solution and precipitated because of changes in solubility (Buffett and Zatsepina, 1999; Xu and Ruppel, 1999; Collet et al., 2009).

Based on the ubiquitous observation of BSRs on multi-channel seismic data, gas hydrate deposits are inferred to be present in the Hikurangi margin, covering an area greater than $50,000 \mathrm{~km}^{2}$. BSRs attributable to gas hydrates are negative polarity reflections that cut across stratigraphic horizons. The negative polarity of the BSR indicates that the reflection results from a decrease in seismic velocity and/or density with depth. This occurs due to the presence of gas charged sediments underlying hydrate-saturated sediments above.

Henrys et al., (2009) in a large-scale study of BSR strength on the southern Hikurangi margin, showed that the BSR reflectivity was significantly stronger (i.e. $<-0.2$, in reference to a weaker BSR reflection which has reflectivity $<0.1$ ) beneath anticlines or structures that promote fluid flow. Crutchley et al., 2010 found that the intensity of the BSR was the greatest close to the centre of the anticline, weakening markedly to about -0.023 towards the limbs of Eastern Porangahau Ridge in the Hikurangi margin. A strong link between gas hydrates and fluid flow is proposed for the margin, with the highest gas hydrate accumulations inferred to exist in close proximity to these types of structures (Crutchley et al., 2010).

This chapter presents the results of a multi-channel seismic reflection study of a weak BSR beneath Puke Ridge, an accretionary ridge in the continental slope of the northern part of the central Hikurangi margin. Two types of analysis are discussed in this chapter: (1) 
analysis of BSR zero-offset reflection coefficients and (2) the nature of BSR from amplitudeversus-offset (AVO) analysis.

Section 4.2 outlines the acquisition parameters for the 05CM04 line. BSRs have been picked interactively for 17 lines in the $05 \mathrm{CM}$ data and is described in section 4.3 . Section 4.4 describes the processing sequence adopted for amplitude-versus-offset (AVO) analysis of the line 05CM04. Section 4.5 reviews the principles of AVO analysis and outlines the critical formulae involved. The application and technique of AVO analysis, together with the results are described in section 4.5.3. These results are discussed in section 4.6.

\subsection{Acquisition parameters}

The $05 \mathrm{CM}$ survey is a regional grid of $2 \mathrm{D}$ seismic reflection data acquired in 2005 . The 05CM survey was undertaken offshore of the east coast. Although primarily intended to identify hydrocarbon plays, the survey was also designed to be capable of seismically imaging the subducted Pacific Plate, using a 12-km-long streamer and $12 \mathrm{~s}$ record lengths. The survey was conducted by New Zealand's Ministry of Economic Development. The survey has numerous dip-oriented profiles across the subduction system (figure 4.1).

Seismic reflection data were acquired by Multiwave Geophysical aboard MV Pacific Titan. A source array of Bolt 1500 and 1900 airguns was used in combination with single airguns and clusters. It had a total volume of 4140 cubic inches (cu.in.) and operated at 2000 psi. Shot intervals were at $37.5 \mathrm{~m}$ with a record length of $12 \mathrm{~s}$ for the line 05CM04 processed in this study. The streamer specification was a $12 \mathrm{~km}$ long active section comprising 960 channels $(12.5 \mathrm{~m}$ channel spacing). A recording filter with a high-cut frequency of $200 \mathrm{~Hz}$ was applied upon acquisition of the data at $37 \mathrm{~dB} /$ Octave. The data was acquired at a sample rate of $2 \mathrm{~ms}$ with a Nyquist frequency of $250 \mathrm{~Hz}$. Data have been processed using the seismic software GLOBE Claritas ${ }^{\mathrm{TM}}$. 


\begin{tabular}{|c|c|}
\hline Source array & 1500 Bolt \\
\hline Total volume & 4140 cubic inches (cu.in.) \\
\hline Tow depth of source & $7 \mathrm{~m}$ \\
\hline Tow depth of streamer & $37.5 \mathrm{~m}$ \\
\hline Shot spacing & $12000 \mathrm{~m}$ \\
\hline Streamer Length & $12.5 \mathrm{~m}$ \\
\hline Group spacing & 960 \\
\hline Number of channels & $166 \mathrm{~m}$ \\
\hline Centre of source to centre of near group & \\
\hline
\end{tabular}

Table 4.1: Acquisition parameters 


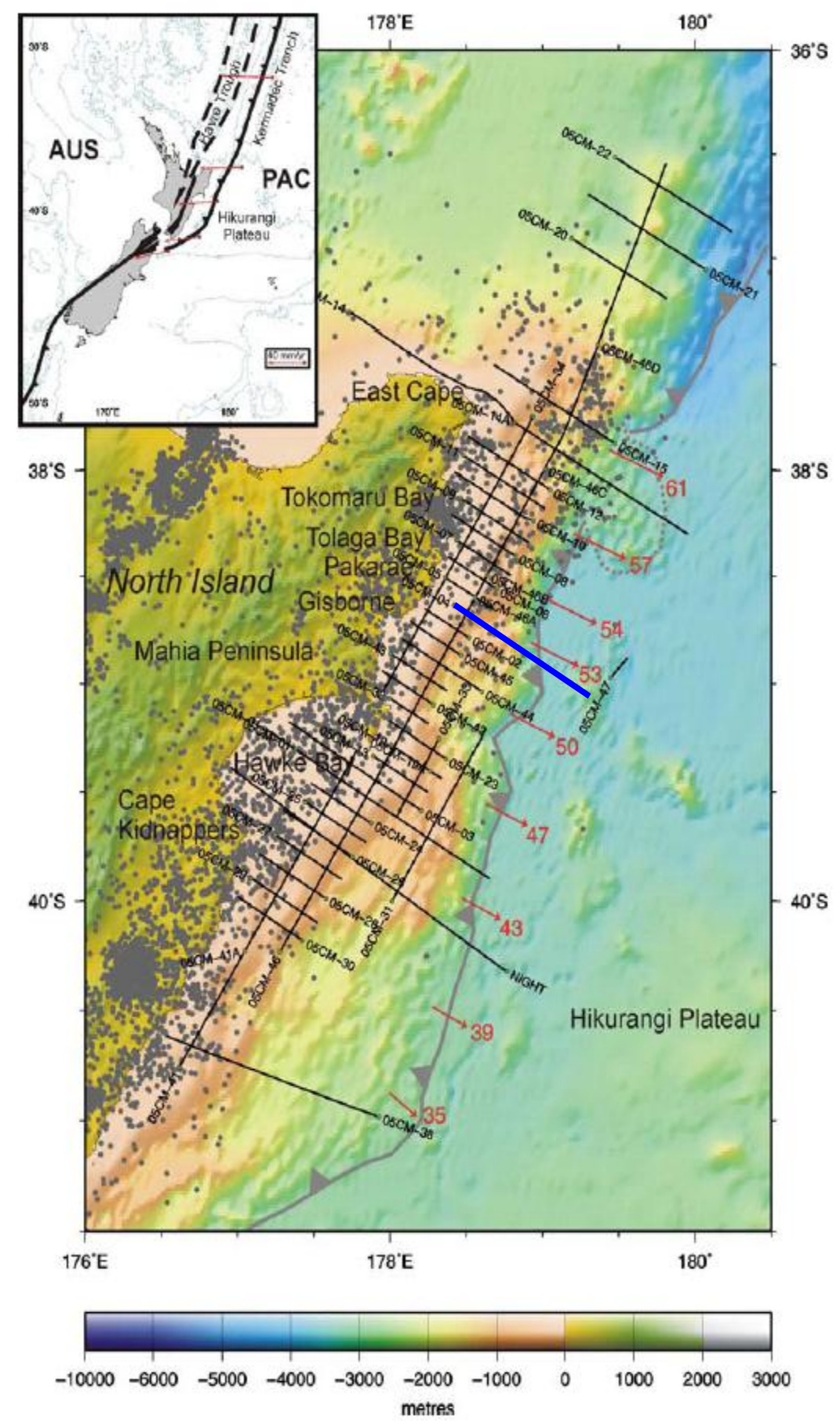

Figure 4.1: Location map showing seismic reflection data coverage of the $05 \mathrm{CM}$ survey across the Hikurangi margin. Inset: Hikurangi Plateau subducts beneath the east coast of North Island, New Zealand (Australian Plate). Bathymetry is 1 minute resolution redicted bathymetry (Smith and Sandwell, 1997) with higher resolution swath bathymetry superimposed where available. Red vectors show the long-term estimate of convergence between the rotating east coast margin relative to the Pacific Plate in $\mathrm{mm} / \mathrm{yr}$ (Wallace et al., 2004). The bold blue line is the 05CM04 seismic line discussed in this chapter. Figure reproduced from Barker et al. (2009). 


\subsection{Mapping of BSRs}

Seventeen seismic lines were mapped for BSRs using Opendtect ${ }^{\mathrm{TM}}$. The line 05CM04 has been processed for AVO analysis of a weak BSR in this study.

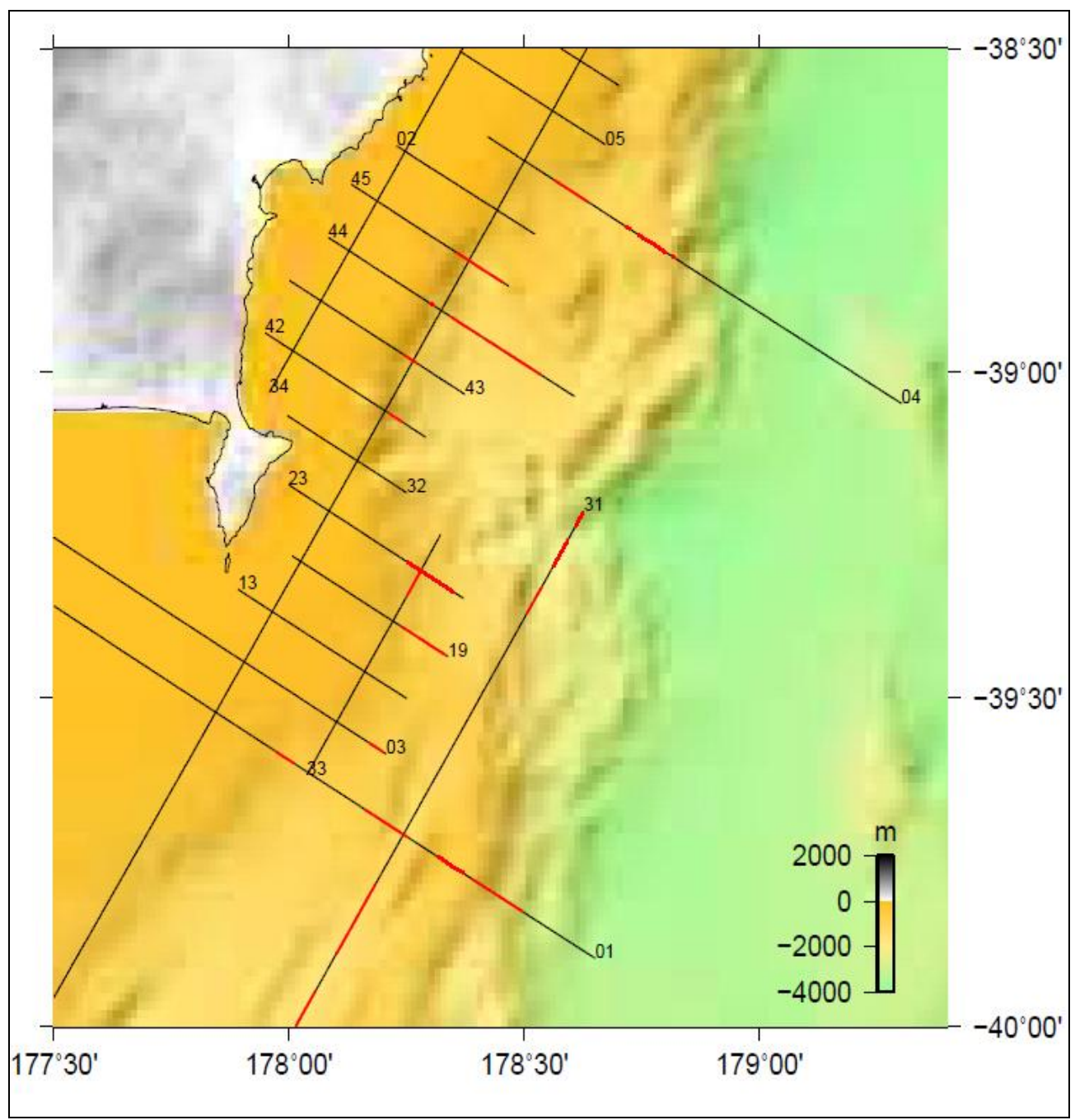

Figure 4.2: BSR distribution in the northern part of the Hikurangi margin. The BSRs mapped are shown in red.

The following figures show a few examples of the type of BSRs found in this part of the margin. 


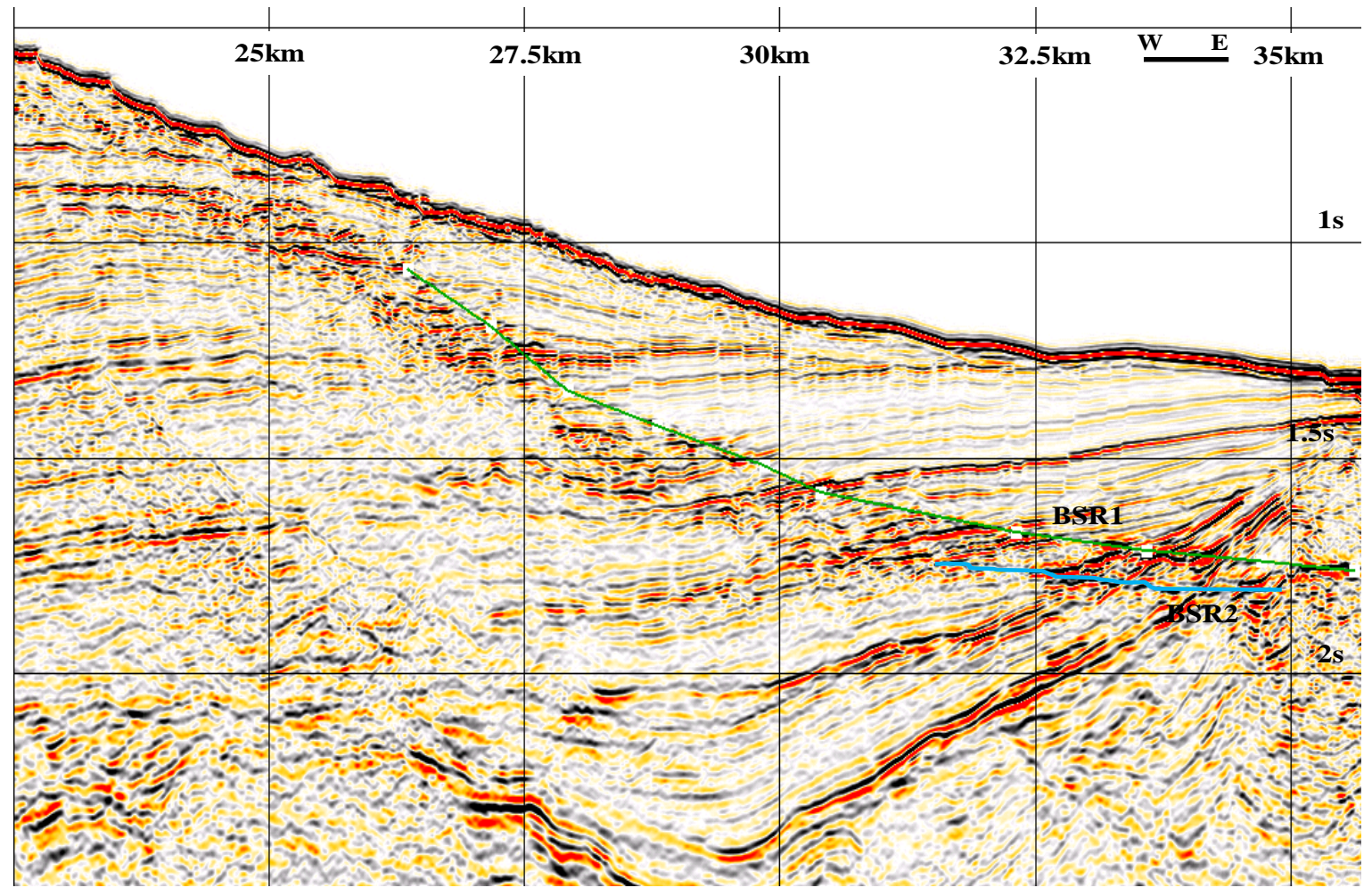

Figure 4.3: Example of termination of gas charged layers forming a BSR as seen on line 05CM19. The solid green line marked as BSR1 is the termination of gas charged layers, while the solid blue line represents BSR2 is the residual of BSR1.

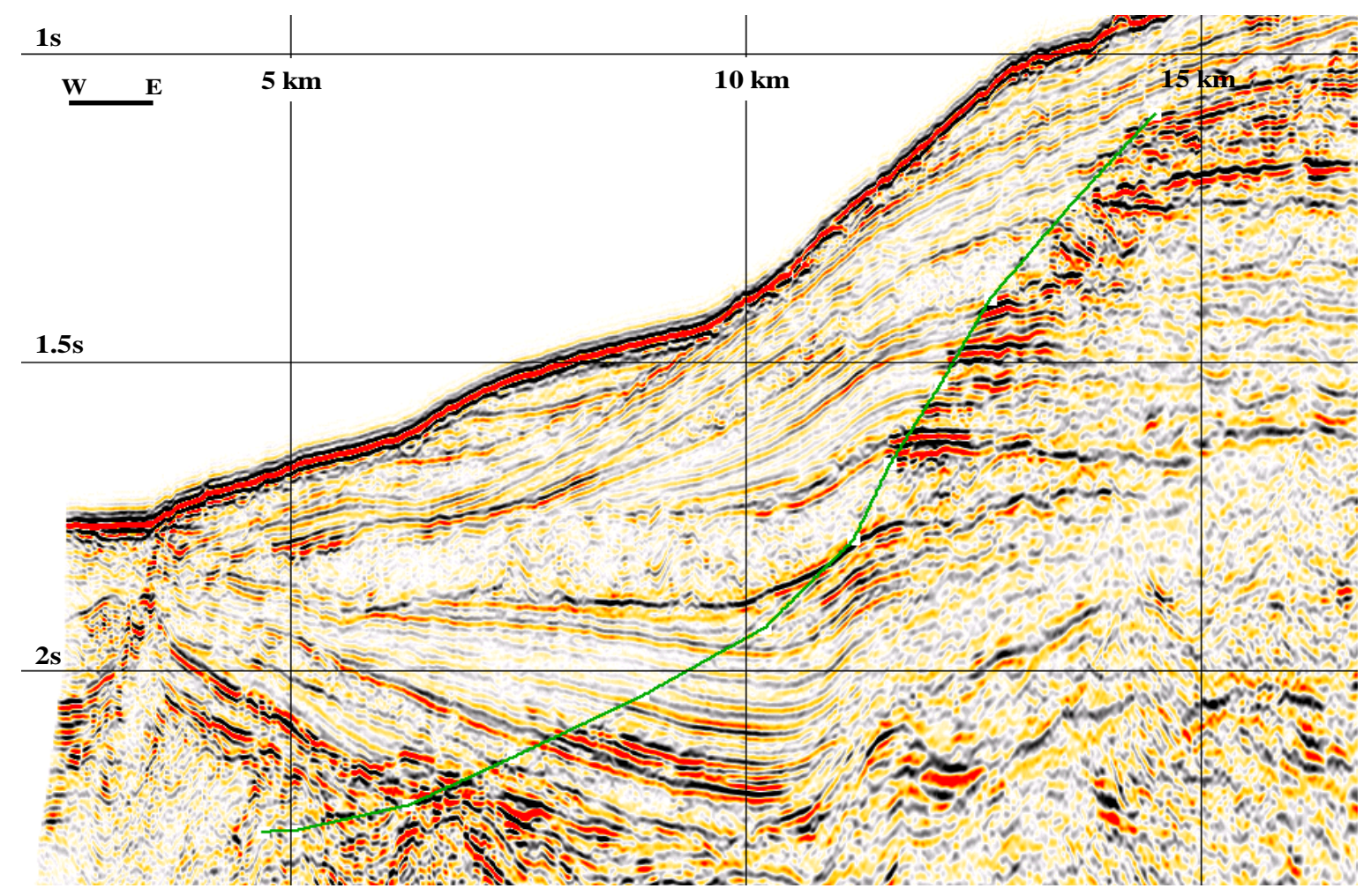

Figure 4.4: Example of termination of gas charged layers forming a BSR as seen on line 05cm23. BSR is marked in green. 


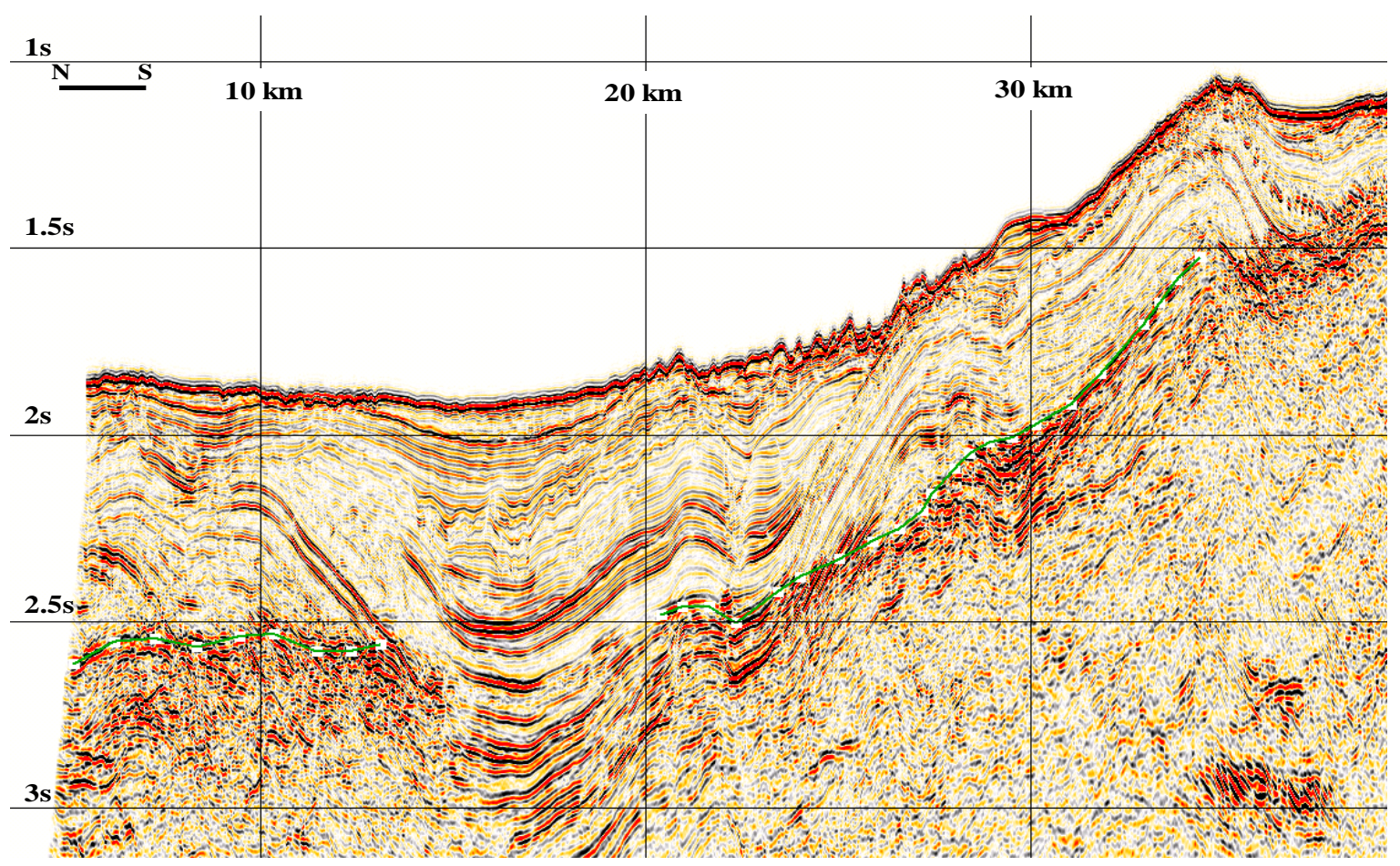

Figure 4.5: Example of termination of gas charged layers forming a BSR as seen on line $05 \mathrm{~cm} 31$. BSR is marked in green.

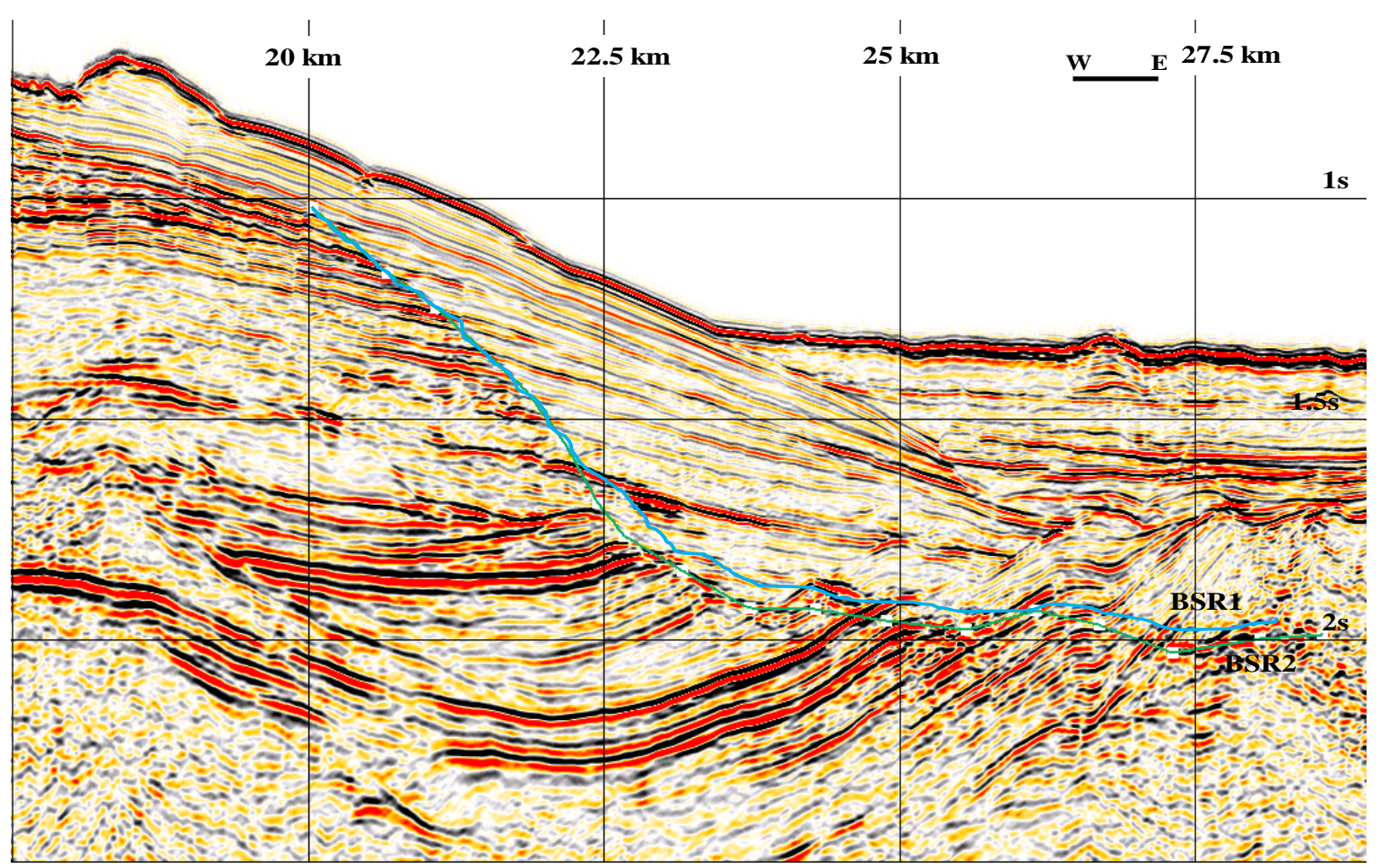

Figure 4.6: Example of termination of gas charged layers forming a BSR as seen on line $05 \mathrm{~cm} 04$ is represented by the thick blue line, BSR1. The residual BSR is represented by the thick green line, BSR2. 
Depending on the concentration of hydrate, enhanced or suppressed seismic reflectance is observed (Holbrook et al., 2002). At high hydrate saturation hydrate-bearing layers can have velocities greater than the surrounding sediments, thus generating positive reflectance. The accumulation of free gas below the Gas Hydrate Stability Zone (GHSZ) increases the impedance contrast between sedimentary layers as P-wave velocity decreases strongly in the presence of small quantities of free gas. Termination of enhanced reflections also locally forms a BSR in uplifted sediments as seen in figures 4.3 and 4.4.

The reflectivity seen at and beneath the BSRs (figures 4.3, 4.4, 4.5 and 4.6) indicates layers containing trapped gas in pore fluids. The numerous reflections below the BSR indicate that gas is trapped between stratigraphic layers, probably by differences in permeability between sand-rich and clay-rich layers. This kind of 'segmented BSRs' are also found in the Gulf of Mexico (Shedd et al.,2009).

In figure 4.3 and 4.6, a double BSR is observed. The upper BSR (BSR1) is the active methane hydrate BSR is traced for approximately $9 \mathrm{~km}$ in figure 4.3 and $17 \mathrm{~km}$ in figure 4.6. The lower BSR (BSR2) is a residual of BSR1. This could be due to the migration of the base of the methane hydrate stability zone from the lower BSR to the upper one. Pressure and temperature changes can displace the hydrate stability field. Hence it is hypothesized that this could be because of 'thermal blanketing' from high sedimentation rates in this part of the margin, where low thermal conductivity sediments at the surface substantially increases heat retention generating elevated temperatures within underlying sediments. 


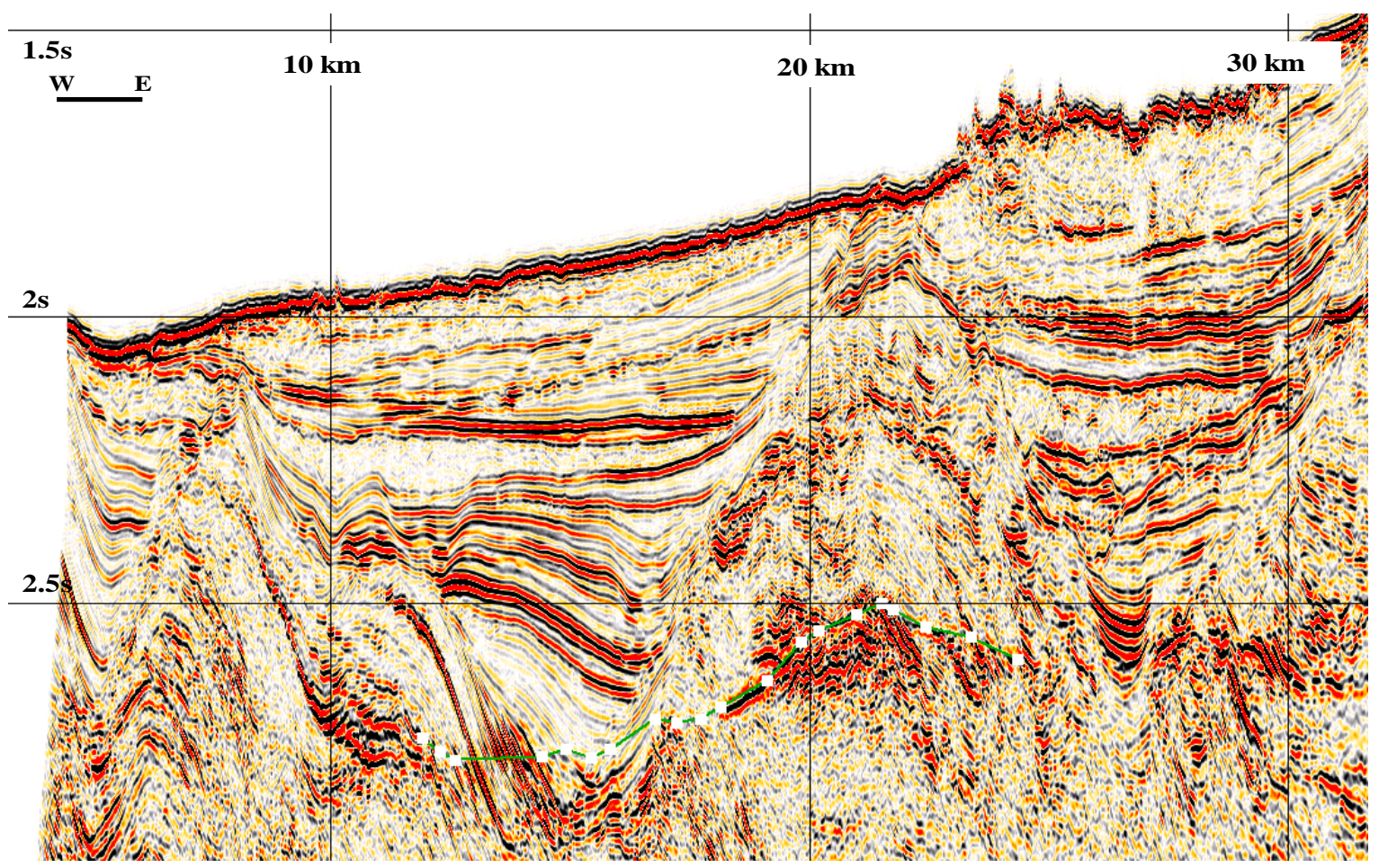

Figure 4.7: Example of a deep BSR as seen on line $05 \mathrm{~cm} 44$.

In general, the BSR distribution is shallower towards the western side of the study area than near the shelf edge and slope. This corresponds to the sediment accumulated in this region transported from the Waipaoa river catchment as described in Chapter 3. As seen in figure $4.5 \& 4.7$, the BSR on lines $05 \mathrm{~cm} 31 \& 05 \mathrm{~cm} 44$ is deeper at a two-way travel time (TWT) of approximately 2.6 and $2.7 \mathrm{~s}$ respectively. This could be because of 'thermal blanketing' from high sedimentation rates in this part of the margin, where low thermal conductivity sediments at the surface substantially increases heat retention generating elevated temperatures within underlying sediments.

\subsection{Processing sequence}

High resolution seismic processing was performed for the seismic character study of gas hydrates. The aim of processing has been to preserve the seismic amplitudes. The main processing sequence includes geometry definition, trace editing, spherical divergence correction, velocity analysis, Normal Moveout (NMO) correction, stacking and migration. Many other procedures like deconvolution, and amplitude balancing were not used in this study in order to avoid non-linear influence on the waveform and amplitude of the BSR. 
1) Seismic shot quality control - Shots were read from digital tapes in SEG-D format and converted to SEG-Y format and written out to a disk. Initial shot quality control checks were performed by ensuring that each shot contained the same number of traces, auxiliary and dead traces as well as bad shots were removed. A Butterworth filter with corner frequencies of $2,8,90$, and $120 \mathrm{~Hz}$ was applied to remove lowfrequency and high-frequency noise. The application of the Butterworth filter is shown in figure 4.8 as an example on shot 2000.

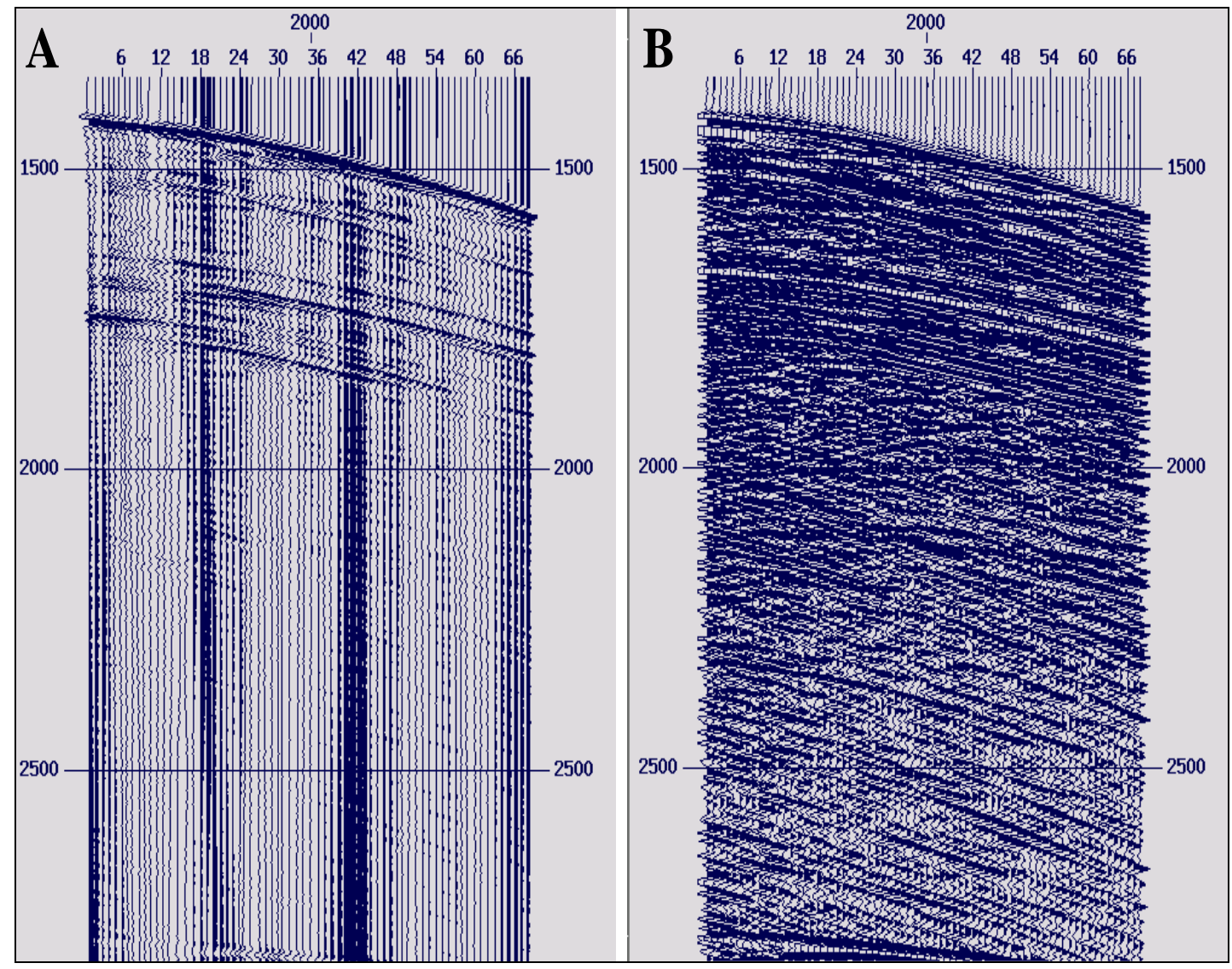

Figure 4.8: Variable area wiggle display of shot 2000. A) Part of raw shot gather without the Butterworth filter and B) Same part of raw shot gather with the Butterworth filter.

2) Geometry and near trace gather - The source and receiver geometry was defined from UKOOA (United Kingdom Offshore Operators Association) format files. UKOOA is an industry standard format for seismic navigation data. Near Trace Gathers are created by taking a subset of a field seismic shot where the trace nearest the seismic source is gathered from every record in the seismic line. A Near Trace Gather is typically unprocessed and un-interpreted field seismic data. Gathering the near trace from all the seismic records in line and placing them into a single SEGY 
file in the order in which they were recorded a simple but informative view as to the quality of the seismic data in the line.

3) Refraction mute, CDP sort and Normal-Move-Out (NMO) correction - After muting out the direct wave which travels from source to receiver without appreciable reflection, data were sorted from shot to Common Depth Point (CDP) domain. This CDP domain is the midpoint of shot-receiver array used to measure the seismic energy on the surface. The data are displayed as CDP gathers as shown in figure 4.9.

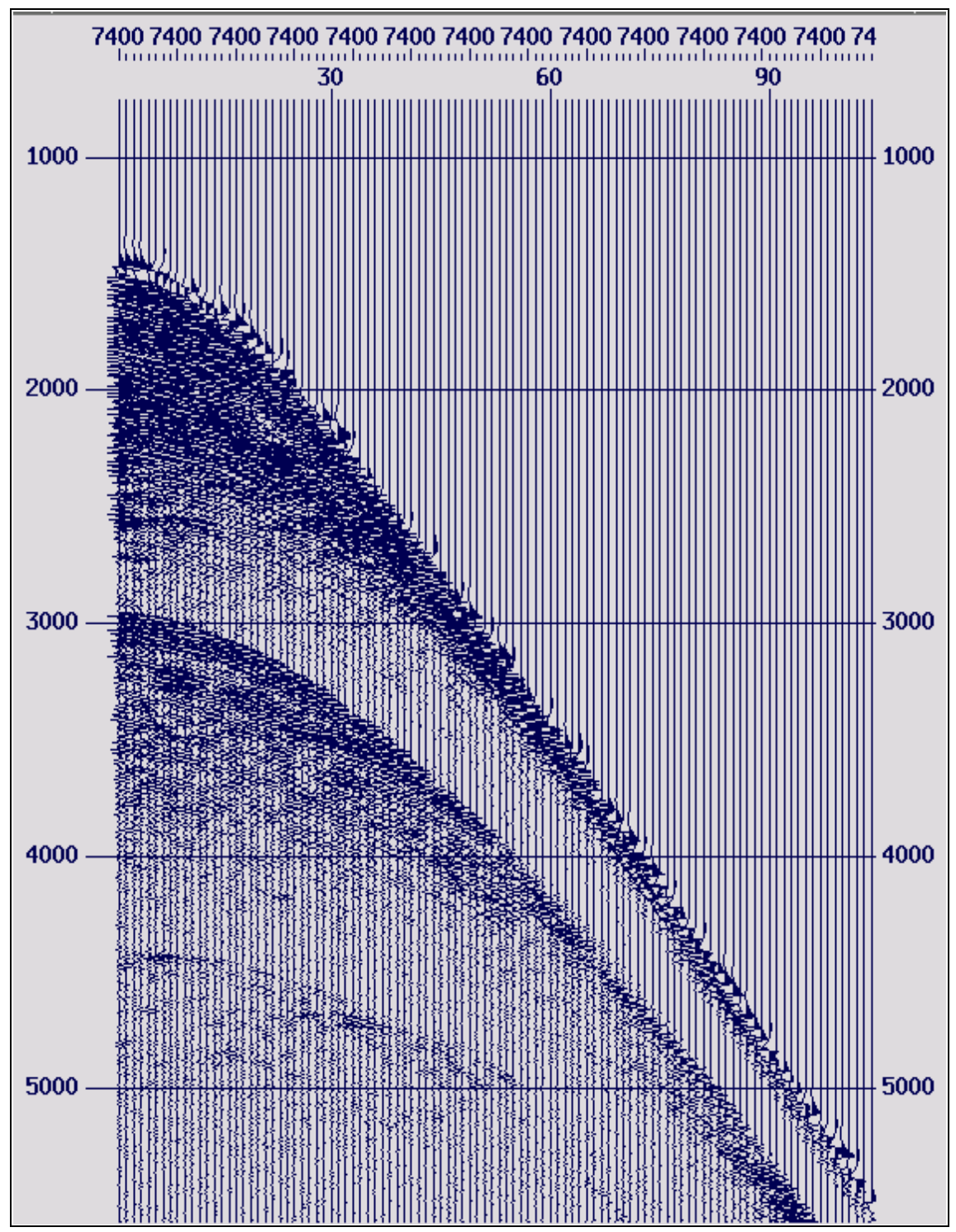

Figure 4.9: Variable area wiggle plot of CDP 7400 with offsets increasing to the right.

A reflection typically arrives first at the receiver nearest the source. The offset between the source and other receivers induces a delay in the arrival time of a 
reflection from a horizontal surface at depth. Hence the reflections, in simplified terms, will have a hyperbolic movement which is apparent in figure 4.10. NMO correction compensates for the effects of the separation between seismic sources and receivers in the case of a horizontal reflector by stretching the time axis of all traces to make them look like zero-offset traces. NMO was initially applied by assuming an constant velocity of $1500 \mathrm{~m} / \mathrm{s}$. To reduce the effect of the stretching on the result of the stacking procedure, the part with severe stretching of the data is muted.

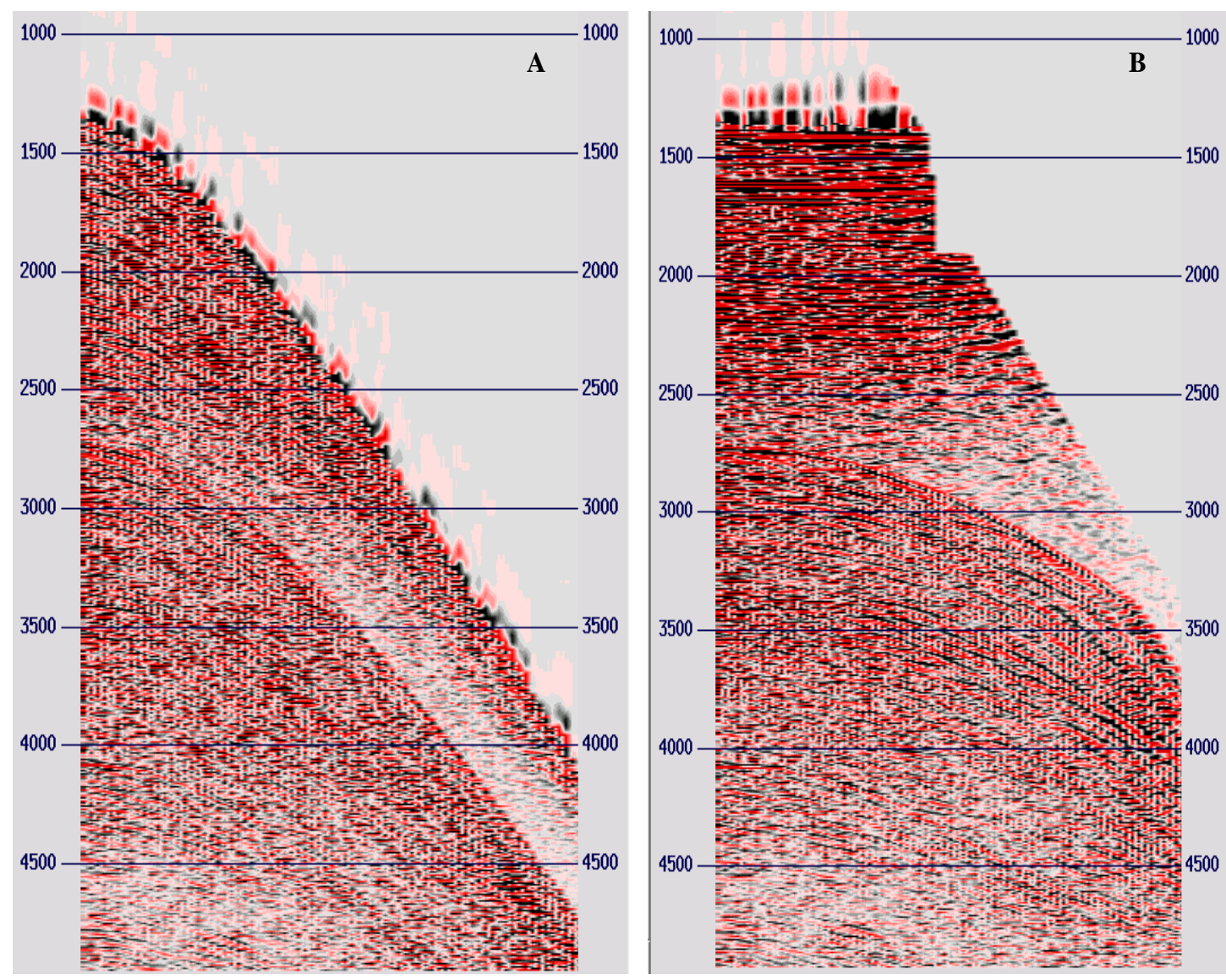

Figure 4.10: Variable density display of CDP 5000. A) Before NMO correction and B) After NMO correction with an automatic stretch mute of $80 \%$.

4) Amplitude corrections - In order to prevent amplitude losses due to wavefront divergence, spherical divergence corrections have been applied to the data. The spherical divergence correction uses a time-dependent gain function to correct for amplitude losses at later recording times. Since no amplitude normalization is used, this technique preserves relative amplitude variations. The formula used is as follows:

$$
u(t)=u\left(t_{0}\right) \frac{r_{0}}{r(t)} \text { where } r(t)=\sum_{i=1}^{n} V_{r m s i}^{2} t_{i}^{2}
$$


where $u$ is the displacement amplitude of the wave, $r_{0}$ is the radius of the spherical wavefront at the first sample and $r$ is the radius of the spherical wavefront at time $t$ and $V_{r m s i}$ is the root mean square velocity in layer $i$. Wavefront radius is calculated using the method of Newman (1973) for a horizontally layered earth.

5) Velocity analysis and stacking - Seismic velocity analysis was carried using semblance and velocity panel techniques (Sheriff and Geldart, 1995). The RootMean-Square (RMS) velocity was picked every 200 CDP. RMS velocities were converted into interval velocities using Dix equation which is used for stacking. Next, traces are summed during stacking to improve the signal-to-noise ratio, reduce noise and improve seismic data quality. Traces from different shot records with a common midpoint data, are stacked to form a single trace.

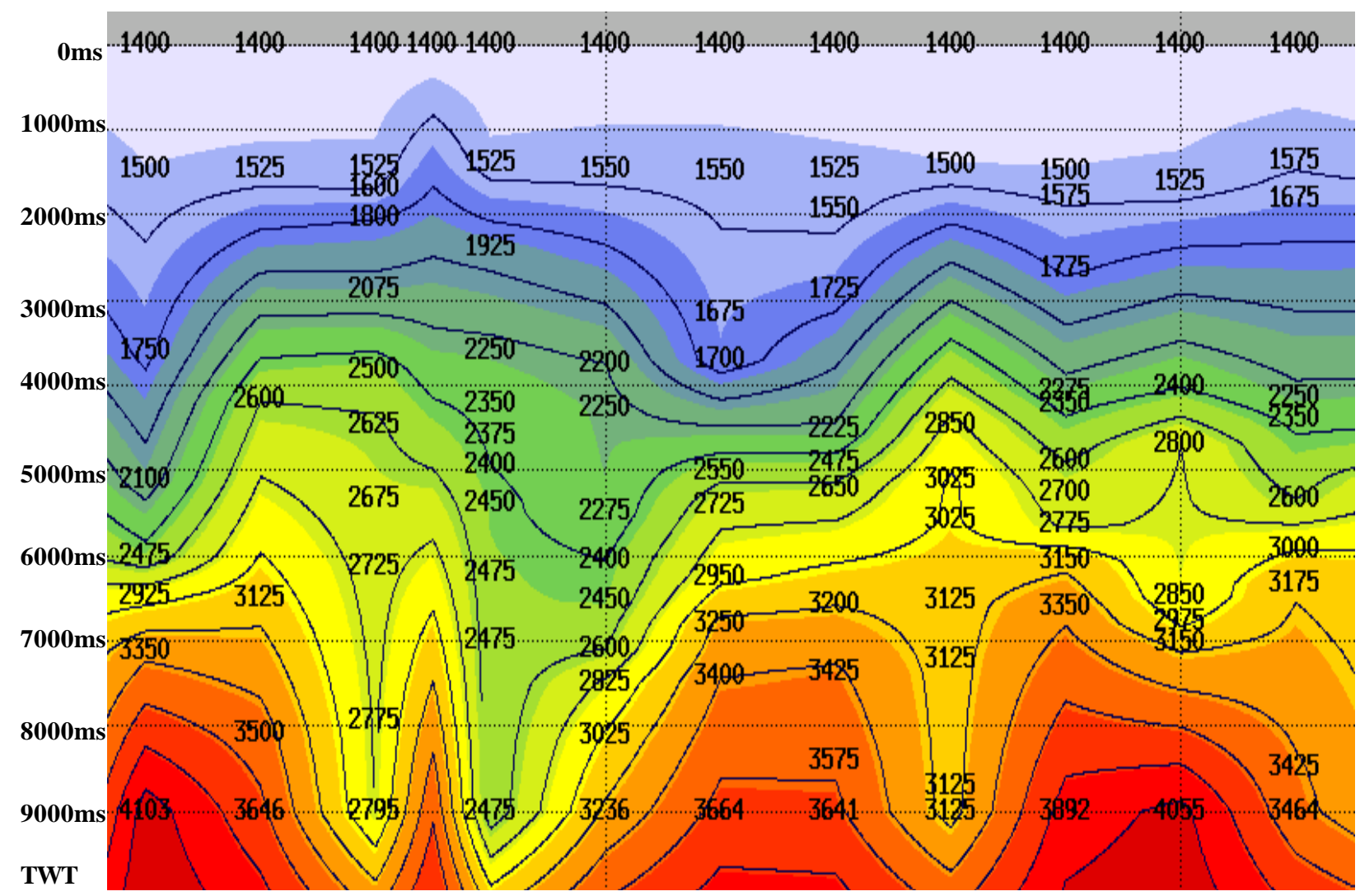

Figure 4.11: RMS Velocities for CDPs in the range 2200-2400. 


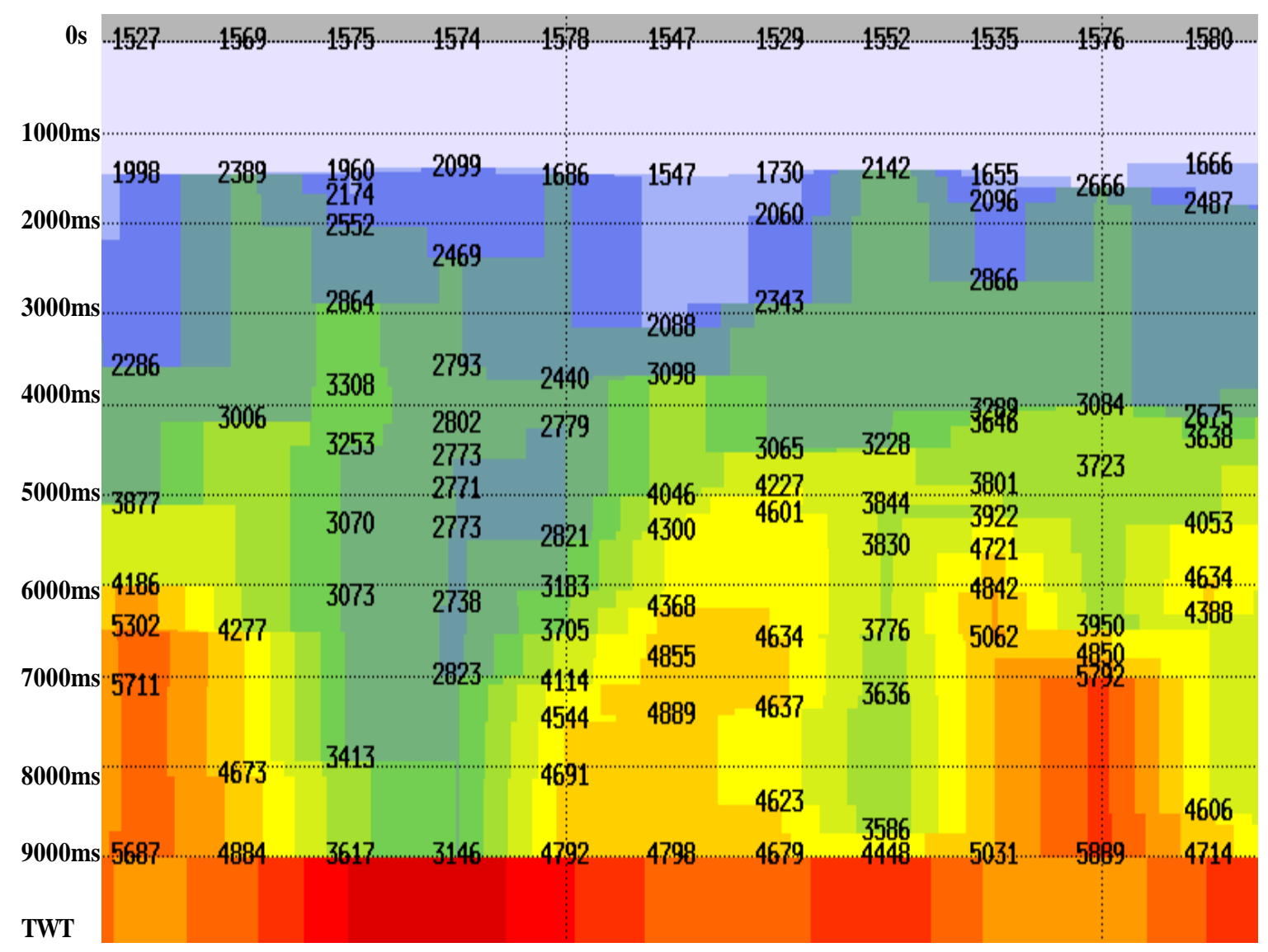

Figure 4.12: Interval velocity converted from RMS velocities for CDPs from 2200-2400.

6) Post stack migration - In order to get an accurate picture of the sub-surface layers the reflected signals are geometrically repositioned to show a layer structure, where it is being hit by the seismic wave rather than where it is being picked up. An example of this section, spanning CDP's 7300-7900 is shown in figure 4.13.

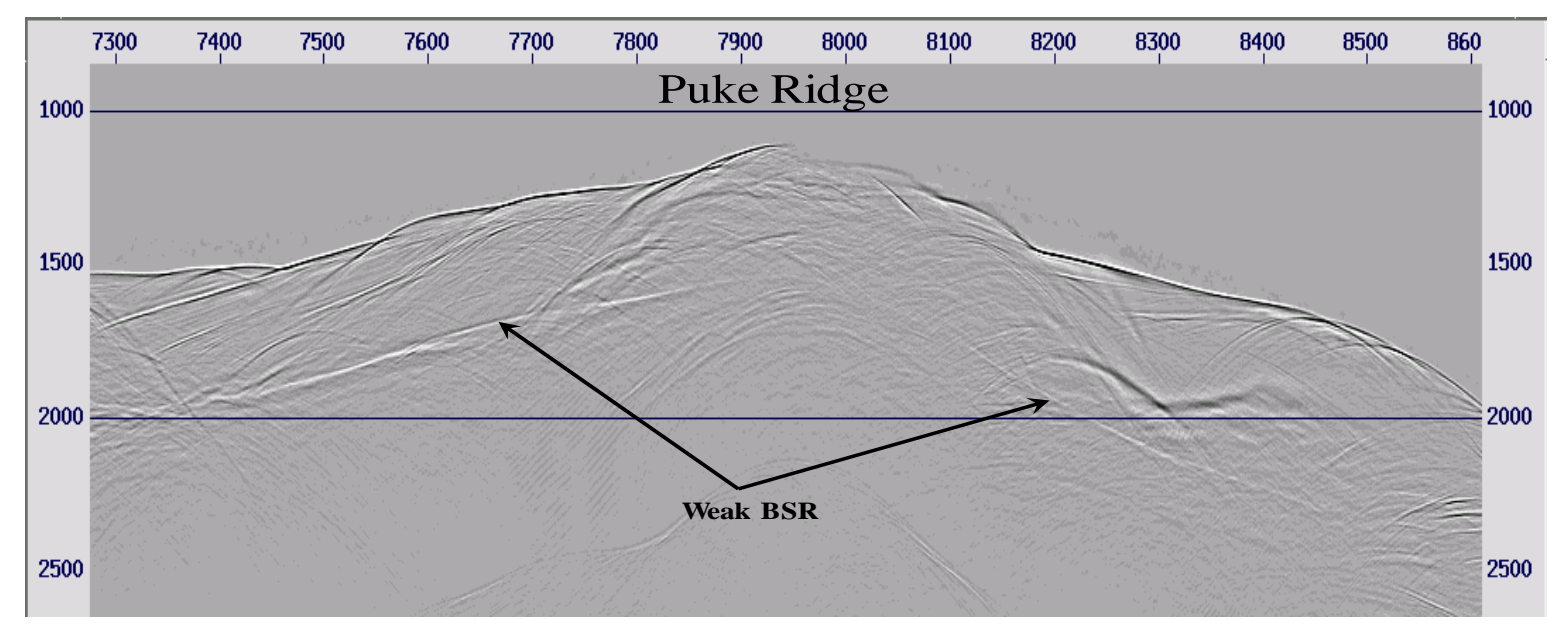

Figure 4.13: Variable density display of migrated stacked section of the line 05CM04 between CDPs 7300-8600. The western side of the Puke ridge has a weaker BSR in comparison to the eastern side. 


\subsection{Modelling of Amplitude Versus Offset (AVO)}

\subsubsection{Introduction}

The variation of reflection and transmission coefficients with Angle of incidence (AVA) and corresponding increasing offsets is often referred to as offset-dependent reflectivity and is the fundamental basis for Amplitude-Versus-Offset (AVO) analysis (Zhang, H. and Brown, R.J. 2001).

Changes in the character of seismic pulses returning from a reflector can be interpreted to ascertain the depositional history of a basin, the rock type in a layer and even the nature of pore fluid. This last refinement, pore fluid identification is the ultimate goal of AVO analysis (Zhang, H. and Brown, R.J. 2001). Appropriate data processing scheme has been adopted as described in section 4.4 where noise has been suppressed and care has been taken to not bias or otherwise corrupt the reflectivity variation with offset.

\subsubsection{Principles}

Gas within the pore space of a rock dramatically lowers the P-wave velocity but the shearwave velocity is not significantly affected by changes in the fluid content of the rock (Domenico et al., 1977). Because the P-wave velocity to $\mathrm{S}$-wave velocity ratio (Vp/Vs) is dramatically different for gas-charged layers as opposed to water-bearing layers, gas-charged layers are different when compared to most other reflectors. Reflections associated with gasbearing layers exhibit an increase in absolute amplitude with offset when compared to gasfree reflectors.

The Bottom Simulating Reflection (BSR) marks the interface between sediments containing gas hydrate and free gas beneath the gas hydrate stability zone. Hence a downward transition to sediment containing free gas with low $\mathrm{Vp} / \mathrm{Vs}$ ratio from overlying sediments with or without hydrate having a more normal $\mathrm{Vp} / \mathrm{Vs}$ ratio gives a reflection with negative amplitudes that become substantially larger with angle of incidence or offset. The BSR acts as a strong seismic reflector with negative polarity, the amplitude of which depends on the degree of saturation of sediments by hydrates above and by gas below it. When a plane P-wave strikes such an interface at angles other than normal-incidence, some portion of the P-wave is converted to an S-wave (figure 4.14). The angles for incident, reflected and transmitted rays synchronous at the boundary are related according to Snell's law by: 


$$
p=\frac{\sin \theta_{1}}{V p_{1}}=\frac{\sin \theta_{2}}{V p_{2}}=\frac{\sin \varphi_{1}}{V s_{1}}=\frac{\sin \phi_{2}}{V s_{2}}
$$

where $\mathrm{Vp}_{1}=\mathrm{P}$-wave velocity in medium $1, \mathrm{Vp}_{2}=\mathrm{P}$-wave velocity in medium $2, \mathrm{Vs}_{1}=\mathrm{S}$ wave velocity in medium $1, \mathrm{Vs}_{2}=\mathrm{S}$-wave velocity in medium $2, \theta_{1}=$ incident $\mathrm{P}$-wave angle, $\theta_{2}=$ transmitted $\mathrm{P}$-wave angle, $\varphi_{1}=$ reflected S-wave angle, $\varphi_{2}=$ transmitted S-wave angle and $\mathrm{P}=$ ray parameter.

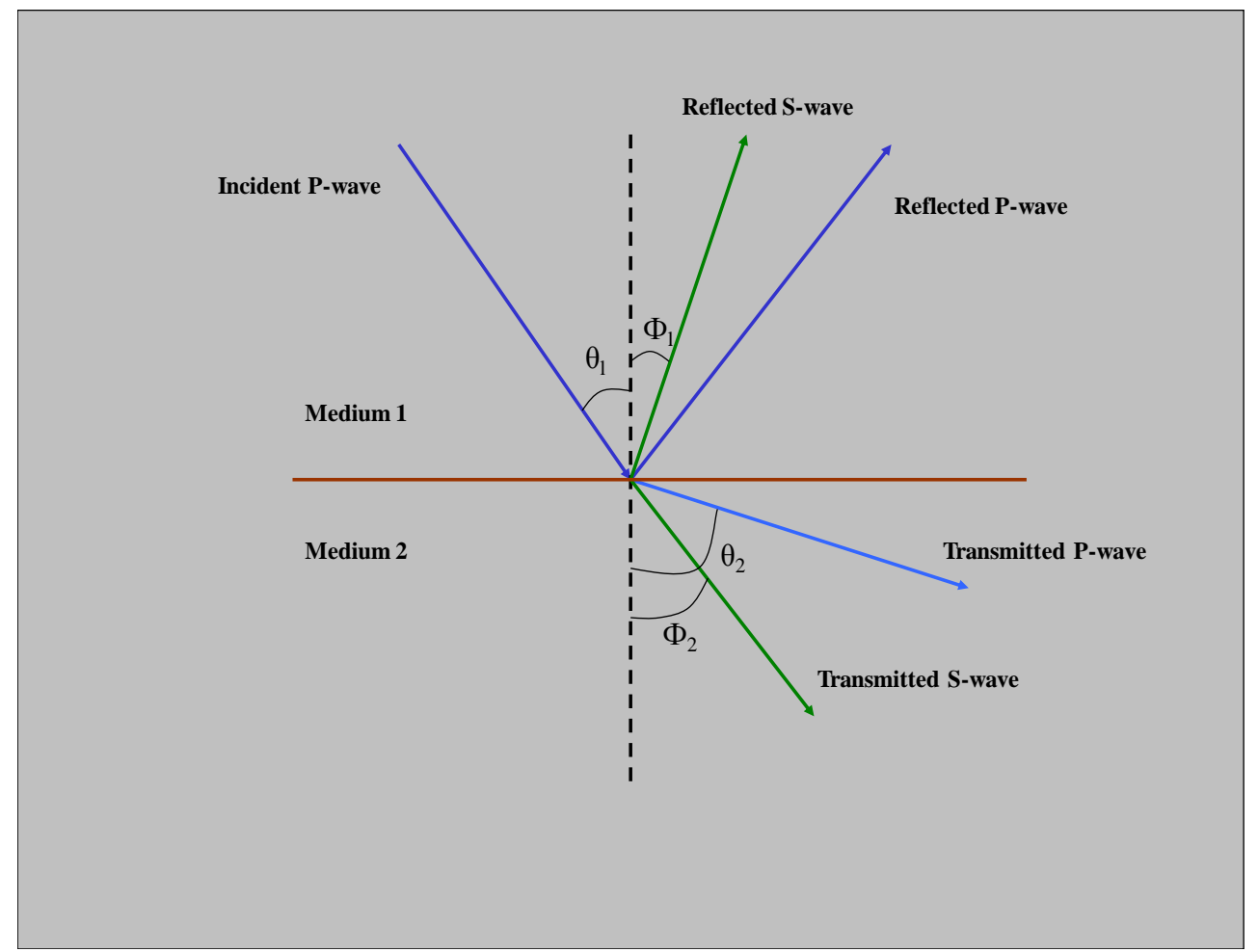

Figure 4.14: Reflection and transmission at an interface between two infinite elastic half spaces for an incident $P$ wave (Yilmaz, 2001).

Zoeppritz derived equations to describe the amplitudes of the reflected and transmitted waves with respect to the amplitude of the incident plane wave. As these equations were very complex, many approximations have been developed. The simplest useful approximations to the Zoeppritz theory are Shuey's approximation which is valid for angles of incidence $\theta$ up to $30^{0}$. This is given by:

$$
R(\theta)=A+B \sin ^{2} \theta
$$

where A represents the normal incidence P-wave reflectivity (AVO intercept) and B represents the AVO effects (AVO gradient). They are given by 


$$
A=\frac{1}{2}\left(\frac{\Delta V p}{V p}+\frac{\Delta \rho}{\rho}\right) \text { and } B=\frac{A A_{0}}{(1-\sigma)^{2}}
$$

In addition,

$$
\begin{gathered}
A_{o}=B_{o}-2\left(1+B_{o}\right) \frac{1-2 \sigma}{1-\sigma} \text { and } B_{o}=\frac{\frac{\Delta V p}{V p}}{\frac{\Delta V p}{V p}+\frac{\Delta \rho}{\rho}} \\
V p=\frac{\left(V p_{2}+V p_{1}\right)}{2}, V s=\frac{\left(V s_{2}+V s_{1}\right)}{2}, \rho=\frac{\rho_{2}+\rho_{1}}{2}, \sigma=\frac{\sigma_{2}+\sigma_{1}}{2} \\
\Delta V p=\left(V p_{2}-V p_{1}\right), \Delta V s=\left(V s_{2}-V s_{1}\right), \Delta \rho=\left(\rho_{2}-\rho_{1}\right), \Delta \sigma=\left(\sigma_{2}-\sigma_{1}\right)
\end{gathered}
$$

The values $\mathrm{Vp}, \mathrm{Vs}$ and $\rho$ are the $\mathrm{P}$-wave velocity, S-wave velocity and density respectively. Subscripts 1 and 2 represent the parameters of overlying and underlying layers respectively.

The numerical measure of the effect of an interface on wave propagation for a vertical incidence wave is calculated as the ratio of the amplitude $A_{1}$ of the reflected ray to the amplitude $A_{2}$ of the incident ray. This is called as reflection coefficient and is given by:

$$
R=\frac{A_{1}}{A_{0}}
$$

The total energy reflected or transmitted must be equal to the energy of the incident ray. The relative proportions of energy transmitted or reflected are determined by a contrast in acoustic impedance $\mathrm{Z}$ across the interface (Kearey et al., 2002). The acoustic impedance of a rock is the product of its density $\rho$ and wave velocity $\mathrm{V}$ given by:

$$
Z=\rho V
$$




\subsubsection{Method and Results}

AVO analysis involves evaluation of reflection amplitudes at varying source-receiver offsets. A portion of CDP 7600 is shown in figure 4.15 illustrating the Common Depth Point (CDP) gather consisting of a set of ray paths sampling the same subsurface point at increasing offset and angle of incidence. The CDP gather is the starting point for AVO analysis. The amplitudes across the BSR are picked and only geometric spreading corrections have been applied to the true amplitude data.

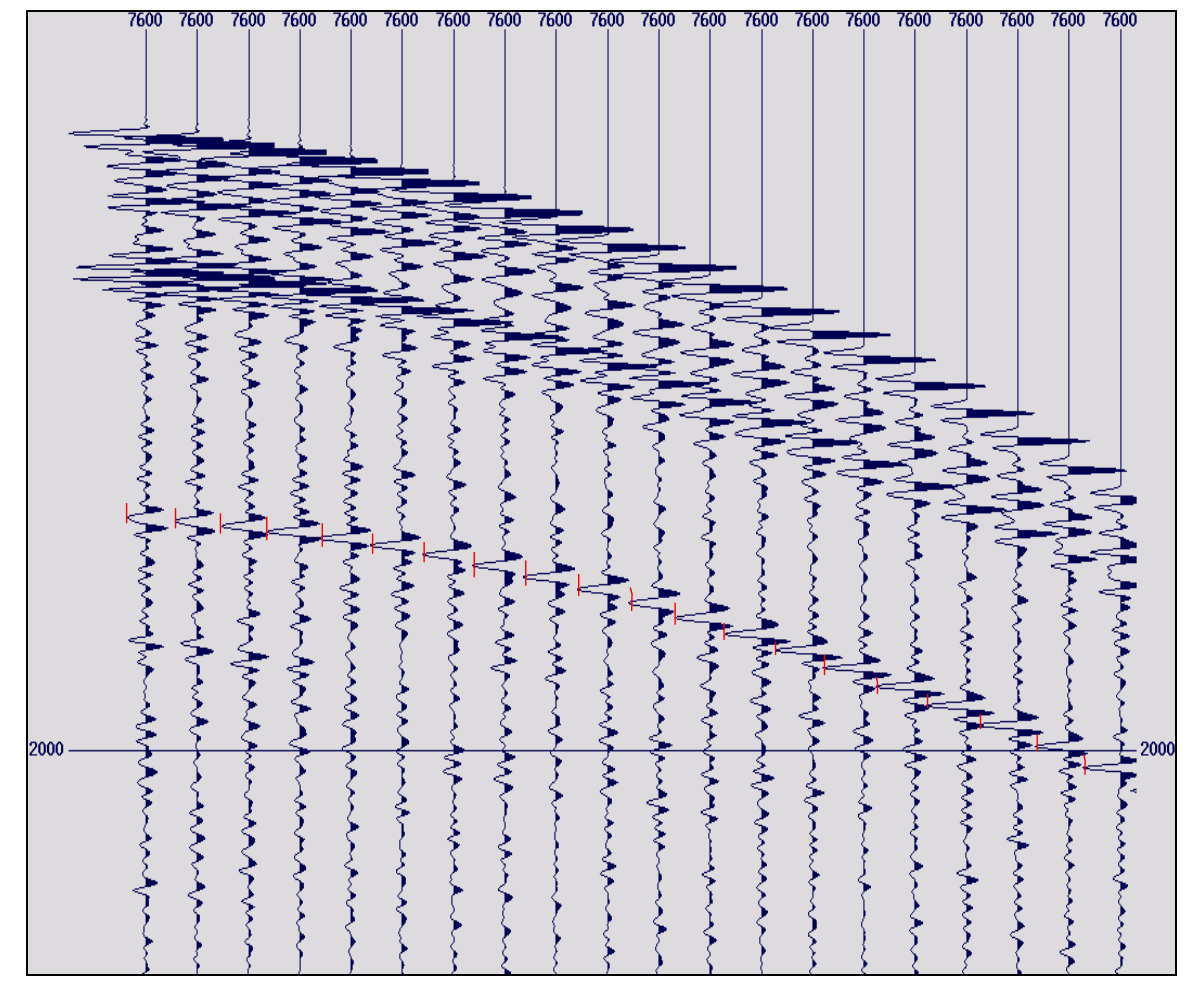

Figure 4.15: A portion of CDP 7600 showing the peak BSR amplitudes picked in red.

Once the BSR amplitudes were picked, they were corrected for the directivity of hydrophone array. No directivity correction of the air gun array was applied to the data as the source used, is treated as a point source. Directivity correction to the BSR reflection amplitude was calculated according to the formula:

$$
F=\left|\frac{\sin \left[\Pi n\left(\frac{\Delta x}{\lambda}\right) \sin \theta\right]}{n \sin \left[\Pi\left(\frac{\Delta x}{\lambda}\right) \sin \theta\right]}\right|
$$


where $\theta$ is the angle of incidence, $\mathrm{n}$ is the number of hydrophones in each group, $\Delta x$ is the distance between the hydrophones, $\Pi$ is 3.1415 and $\lambda$ is the wavelength of the BSR. Ray trace modelling has been done to relate offset to the angle of incidence. The BSR amplitudes corrected for hydrophone array attenuation as a function of offset and as a function of angle of incidence for CDP 7600 are displayed in figure 4.16. 

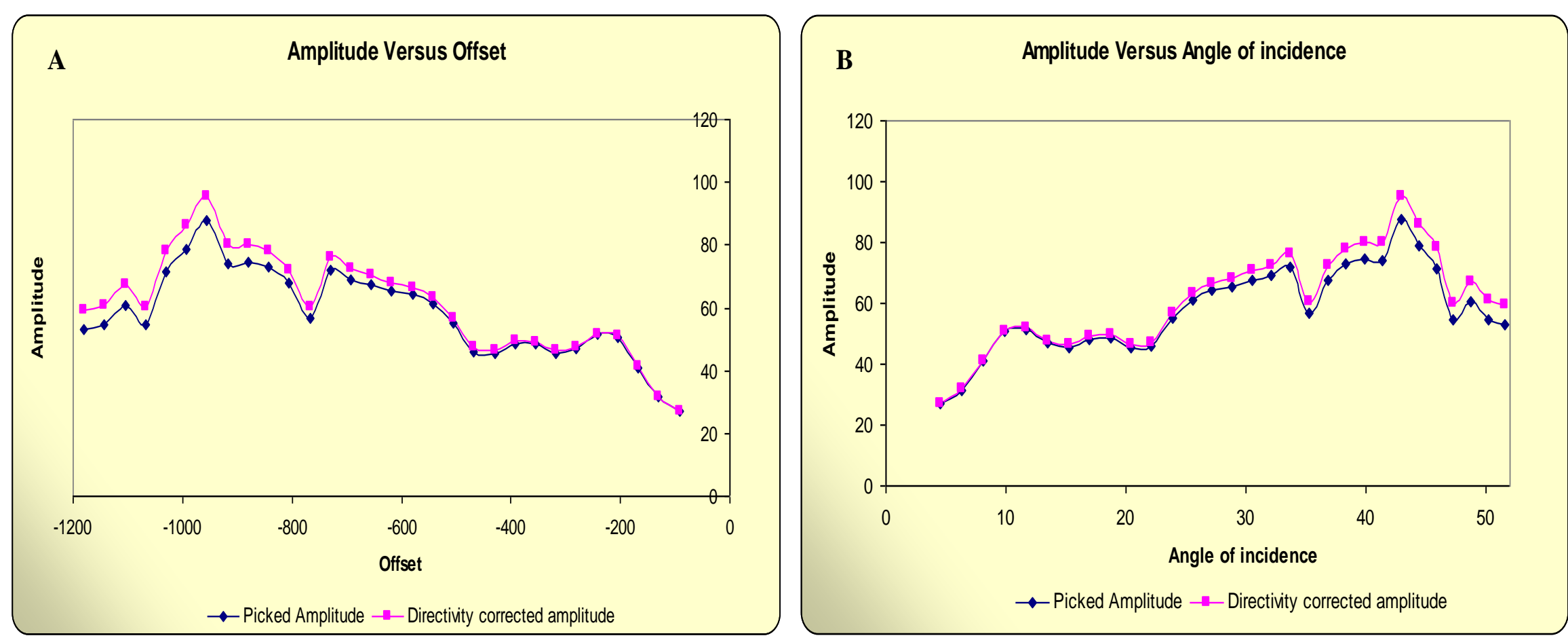

Figure 4.16: A) Amplitude versus offset plot of CDP 7600 across the BSR. Here the amplitudes are multiplied by -1, B) Amplitude versus angle of incidence plot of CDP 7600 across the BSR. Here the amplitudes are multiplied by $\mathbf{- 1}$. Offsets are converted to angle of incidence by ray tracing method. 
BSR Reflection Coefficient - Once the bottom-simulating reflections (BSR) amplitudes were extracted, the zero-offset reflection coefficient was estimated by comparison of the BSR amplitude with the amplitude of the seafloor reflection. The reflection coefficient of the seafloor is in turn estimated from the relative amplitude of the primary seafloor reflection and it's multiple(Warner, 1990). The reflection coefficient of the seafloor is given by:

$$
R_{s f}=-\frac{A_{m u l}}{A_{s f}}
$$

where $A_{m u l}$ is the amplitude of the multiple and $A_{s f}$ is the amplitude of the seafloor. The seafloor reflection coefficient is plotted as a function of the angle of incidence (Figure 4.17).

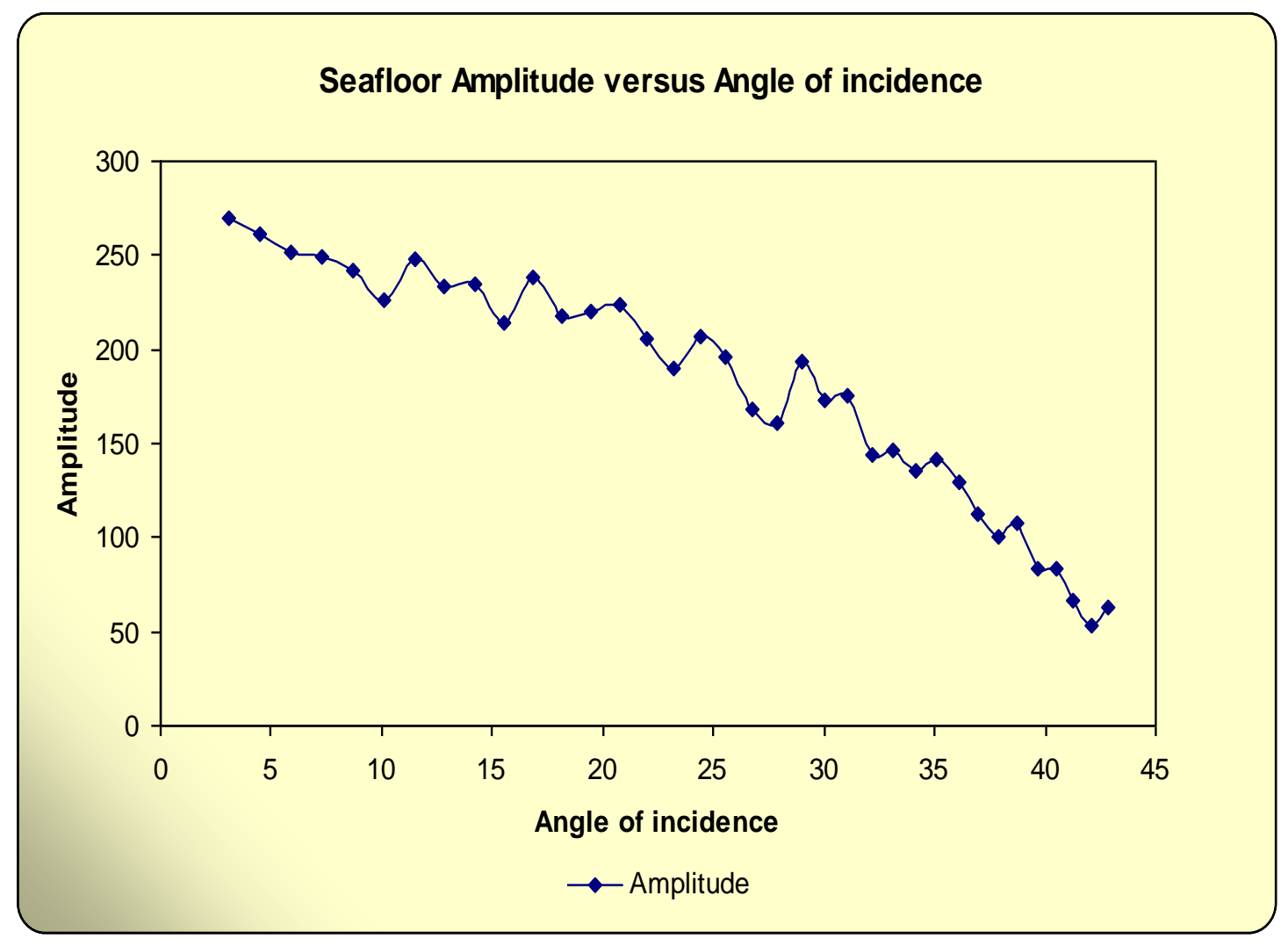

Figure 4.17: Plot of sea floor amplitude versus angle of incidence for CDP 7600.

The reflection coefficient of the BSR is given by:

$$
R_{b s r}=R s f * \frac{A_{b s r}}{A_{m u l}}
$$


where $A_{b s r}$ is the amplitude of BSR.

The reflection coefficients were calculated as a function of incident angle for individual CDP's and near-vertical traces for a range of 25 CDP's (i.e. CDP's 7595-7620). The reflection coefficient of CDP 7600 as a function of angle of incidence shown in figure 4.18. Figure 4.19 shows the variation of reflection coefficients for near-vertical traces of 25 CDP's.

The AVO intercept (A) or the normal incidence P-wave reflectivity and the AVO gradient (B) are calculated for the same 25 CDP's (i.e. 7595-7620) across the BSR by weighted leastsquares fitting for each supergather of two consecutive CDPs across the section (figure 4.20). These calculations were carried out in a simple Microsoft Excel ${ }^{\mathrm{TM}}$ spreadsheet where the intercept and gradient are based on a best-fit regression line plotted through the calculated Reflection coefficients of the weak BSR and sine square of the angle of incidence.

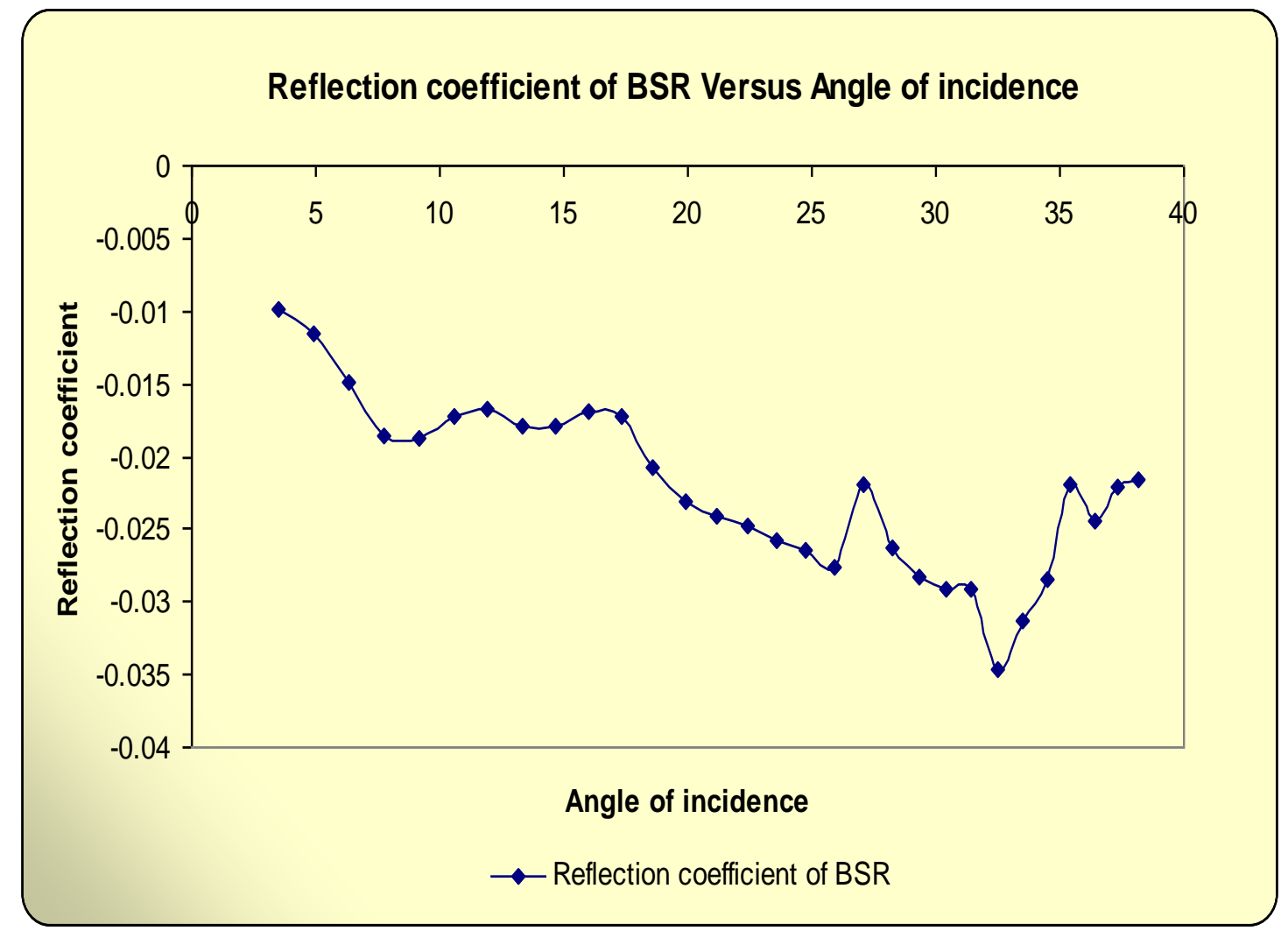

Figure 4.18: Reflection coefficient of BSR across the CDP 7600 plotted against angle of incidence. Offsets were converted to angle of incidence by tray tracing method 


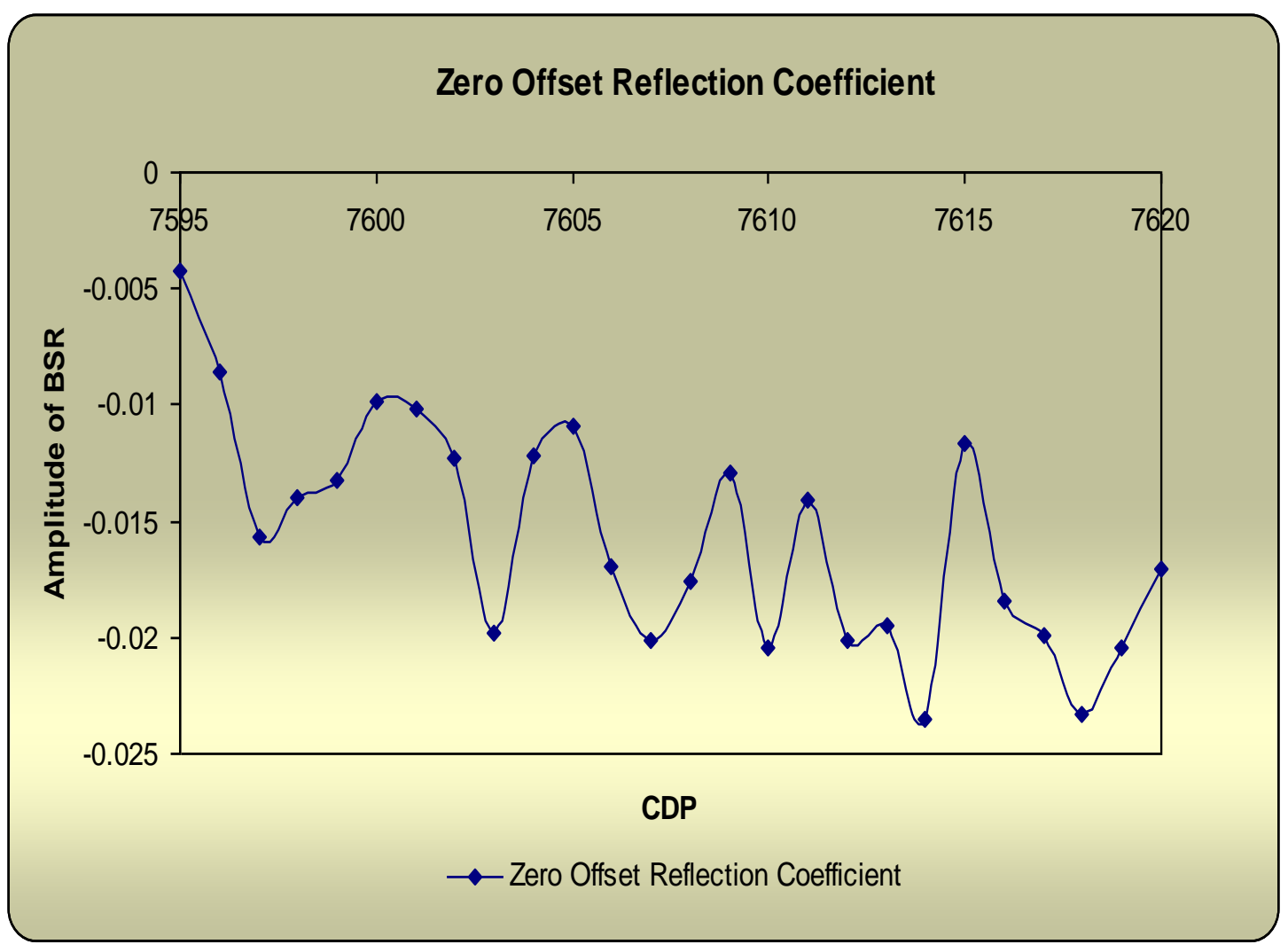

Figure 4.19: Plot of zero-offset or near vertical BSR reflection coefficients for CDP's 7595-7620

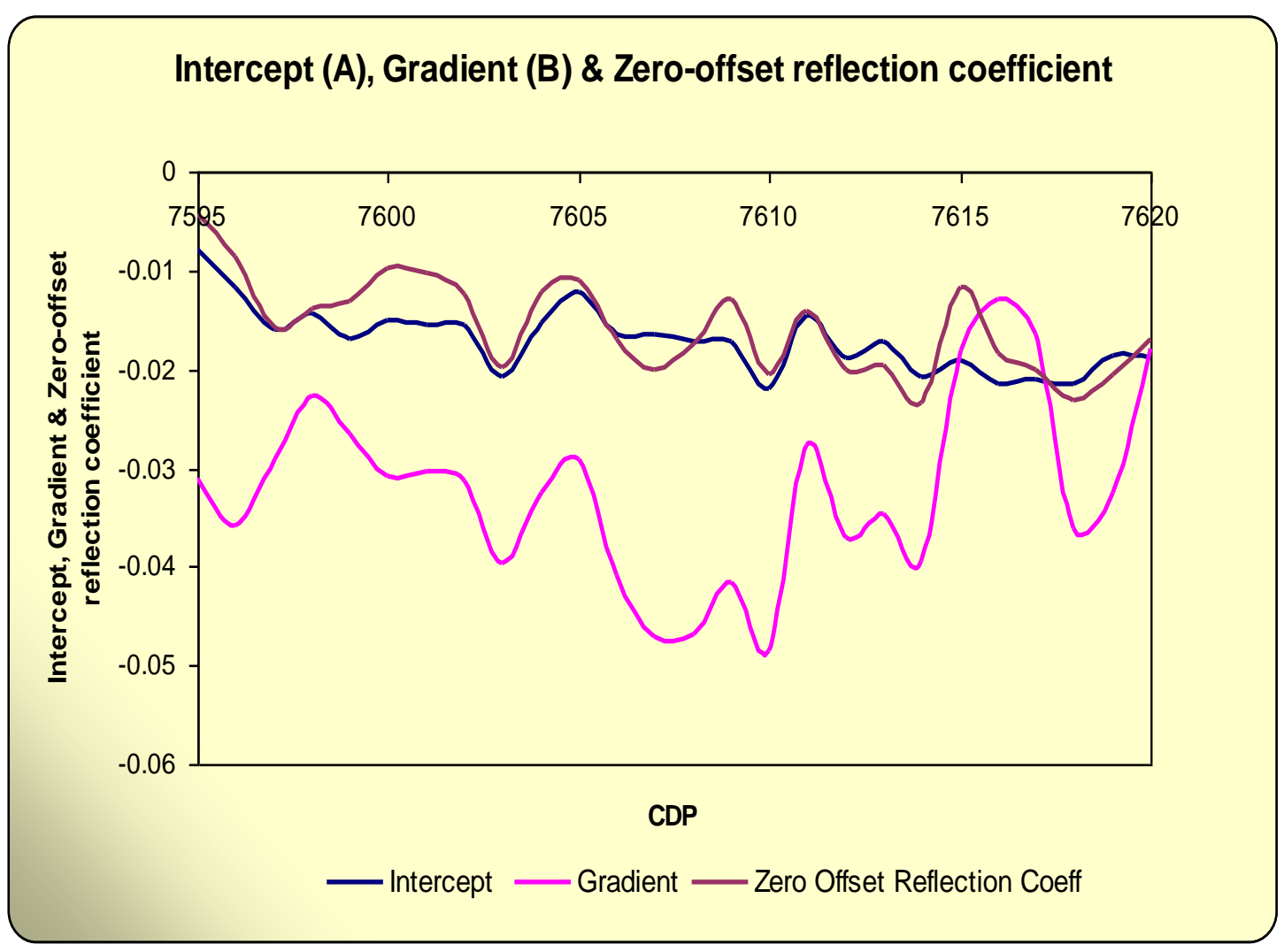

Figure 4.20: Plot of Intercept, Gradient and Zero-offset reflection coefficient of 25 CDP's across the BSR 


\subsection{Discussion and Hypothesis}

The AVO (Amplitude Versus Offset) processing techniques, in theory, enable the identification of the presence of disseminated gas within sediments. These techniques are based on the variation of the amplitudes of seismic reflections with the offset sourcereceiver.

The 05CM04 seismic line has been processed by preserving the amplitude and care has been taken to not bias the variation of reflectivity coefficient with offset. A BottomSimulating Reflection (BSR) is clearly observed at about $0.4-0.5$ s below the seabed on the seismic section with a reversed polarity compared to that of the seabed reflection.

From figure 4.18 the average zero-offset reflection coefficient or AVO intercept (A) is 0.015 and the AVO gradient (B) is between -0.015 to -0.03 . Comparison of images shown in Pecher et al.,(2010) suggest that weak BSRs are found in this part of the Hikurangi margin, especially beneath some anticlines (figure 4.19).

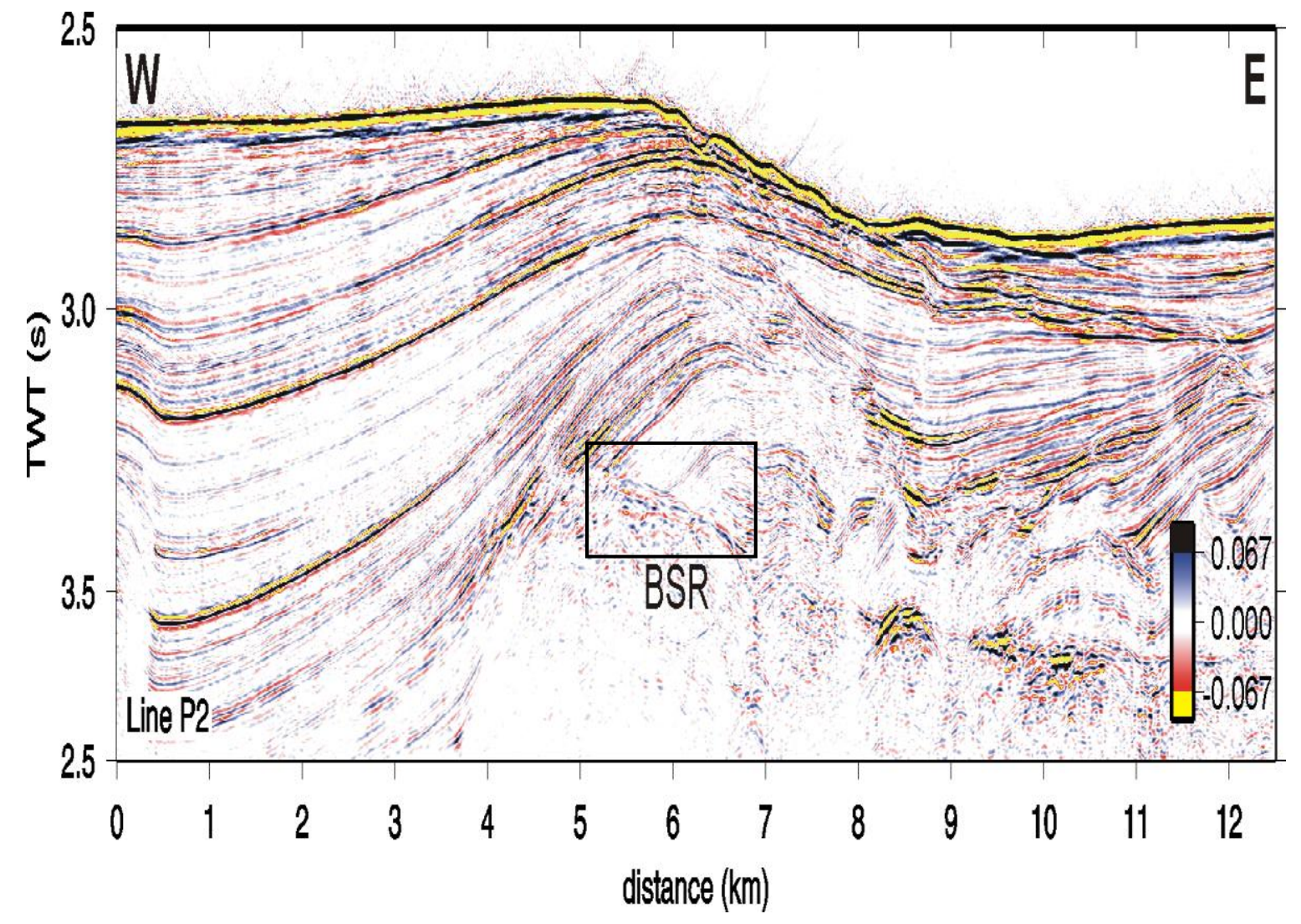

Figure 4.21: Example of a weak BSR with low reflectivity beneath Porangahau ridge on the line 05cm38. Image after Pecher et al., 2010.

Hence it is hypothesized that the hydrate and gas concentration is indeed low in the Hikurangi margin, thus accounting for the low reflectivity. 



\section{CHARACTERIZATION OF BOTTOM SIMULATING REFLECTIONS (BSRS)}

5.1. Introduction 53

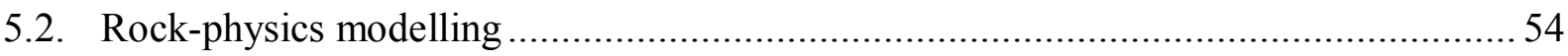

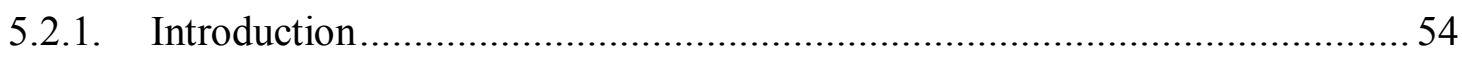

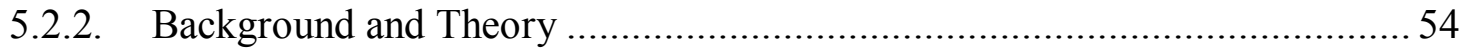

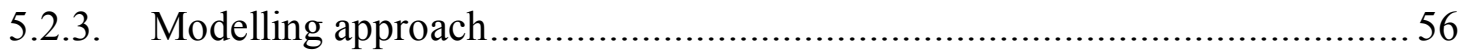

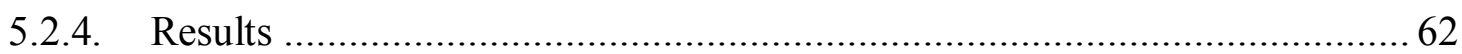

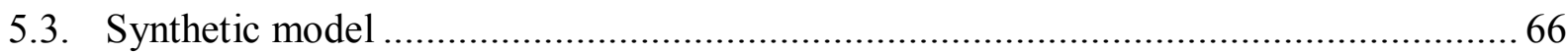

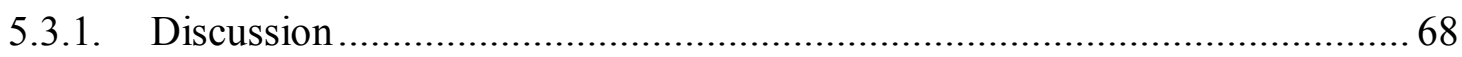

\subsection{Introduction}

Quantification of gas hydrates and free gas from seismic velocities based on rock physics models can give valuable information before drilling for site selection and assist further research for exploration. Quantification from downhole logs requires background or reference log values (physical parameters without gas hydrate and free gas), which is not easy to obtain (Hyndman et al., 1999; Riedel et al., 2006). P-wave and S-wave velocities are the commonly physical properties used to determine hydrate or free gas concentrations as it is easier to obtain a background velocity profile by not accounting for the change in velocities due to the presence of hydrate and free gas. Hence seismic reflection data are not only useful but cost-effective in estimating gas hydrate and free gas concentrations across a Bottom Simulating Reflection (BSR) with depth.

A variety of rock physics theories based on empirical relations exist for translating seismic velocity in terms of gas hydrate and free gas saturation, including (1) time average equations (Miller et al., 1991; Wood et al., 1994); (2) the cementation theory (Dvorkin et al., 1994; Guerin et al., 1999); (3) the pore-filling model (Hyndman and Spence, 1992); (4) the weighted equation (Lee and Collett, 2001 ; Lee et al., 1996). This chapter attempts to estimate the saturation and distribution of gas hydrate and free gas based on the results of seismic reflection Amplitude Variations with Offset (AVO) from chapter 4 and rock physics modelling. This approach is similar to the approach by Ojha et al. (2010), and a comparison between the AVO intercept A and gradient B estimated from the BSR with those values estimated from rock-physics models to quantify the saturations of gas hydrate and free gas across the BSR is done. Also in this chapter, zero-offset synthetic seismic data from an earth 
model is used to illustrate that in principle, the low reflectivity of the BSR can be caused either due to the very low concentration of gas below the BSR or due to gradational gas layers with patchy saturations.

\subsection{Rock-physics modelling}

\subsubsection{Introduction}

Appropriate models to predict seismic velocities as a function of porosity, mineralogy and fluid-content in unconsolidated sediments are crucial for the evaluation of shallow hydrocarbon prospects.

Helgerud et al. (1999) introduced a physics-based model for gas hydrate-bearing marine sediments called the Effective Medium model. In this model, the elastic modulii of dry sediment frame is determined according to Dvorkin et al. (1999). In the Effective Medium Theory (EMT), hydrate is considered to be part of the rock frame. Here, we use the approach by Ojha et al. (2010) and use the EMT model, where hydrates are considered part of the sediment frame to calculate the AVO intercept (A) and gradient (B) for various gas hydrate and free gas saturations.

\subsubsection{Background and Theory}

The elastic properties of hydrate systems depend on: 1) the volume fractions of various constituents, 2) the elastic properties of the host sediments, 3) the elastic properties of pure hydrates, and 4) the geometric details of how the hydrates are distributed within the sediments.

Before deposition, sediments exist as particles suspended in water. The porosity at which a granular composite ceases to be in suspension and becomes grain-supported is called critical porosity. The EMT theory by Helgerud et al. (1999) is based on the baseline model of Dvorkin et al, (1999). Dvorkin et al, (1999) assume that at critical porosity, the elastic moduli of dry mineral frame can be calculated from the Hertz-Mindlin contact theory. For porosities less than the critical porosity, the elastic moduli of the dry sediment frame is calculated from the modified Hashin-Shtrikman lower bound while for porosities greater than the critical porosity, the modified Hashin-Shtrikman upper bound is used. Gassmann's theory (1951) is then used to estimate the elastic properties of the sediments saturated with fluid. 


\subsubsection{Hertz-Mindlin contact theory}

The Hertz-Mindlin theory is used to predict the elastic moduli of unconsolidated sediments. This model assumes that the grains are in the shape of spheres with random packing. Mindlin (1949) assumes that there is no slip along the contact surface between the grains and the contact stiffness is measured both in the normal and tangential directions. The effective bulk and shear modulus of the granular material is given by:

$$
K_{H M}=K_{e f f}=\sqrt[3]{\frac{C^{2}(1-\phi)^{2} G^{2}}{18 \Pi^{2}(1-v)^{2}}} P \text { and } G_{H M}=G_{e f f}=\frac{5-4 v}{5(2-v)} \sqrt[3]{\frac{3 C^{2}(1-\phi)^{2} G^{2}}{2 \Pi^{2}(1-v)^{2}}} P
$$

where $\mathrm{C}$ is the coordination number, which represents the average number of contacts between neighbouring grains, $\rho$ is the porosity, $G$ is the shear modulus of the grains, $P$ is the confining pressure acting upon the sediment package and $\mathrm{v}$ is the Poisson's ratio.

\subsubsection{Hashin-Shtrikman bounds}

The best bounds for an isotropic elastic mixture, defined as giving the narrowest possible range of elastic moduli without specifying anything about the geometries of the constituents, are the Hashin-Shtrikman bounds (Hashin and Shtrikman, 1963). For a mixture of two constituents, the Hashin-Shtrikman bounds are given by:

$$
\begin{gathered}
K^{H S \pm}=K_{1}+\frac{f_{2}}{\left(K_{2}-K_{1}\right)^{-1}+f_{1}\left(K_{1}+\frac{4}{3} \mu_{1}\right)^{-1}} \text { and } \\
\mu^{H S \pm}=\mu_{1}+\frac{f_{2}}{\left(\mu_{2}-\mu_{1}\right)^{-1}+\frac{2 f_{1}\left(K_{1}+2 \mu_{1}\right)}{5 \mu_{1}\left(K_{1}+\frac{4}{3} \mu_{1}\right)}}
\end{gathered}
$$

where $\mathrm{K} 1$ and $\mathrm{K} 2$ are the bulk moduli, $\mu_{1}$ and $\mu_{2}$ are the shear moduli and $\mathrm{f}_{1}$ and $\mathrm{f}_{2}$ are the volume fractions of individual phases. Upper and lower bounds are computed by interchanging which material is subscripted 1 and which is subscripted 2. Generally, the expressions give the upper bound when the stiffest material is subscripted 1 in the expressions above, and the lower bound when the softest material is subscripted 1. 


\subsubsection{Modelling approach}

Assuming that the hydrate concentrations above the BSR are either low or they exist in thin layers, an initial background P-wave velocity (in the absence of gas and hydrate) of $1917 \mathrm{~m} / \mathrm{s}$ is used from the Normal Moveout (NMO) interval velocities for the EMT rock physics model. The porosity is estimated from the porosity-density relationship which is given by:

$$
\rho=\phi \rho_{f l}+(1-\phi) \rho_{g r a i n}
$$

where $\rho_{\mathrm{fl}}$ is the density of fluid or water, $\rho_{\text {grain }}$ is the grain density and $\Phi$ is the porosity. The initial fractional porosity calculated is about 0.4 which is greater than the critical porosity of 0.36 used by Helgerud et al. (1999). The parameters used in the calculation, are lithostatic pressure: $1.75 \times 10^{7} \mathrm{~Pa}$, pore pressure: $1.42 \times 10^{7} \mathrm{~Pa}$, differential pressure: $0.33 \times 10^{7} \mathrm{~Pa}$ and a clay fraction of $14.3 \%$ using a temperature of $15.5^{\circ} \mathrm{C}$ obtained from phase boundary and the bottom-water temperature average taken from Pecher et al. (2005). Other parameters used are shown in table 5.1.

\begin{tabular}{|c|c|c|c|}
\hline Component & Bulk Modulus (GPa) & Shear Modulus (GPa) & $\rho\left(\mathrm{g} / \mathrm{cm}^{3}\right)$ \\
\hline Quartz & 37 & 44 & 2.65 \\
\hline Clay & 20.9 & 6.85 & 2.58 \\
\hline Hydrate & 7.70 & 3.21 & 0.91 \\
\hline Methane* & 0.015 & - & 0.12 \\
\hline Water & 2.25 & - & 1.035 \\
\hline
\end{tabular}

Table 5.1: Parameters used in theoretical calculations from Lee, (2002)

* Gas properties of Methane as in (Pecher et al., 2010) and adjusted to the predicted temperature and pressure conditions in the study area.

The elastic properties of unconsolidated sediments are calculated using the following steps:

1) Computed the bulk and shear moduli of the dry mineral frame at 0.40 or $40 \%$ background porosity by using the Hashin-Shtrikman upper bound equation given by: 


$$
\begin{aligned}
& K_{d r y}=\left[\frac{\frac{(1-\phi)}{\left(1-\phi_{c}\right)}}{K_{H M}+\frac{4}{3} G_{H M}}+\frac{\frac{\left(\phi-\phi_{c}\right)}{\left(1-\phi_{c}\right)}}{\frac{4}{3} G_{H M}}\right]^{-1}-\frac{4}{3} G_{H M} \text { and } G_{d r y}=\left[\frac{\frac{(1-\phi)}{\left(1-\phi_{c}\right)}}{G_{H M}+Z}+\frac{\left(\phi-\phi_{c}\right)}{\left(1-\phi_{c}\right)}\right]^{-1}-Z \\
& \text { where } Z=\frac{G_{H M}}{6}\left(\frac{9 K_{H M}+8 G_{H M}}{K_{H M}+2 G_{H M}}\right) \text { and }
\end{aligned}
$$

$\mathrm{K}_{\mathrm{HM}}$ and $\mathrm{G}_{\mathrm{HM}}$ are the effective bulk and shear modulus as defined by the HertzMindlin contact theory. The effective pressure $\mathrm{P}$ is calculated as the difference between the lithostatic pressure and hydrostatic pressure given as:

$$
P=\left(\rho_{b}-\rho_{w}\right) g D
$$

where $\rho_{b}$ is the sediment bulk density, $\rho_{\mathrm{w}}$ is water density, $\mathrm{g}$ is the acceleration due to gravity and D is depth below the sea floor. For solid grains of mixed mineralogy, the bulk and shear modulus of the composite material can be computed from the moduli of the individual mineral constituents using Hill's (1963) average defined as:

$$
K=\frac{1}{2}\left[\sum_{i=1}^{m} f_{i} K_{i}+\left(\sum_{i=1}^{m} \frac{f_{i}}{G_{i}}\right)^{-1}\right] \text { and } G=\frac{1}{2}\left[\sum_{i=1}^{m} f_{i} G_{i}+\left(\sum_{i=1}^{m} \frac{f_{i}}{G_{i}}\right)^{-1}\right]
$$

where $m$ is the number of mineral constituents for the solid phase, $f_{i}$ is the volumetric fraction of the $i^{\text {th }}$ constituent. $K_{i}$ and $G_{i}$ are the bulk and shear moduli of the $i^{\text {th }}$ mineral constituent. The Hill's average also known as Voigt-Reuss-Hill average is simply the arithmetic average of the Voigt upper bound and the Reuss lower bound, where $\sum_{i=1}^{m} f_{i} K_{i}$ is the Voigt upper bound and $\sum_{i=1}^{m} \frac{f_{i}}{G_{i}}$ is the Reuss lower bound. The VoigtReuss bounds correspond, respectively to conditions of uniform strain and uniform stress across constituent grains. The Voigt and Reuss bounds are very wide. The Hill average is useful when an estimate of the moduli is needed, not just the allowable range of values.

2) The elastic moduli for the unconsolidated sediments saturated with fluid is computed using Gassmann's (1951) equation given by: 


$$
K_{s a t}=K \frac{\phi K_{d r y}-(1+\phi) K_{f l} K_{d r y} / K+K_{f l}}{(1-\phi) K_{f l}+\phi K-K_{f l} K_{d r y} / K} \text { and } G_{s a t}=G_{d r y}
$$

In the above equation, $\mathrm{K}_{\mathrm{dry}}$ and $\mathrm{G}_{\mathrm{dry}}$ are the bulk and shear modulus of the dry frame.

3) Once the elastic moduli are known, the elastic wave velocities are calculated from the following equation:

$$
V_{p}=\sqrt{\frac{K_{s a t}+\frac{4}{3} G_{s a t}}{\rho_{b}}} \text { and } V_{s}=\sqrt{\frac{G_{s a t}}{\rho_{b}}}
$$

where $\rho_{\mathrm{b}}$ is the bulk density which is given by:

$$
\rho_{b}=\phi\left\lfloor f_{g h} \rho_{g h}+\left(1-f_{g h}\right) \rho_{f l}\right\rfloor+(1-\phi) \rho_{\text {grain }}
$$

where $\rho_{g h}$ is the density of the hydrates, $f_{g h}$ is the fraction of hydrates that replaces the fluid in the pores, $\rho f l$ is the density of the fluid and $\Phi$ is the porosity of unconsolidated sediments.

Gas hydrate saturation - Gas hydrate in marine sediment may exist (a) as part of the pore fluid (non-load-bearing) and does not affect the stiffness of the dry frame, (b) as a component of the dry frame (load-bearing) which reduces the porosity and alters the solid phase elastic property (Helgerud et al., 1999) or c) they can exist as a cementing material between grains, either by coating the grains or by acting as a glue between them (Dvorkin et al.,1991). According to non-load-bearing model, the shear modulus is assumed to be zero for pore fluid (Helgerud, 2001), which is not true for solid gas hydrate remaining as a part of pore fluid. The load-bearing model of gas hydrate predicts better gas hydrate saturation when compared with real data (Dai et al., 2004; Helgerud et al., 1999; Petersen et al., 2007) while cementation in its correct sense has not been reported in nature. Thus, the estimation of gas hydrate saturation is done by assuming a load-bearing model (figure 5.1) 
(a) Host sediment:

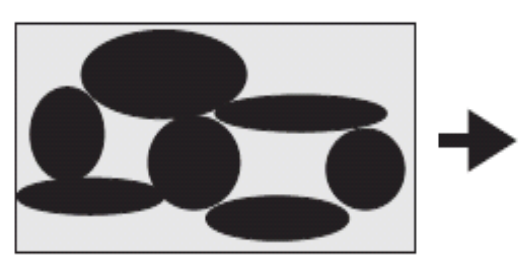

Model:

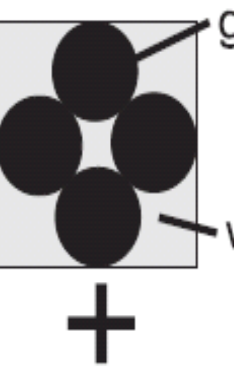

Adding gas hydrate

(b) Pore fill ("floating"):
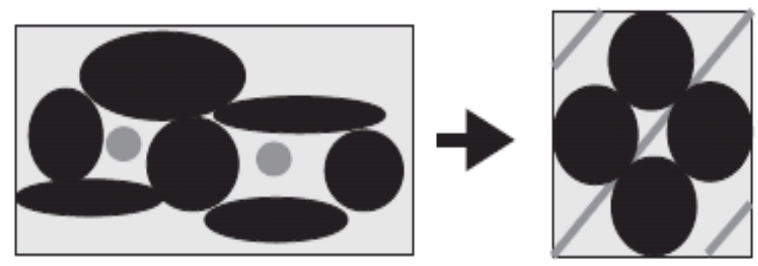

(c) Frame building:
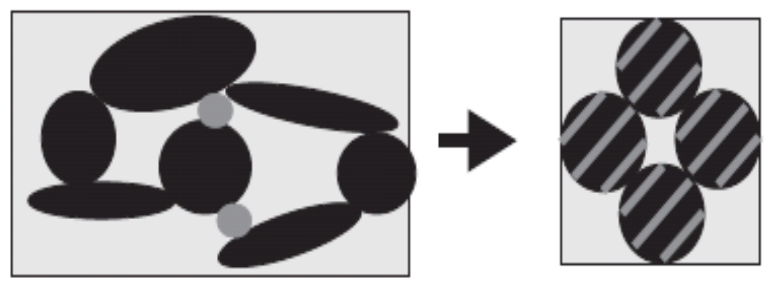

\section{(d) Cementation:}

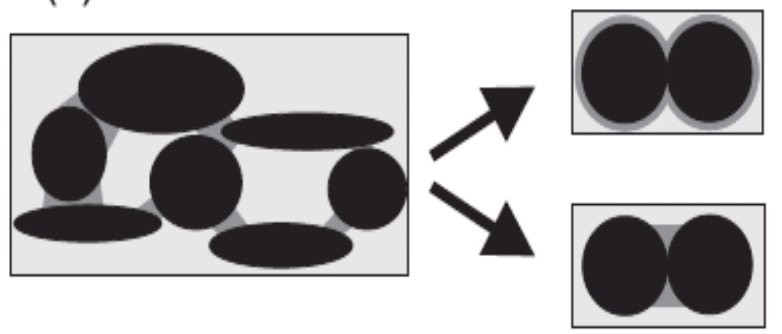

Figure 5.1: Distribution of gas hydrates in sediments. A) Modeling of gas hydrate free host sediment where the sediments are modeled as spheres (Hertz-Mindlin theory). Water is present in the pore space and gas hydrates are added floating in the pores, B) Gas hydrates can be disseminated in the pores without any interaction with the sediment frame, C) Gas hydrates being part of the frame and D) Gas hydrates acting as a cementing agent between grains. Image reproduced after Winters et al.,2004. 
When hydrate is present, the initial porosity $\Phi$ reduces to an effective porosity $\Phi_{\text {eff }}$ which is given by:

$$
\phi_{\text {eff }}=\phi-C_{h}
$$

where $C_{h}$ is the volumetric concentration of hydrate in the unconsolidated rock. When hydrate is part of the mineral frame, the volumetric fraction within the solid phase is given by:

$$
f_{h}=\frac{C_{h}}{1-\phi_{e f f}}
$$

Hence, the volumetric fractions of other mineral constituents change accordingly as

$$
f_{i}^{e f f}=\frac{C_{h}}{1-\phi_{e f f}}
$$

These new volumetric fractions $f_{h}$ and $f_{i}^{\text {eff }}$ will replace the original volumetric fraction $f_{i}$ in the Hill's average equation. In this way, once the new bulk and shear modulus of the dry mineral frame with gas hydrates is calculated, their elastic velocities are also computed by using the equation given in step 3 .

Free gas saturation - Gas may be present with the same proportion of gas and water (uniform distribution) in each pore space or may be concentrated in patches without water (patchy distribution) (Helgerud et al., 1999).

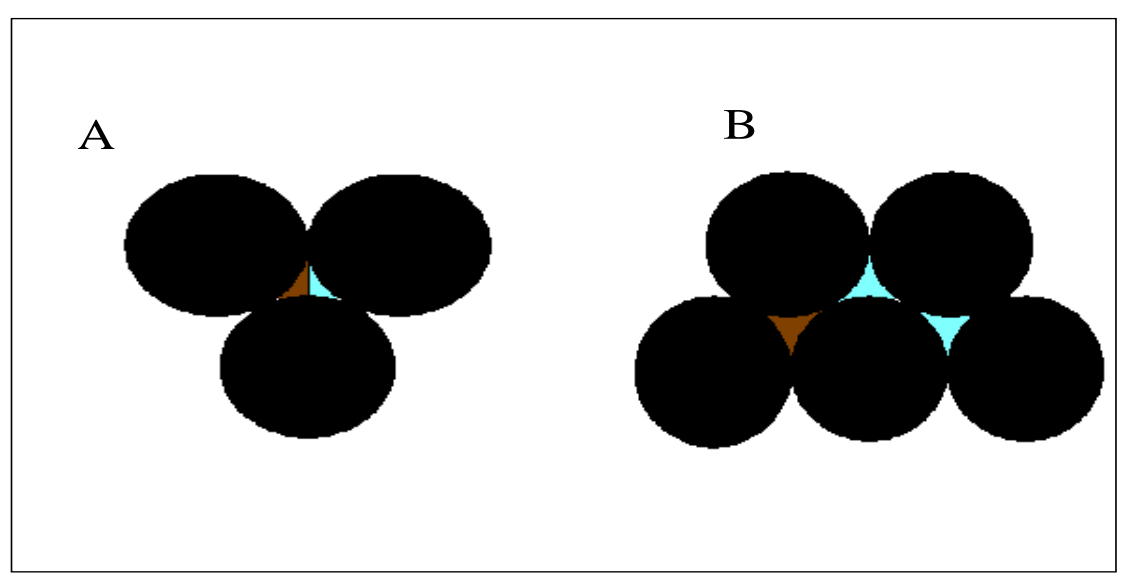

Figure 5.2: A) Even saturation and B) Patchy saturation. 
For a uniform distribution of free gas below the BSR, the bulk modulus of the free gas saturated sediment is computed using the Reuss (isostress) average of bulk moduli of water and gas, whereas, the shear moduli remains same as that of the dry frame (Helgerud et al., 1999). The Reuss (isostress) average is given by:

$$
\bar{K}_{f}=\left[\frac{S_{w}}{K_{w}}+\frac{\left(1-S_{w}\right)}{K_{g}}\right]^{-1}
$$

where $S_{w}$ is the water saturation in pore space, $K_{w}$ and $K_{g}$ are the bulk modulus of water and gas respectively. For patchy distribution of gas, the sediment's effective saturated bulk modulus is calculated from the following relation:

$$
\frac{1}{K_{s a t}+\frac{4}{3} G_{s a t}}=\frac{S_{w}}{K_{s a t W}+\frac{4}{3} G_{s a t W}}+\frac{1-S_{w}}{K_{s a t G}+\frac{4}{3} G_{s a t}}
$$

where $K_{\text {satW }}$ and $K_{s a t G}$ are the bulk moduli of water and gas respectively. $K_{s a t W}$ and $K_{\text {satG }}$ are calculated from Gassmann's equation for unconsolidated sediments by using $K_{w}$ and $K_{g}$ instead of $K_{f}$ in the equation. The shear modulus remains unchanged i.e $G_{s a t}=G_{d r y}$.

The water depth in the study area was $1000 \mathrm{~m}$. The BSR depth is determined to be about $1662 \mathrm{~m}$ i.e $650 \mathrm{~m}$ approximately below the seafloor calculated from the average of interval velocities for 25 CDP's (CDP: 7595-7620) as shown in table 5.2. Modelling was conducted using codes and scripts provided by Dr. Ingo Pecher which was last used for Pecher et al. (2010).

\begin{tabular}{|c|c|}
\hline CDP & $\begin{array}{c}\text { Interval velocities } \\
(\mathrm{m} / \mathrm{s})\end{array}$ \\
\hline 7596 & 1978 \\
7598 & 1925 \\
7600 & 1944 \\
7602 & 1952 \\
7604 & 1932 \\
7606 & 1878 \\
\hline
\end{tabular}




\begin{tabular}{|c|c|}
\hline 7608 & 1944 \\
7610 & 1894 \\
7612 & 1900 \\
7614 & 1872 \\
7616 & 1867 \\
7618 & 1856 \\
Average & 1911.83 \\
\hline
\end{tabular}

Table 5.2: Interval velocities calculated from RMS velocities for CDP's 7595-7620.

\subsubsection{Results}

The AVO intercept (A) and gradient (B) are computed by varying the gas saturation from $0 \%$ to $100 \%$ (both patchy and uniform distribution of free gas) for every $1 \%$ intervals for fixed hydrate saturations of $0 \%$ to $40 \%$ at every $5 \%$ intervals. The variation of $\mathrm{P}$-wave velocity for hydrate saturations $(0 \%-100 \%)$ and for even and patchy gas saturations are shown in figures $5.3,5.4$ and 5.5 .

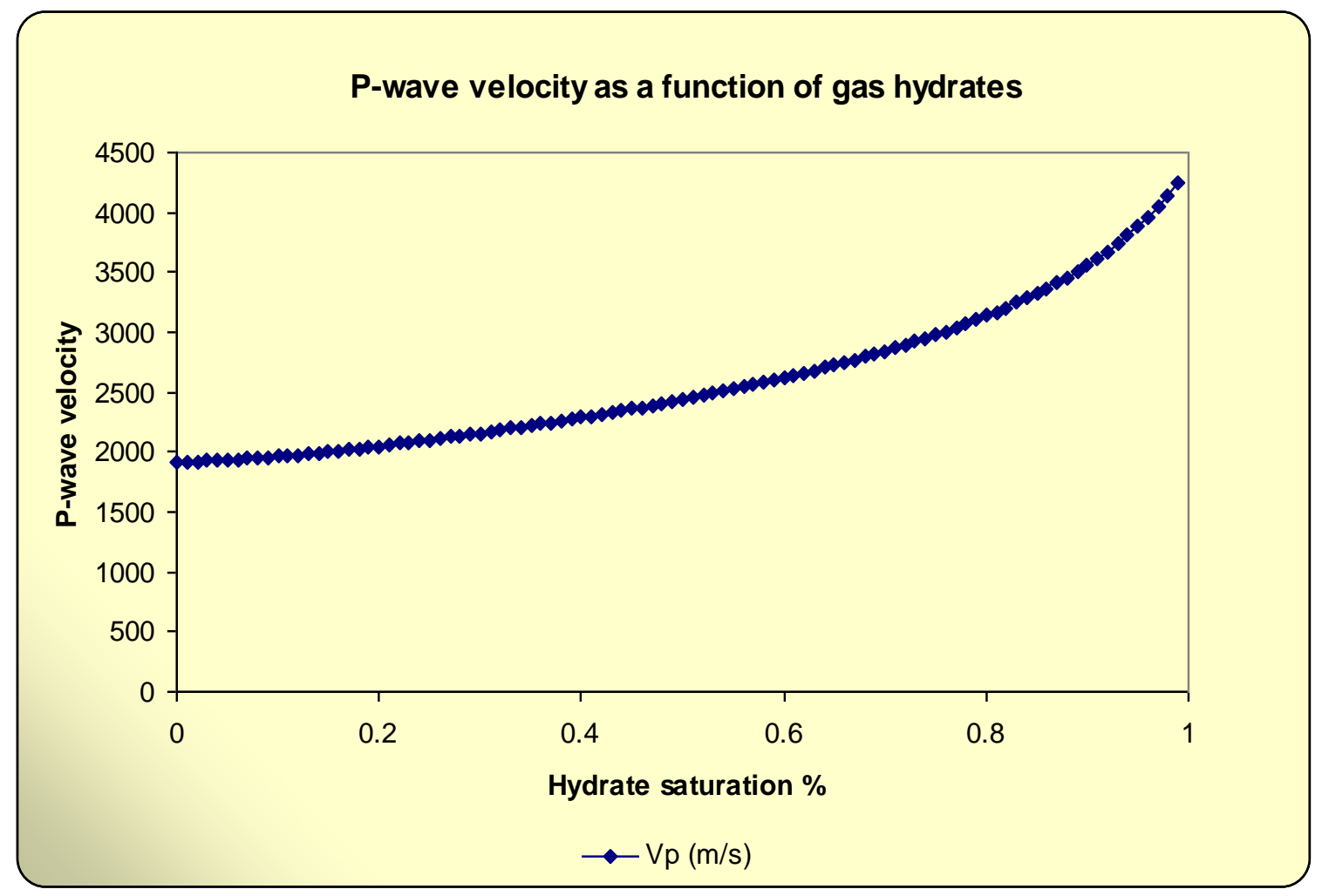

Figure 5.3: Variation of $P$-wave velocity with increasing hydrate saturations. 


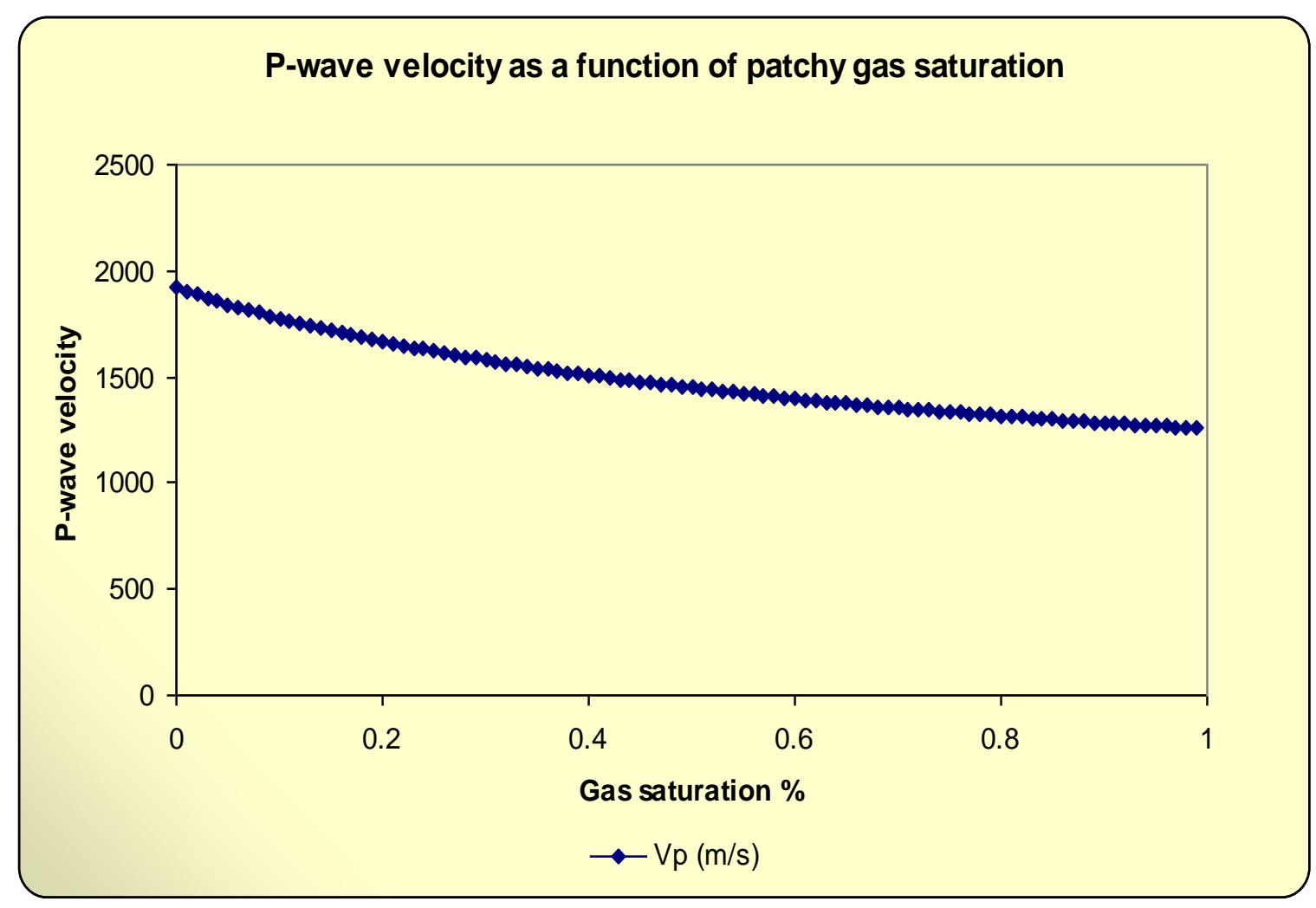

Figure 5.4: Variation of $P$-wave velocity with patchy gas saturations.

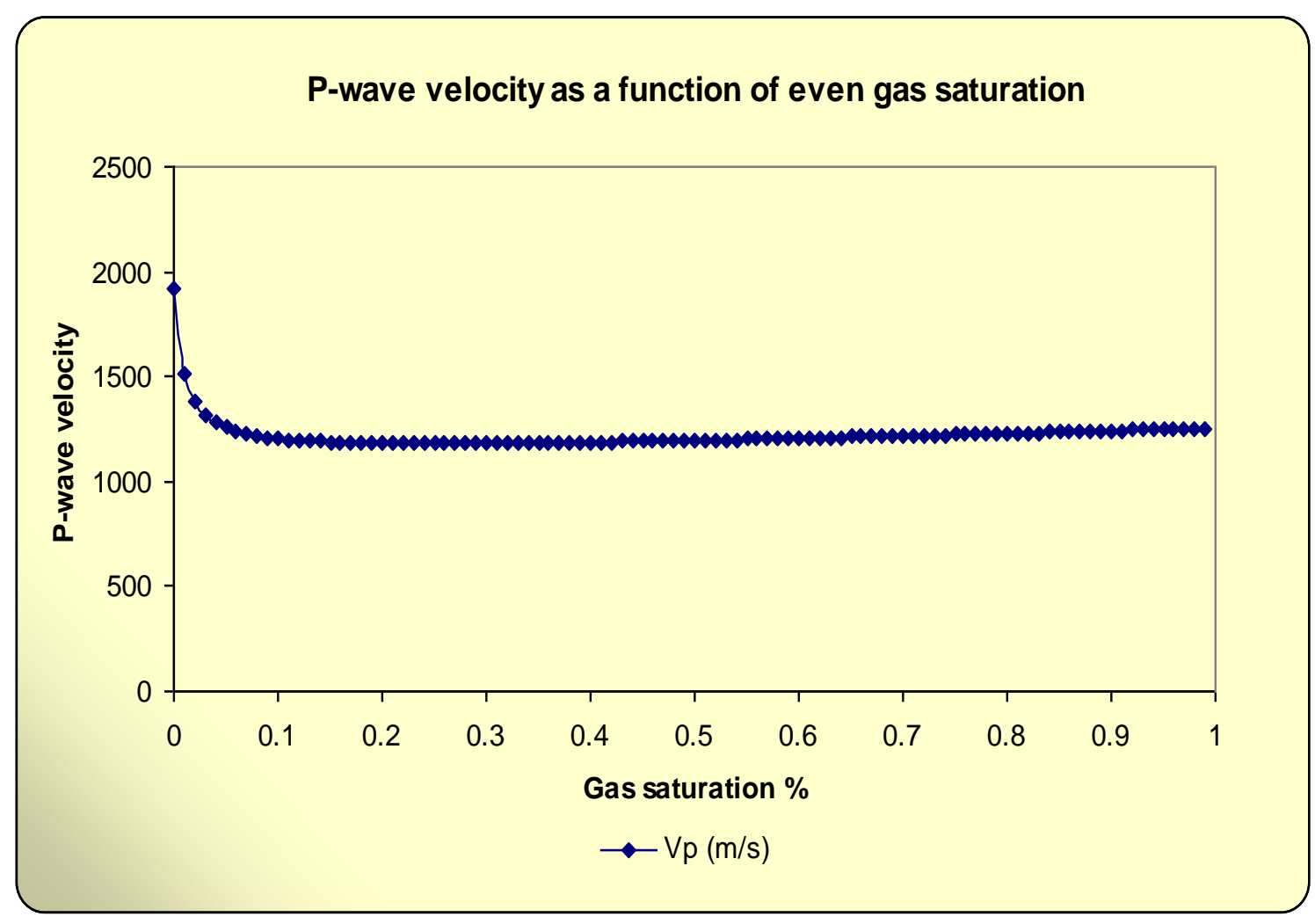

Figure 5.5: Variation of $P$-wave velocity with even gas saturations. 
The possible hydrate and gas saturations that may lead to reflection coefficients in the range of -0.008 to -0.015 are as follows:

- $0 \%$ hydrate and 3\% patchy gas saturation

- $5 \%$ hydrate and $2 \%$ patchy gas saturation

- $13 \%$ hydrate and $0 \%$ gas saturation.

The variations of the reflection coefficients for the above combinations of hydrate and gas saturations with respect to the sine square of the angles of incidence (Shuey, 1985) as shown in figures 5.6, 5.7 and 5.8.

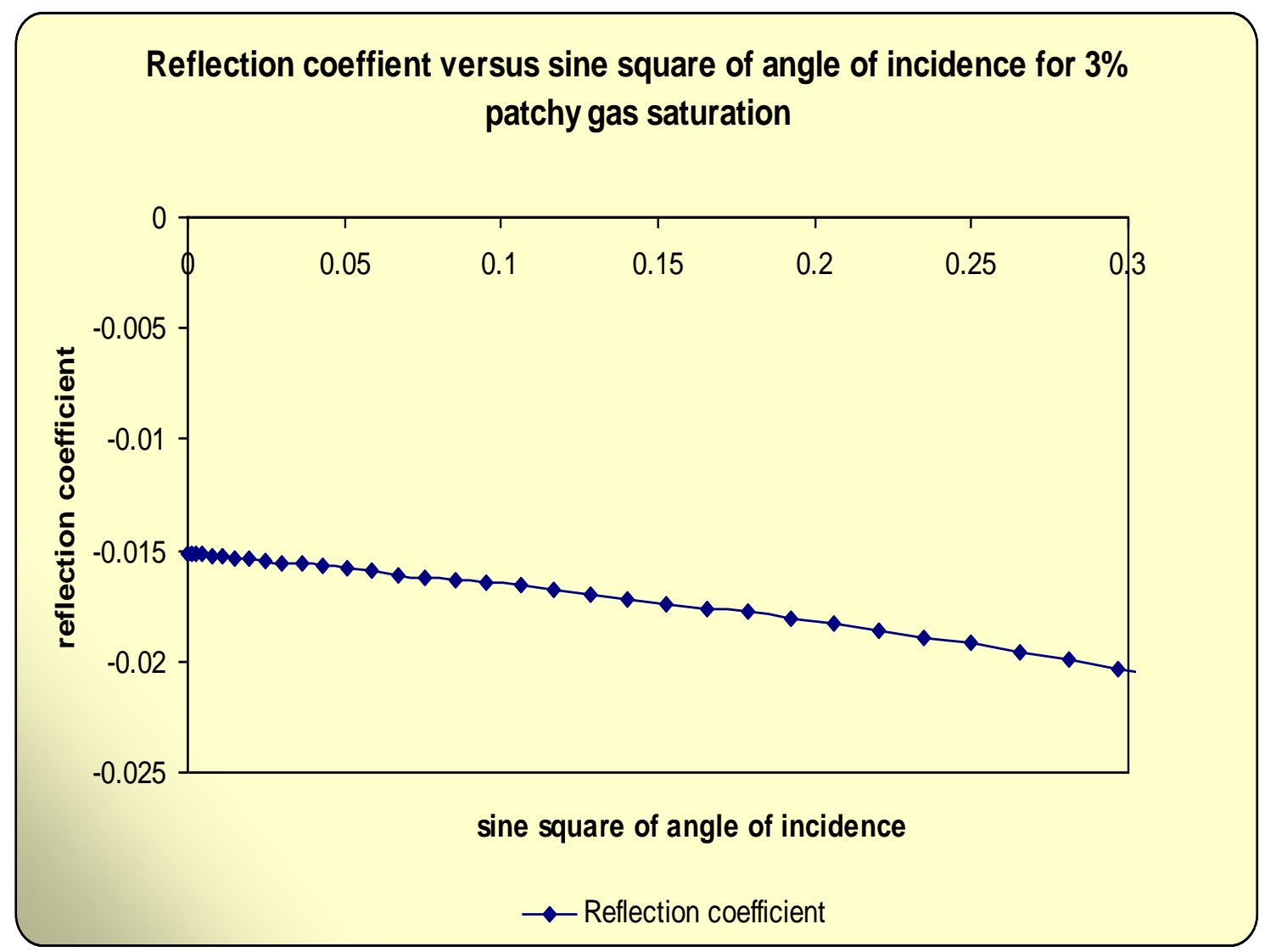

Figure 5.6: Reflection coefficient versus sine square of the angle of incidence for $3 \%$ patchy gas saturation. 


\section{Reflection coefficient versus sine square of angle of incidence for $5 \%$ hydrate saturation and $2 \%$ patchy gas saturation}

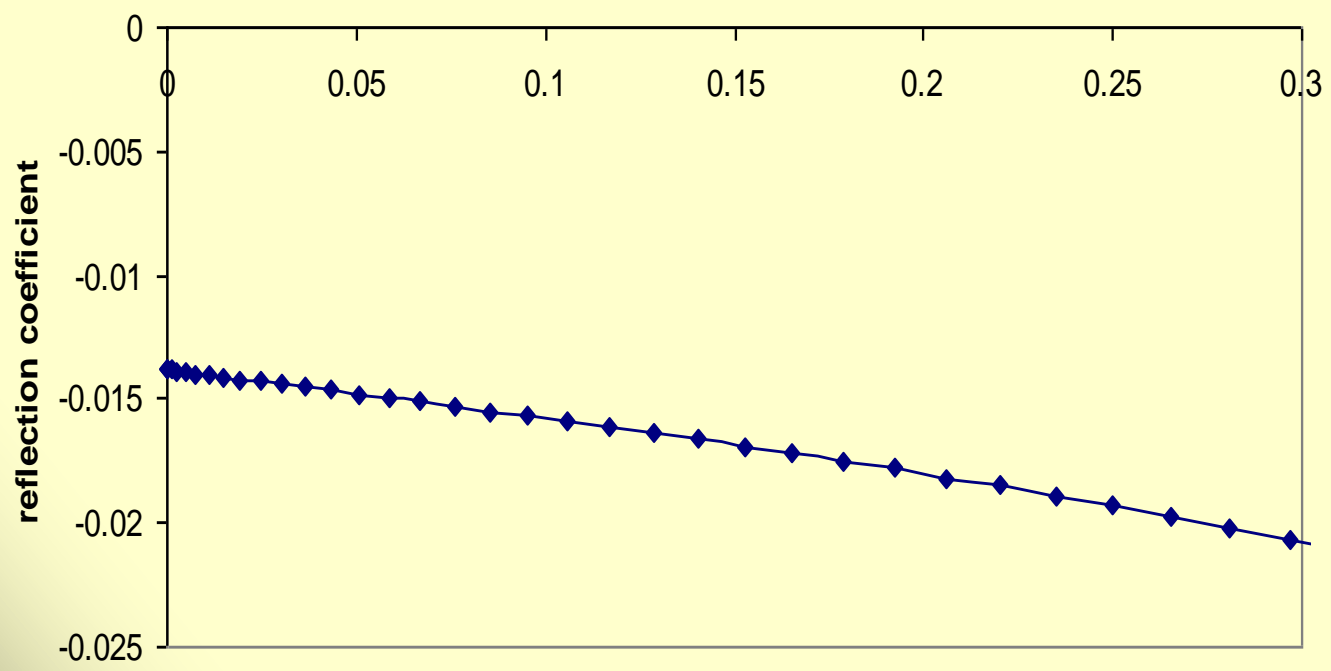

sine square of angle of incidence

$\rightarrow$ Reflection coefficient

Figure 5.7: Reflection coefficient versus sine square of the angle of incidence for $5 \%$ hydrate saturation and $2 \%$ patchy gas saturation.

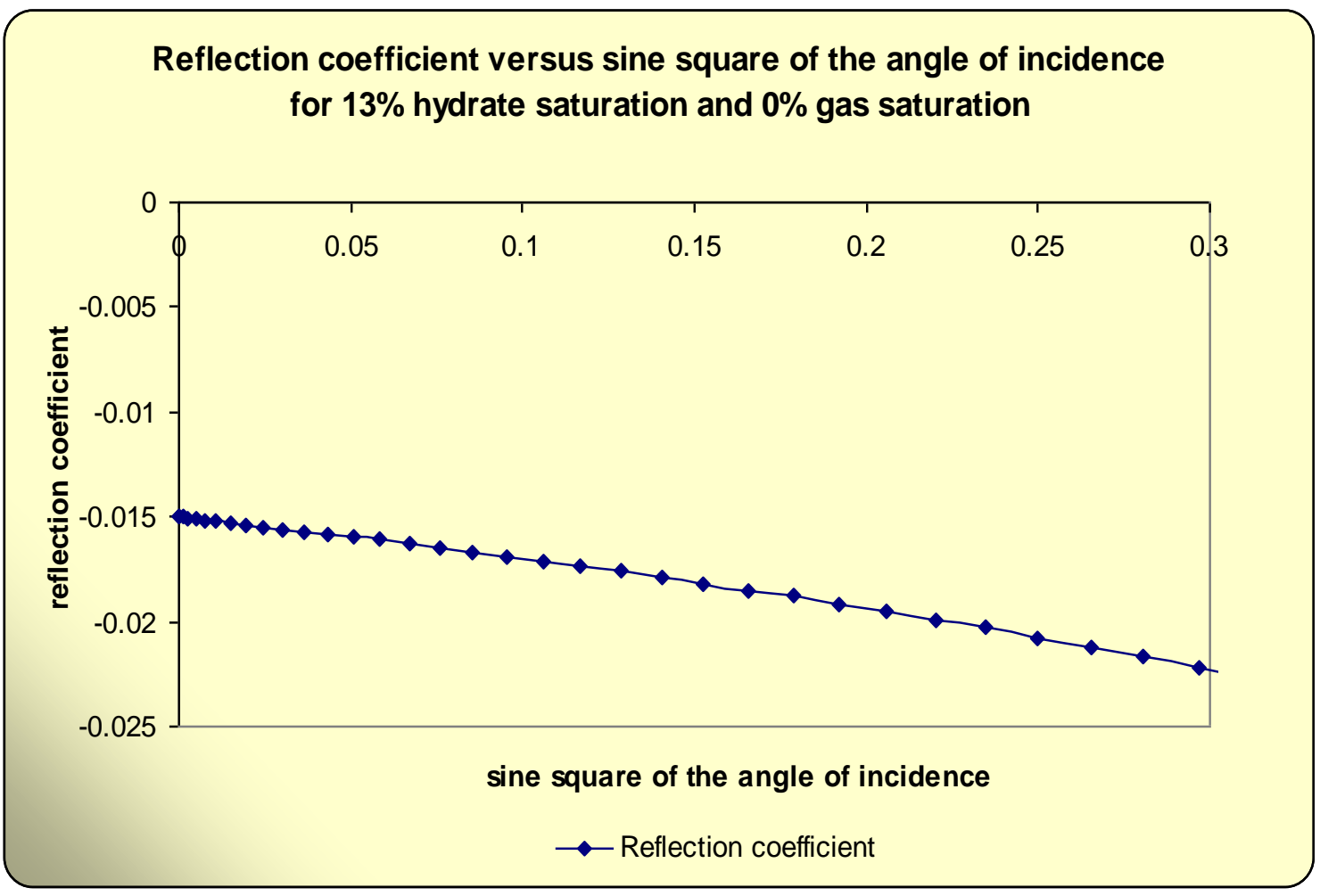

Figure 5.8: Reflection coefficient versus sine square of the angle of incidence for $13 \%$ hydrate saturation and $0 \%$ gas saturation. 
These differences in AVO character are too subtle to distinguish between the end-member models i.e if the BSR is formed due to a transition from an interface containing hydrate to water-saturated sediments or hydrate-free to partially gas-saturated sediments.

\subsection{Synthetic model}

Seismic modelling or synthetic seismic is the process of using the wave equation which governs the passage of acoustic waves through the subsurface to see how the reservoir fluid properties affect the seismic traces and pre-stack gathers. An approximate earth model is built up from the existing information about the subsurface (for example from P-wave and S-wave velocity, density etc). This enables a comparison between the real and synthetic seismic data to make geological inferences from the observed data.

Synthetic seismic shot gathers are generated using an extension of the wave equation reflection/transmission matrix formulation of Kennet (1983), Woodward and Haines (1992). Modelling of synthetic shots has been done by using the Synshot module in GLOBE Claritas $^{\mathrm{TM}}$.

Although extensive testing of various synthetic models was performed, none of the models could replicate the observed Amplitude Versus Offset (AVO) and Amplitude Versus Angle of incidence (AVA) characteristics. This could be due to the shots and receivers wrongly labelled in the manual for the Synshot module. In particular, discrepancy exists between the denotation of pressure or vertical sensors and explosive or horizontal sources. The variation of reflection coefficients for angles of incidence greater than $15^{\circ}$, could not be modelled. Spherical divergence correction was also applied by correcting the data for both spherical (point source i.e 3D model) and cylindrical waves (line source i.e 2D model).

However, Dr. Ingo Pecher has tested and accurately generated the zero-offset reflection coefficients for different models. For a defined impedance contrast, the amplitude of a synthetic reflected wave was calibrated to the predicted reflection coefficient at vertical incidence. This implicitly corrected amplitudes for geometric spreading at zero offset. This impedance contrast was then lowered such that the predicted reflection coefficient was halved. The amplitude of the reflected synthetic wave at zero offset was found to decrease by half. This test ensured that reflected energy was calculated correctly at vertical incidence.

Model 1: The model assumed (figure 5.9) is a uniform layer of gas with patchy distribution of 3\% saturation, with the source and receivers on the upper surface of the upper layer. The elastic properties of the layers are given in table below. In all the models, a Ricker wavelet 
with a frequency of $50 \mathrm{~Hz}$ and compression receivers (representing a pressure sensitive hydrophone) have been used, with calculation of waveforms out to offsets of $2500 \mathrm{~m}$.

\begin{tabular}{|c|c|c|c|}
\hline Depth $(\mathrm{m})$ & $\begin{array}{c}\text { P-wave velocity } \\
(\mathrm{km} / \mathrm{s})\end{array}$ & S-wave velocity $(\mathrm{m} / \mathrm{s})$ & Density $\left(\mathrm{x} 10^{3} \mathrm{~g} / \mathrm{m}^{3}\right)$ \\
\hline 0 & 1.917 & 780 & 1.979 \\
\hline 410 & 1.871 & 780 & 1.979 \\
\hline 600 & 1.917 & 780 & 1.979 \\
\hline
\end{tabular}

Receiver spacing of $12.5 \mathrm{~m}$ and the sampling rate of $2 \mathrm{~ms}$ were used. The zero-offset reflection coefficient obtained on applying a scaling factor of $1.8 \times 10^{11}$ is about -0.0154 , which is approximately equal to the reflection coefficient obtained from the real data as discussed in Chapter 4, section 4.6.

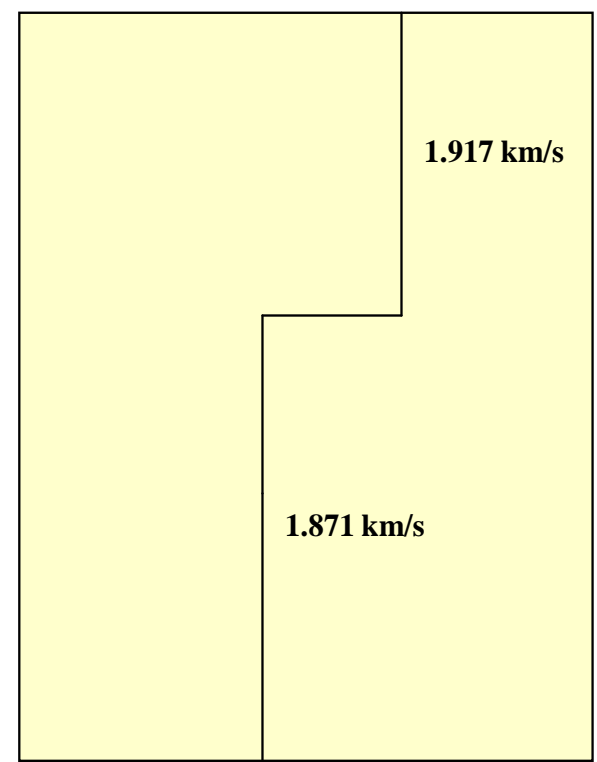

Figure 5.9: Illustration of a uniform layer of gas with patchy distribution of $3 \%$ saturation.

Model 2: The model used here (figure 5.10) has a gradational patchy gas distribution below the BSR with saturations up to $8 \%$. The total free-gas layer thickness used is about $10 \mathrm{~m}$. The elastic properties of the layers are shown in table below.

\begin{tabular}{|c|c|c|c|}
\hline Depth & $\begin{array}{c}\text { P-wave velocity } \\
(\mathrm{km} / \mathrm{s})\end{array}$ & S-wave velocity $(\mathrm{m} / \mathrm{s})$ & $\begin{array}{c}\text { Density } \\
\left(\times 10^{3} \mathrm{~g} / \mathrm{m}^{3}\right)\end{array}$ \\
\hline 0 & 1.917 & 780 & 1.979 \\
\hline
\end{tabular}




\begin{tabular}{|l|l|l|l|}
\hline 410 & 1.800 & 780 & 1.979 \\
\hline 415 & 1.830 & 780 & 1.979 \\
\hline 420 & 1.870 & 780 & 1.979 \\
\hline 600 & 1.917 & 780 & 1.979 \\
\hline
\end{tabular}

The zero-offset reflection coefficient is also approximately equal to -0.0154 using the same scaling factor as used in model 1.

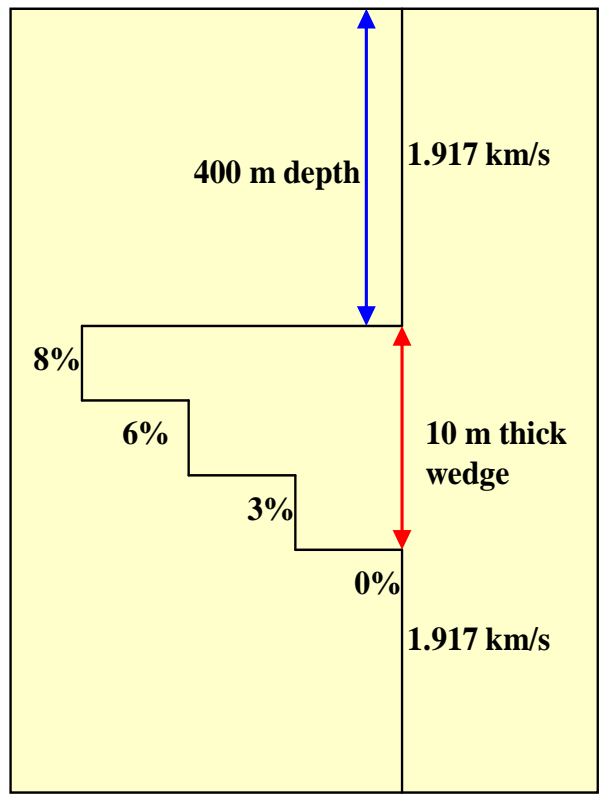

Figure 5.10: Illustration of layered gas model of patchy distribution with saturations up to $8 \%$.

\subsubsection{Discussion}

The most likely explanation for the observed weak BSR with the AVO intercept (A) in the range of -0.008 to -0.015 and gradient (B) with an average value of -0.032 is that gas may be patchily distributed below the BSR with low saturations of up to $3 \%$ and negligible hydrate saturation may exist above the BSR.

In Liu and Flemmings, 2007 model, methane is transported by buoyancy as a continuous gas phase into the regional hydrate stability zone (RHSZ). According to this model, in zones of high flux, free gas supplied from depth forms hydrate thus depleting water and elevating salinity until pore water is too saline for further hydrate formation. Observational evidence (Paull et al., 1996) and theoretical modelling (Buffett and Zatsepina, 1999; Xu and Ruppel, 1999; Liu and Flemmings, 2007) indicate that gas hydrates can be present even when an underlying BSR is absent. In fact, a BSR is present only when the supply of gas exceeds a 
certain threshold that brings the base of the hydrate zone into coincidence with the top of the free gas zone. Hence as seen from the rock-physics modelling results described in section 5.2.4, the other possibility of $13 \%$ hydrate saturation with no gas present beneath the BSR is difficult to explain with current models for hydrate formation (Buffett and Zatsepina, 1999; Xu and Ruppel, 1999; Liu and Flemmings, 2007).

It is difficult to distinguish between the different combinations of hydrate and gas saturations that result in low reflectivity of BSR, as S-wave velocity and thus AVO is marginally affected by low hydrate saturations but the above hydrate-formation models favour the dominant factor causing these weak BSRs.

An alternative explanation for the low reflectivity of the BSR could be due to the presence of thin layers of gas of similar thicknesses as seen from the synthetic model. This "gas wedge" should exist with the same thickness beneath the entire ridge, which is geologically unlikely. Although the gradational transition from hydrate layers to gas layers have not been modelled, it is possible that such a model can reproduce the low reflection coefficient of the BSR provided this gradational transition is even across the entire ridge, which again is geologically unlikely. 

CHAPTER 6

CONCLUSIONS

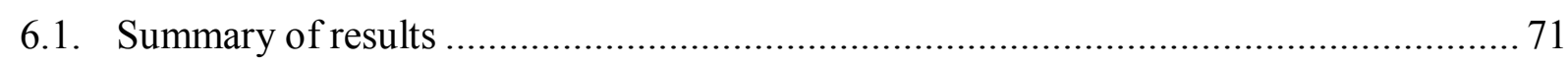

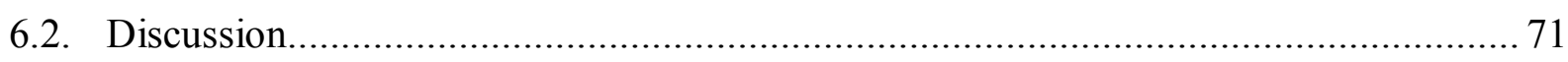

6.2.1. Effects of uncertainties in data analysis .............................................. 73

\subsection{Summary of results}

- The Hikurangi margin is characterized by weak BSRs beneath many thrust ridges. Results of Amplitude Versus Offset (AVO) analysis (Shuey, 1985) of a weak BSR beneath the Puke Ridge, a thrust ridge in the accretionary wedge in the North Island, gives an AVO intercept reflection coefficient (A in Shuey, 1985) between -0.018 and -0.015 which is significantly much lower than the high values of -0.1 and -0.2 which is characteristic of a strong BSR. The AVO gradient (B in Shuey, 1985) is in the range of -0.02 to -0.06 which results in low reflection strength at far offsets and thus in full-offset stacks.

- Rock-physics modelling of the weak BSR beneath Puke Ridge, suggests very low saturations of hydrate above the BSR and patchy gas saturations of 3\% below the BSR. An alternative explanation for the low reflectivity of the BSR may that the transition between hydrate sediment and the gas layer below may be gradational within a small depth interval of $10 \mathrm{~m}$. Alternatively, the weak BSR reflectivity could be due to the presence of thin layers of gas of similar thicknesses as seen from the synthetic model. The latter two models are considered geologically unlikely.

- At some locations in the Hikurangi margin, high amplitude patches are present along weak BSRs. The most likely lithologic explanation for this reflection pattern is the concept of segmented BSRs (Shedd et al., 2009). Weak BSRs may be due to low saturations of gas in low-permeability or shale-dominated layers. The bright spots may represent higher saturations of gas or hydrates in high-permeability sanddominated layers that act as conduits transporting gas for hydrate formation.

\subsection{Discussion}

Gas-hydrates have drawn considerable attention in the scientific community due to their importance as an alternative energy source. They are no longer thought to be ubiquitous materials which are controlled by the correct pressure and found in zones with relatively 
uniform temperature. Instead, the Gas Hydrate Stability Zone (GHSZ) has been found to have a complex geometry (eg: Keathley Canyon in the Gulf of Mexico) and may have lateral and vertical variations in pore water salinity and heat flow.

One of the best tools for hydrate exploration is conventional 2D reflection seismic, which records the base of the hydrate stability zone manifested in the form of a Bottom Simulating Reflection (BSR). The conventional seismic data depict the BSR as a continuous layer and this can be misleading in the mapping and prediction of reserves.

The Hikurangi margin, because of its geologic similarity to the Nankai Trough (Japan's focus area for future production of gas from hydrates) combined with its proximity to major population centres (Auckland, Wellington), make it the most promising gas hydrate province off New Zealand for possible future gas extraction.

In the present study area, beneath Puke Ridge, although the BSR is weak, it is relatively continuous over the eastern flank of the ridge. The seafloor reflection coefficient is used as a calibration in calculating the BSR reflection coefficient. The seafloor reflection coefficients average 0.10 and BSR reflection coefficients $(\sim-0.008$ to -0.015$)$ of the study area are much lower than observed in a number of other areas like the Nankai Trough and Cascadia offshore Vancouver Island where the typical BSR reflection coefficient is about -0.1 (Chapman et al., 2002).

The simple use of reflection coefficients cannot resolve the question whether the reflection is due to overlying gas hydrate, underlying free gas or a combination thereof. The calculations employed in this study are done by assuming that the BSR is entirely due to free gas below the interface. If the reflection is solely due to overlying high-velocity hydrate, the concentration could be about 13\% saturation, using a simple Effective Medium Theory (EMT) rock-physics model. If the BSR reflection is solely due to underlying low-velocity free gas, the gas concentration required is about 3\% if the gas is patchily distributed throughout the sediment, which seems to be a more geologically acceptable explanation for the low BSR reflection coefficient. Other alternatives, such as a thin gas layer, cannot be ruled out but are also unlikely.

The BSR beneath Puke Ridge may result from focusing of rising fluids carrying methane toward the center of the structure. BSRs are present widely further south of the study area, but are localized and patchy beneath most anticlines (eg: Porangahau anticline). Bright highamplitude patches within weak BSRs are present beneath some thrust ridges on the Hikurangi Margin further south. The most likely lithologic explanation for this reflection pattern is the 
concept of segmented BSRs proposed for the Gulf of Mexico - while weak BSRs may be caused by low saturations of gas in shale-dominated layers, the bright spots may mark higher saturations of gas and possibly, hydrates, in high-permeability sand-dominated layers that act as conduits transporting gas for hydrate formation. It is therefore likely that on the parts of the margins where BSRs are generally weak, high-amplitude patches may constitute a lithologic indicator for highly permeable sand layers.

Gas hydrate resources in finely-disseminated accumulations, in which large volumes of gas hydrate are relatively evenly distributed through vast volumes of fine-grained and relatively undeformed sediment at low ( $\sim 10 \%$ or less) saturations, like those found in the present study are perhaps the bulk of the world's global gas hydrate in-place resource (in the hundreds of Tcf gas-in-place). Unfortunately, the prospects for economic recovery of natural gas from this highly disseminated resource are very poor with current technologies. A major paradigm shift will be necessary to enable commercial extraction from such deposits.

In order to assess the future energy supply potential of gas hydrates, investigation of sand and sandstone reservoirs is of highest priority. The development of remote sensing systems, and the advancement of geologic models to better constrain the scale and nature of the marine gas hydrate resource, both in sandstones (highest initial priority) and in dense accumulations of massive forms associated with fracturing will provide an improved understanding of the variety of natural geological systems that produce such deposits.

\subsubsection{Effects of uncertainties in data analysis}

The calculations of free-gas and hydrate saturations requires some assumptions due to the lack of a drill hole. Nevertheless, the key conclusion of weak BSRs caused by gas at low concentration and patchy distribution is robust. Uncertainties with the gas and hydrate-free reference velocity have minimal impact on our results because the modelled reflection coefficients are determined largely by velocity contrasts rather than absolute velocities.

The models described may not reflect the actual sediment composition of the host sediment. The purpose of these models was to replicate realistic elastic properties for the subseafloor reservoir rock and then allow predicting the effect of adding gas and gas hydrate to the reservoir.

Uncertainties associated with our data analysis include in particular ignoring seismic attenuation and transmission losses at reflectors. Transmission losses are negligible while within normal ranges for marine sediments. 



\section{CHAPTER 7}

\section{APPENDIX}

7.1. Ray tracing method to relate offset to angle of incidence. 75

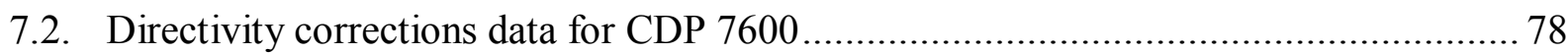

7.3. Seafloor reflection coefficients as a function of angle of incidence for CDP 7600 ...... 80

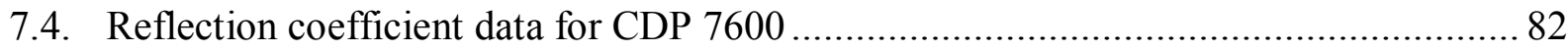

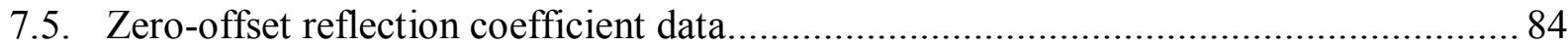

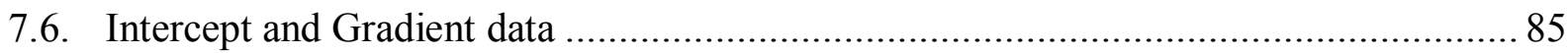

\subsection{Ray tracing method to relate offset to angle of incidence}

A CDP gather orders traces by offset, not angle of incidence. Consequently, the relationship between offset and angle of incidence can be determined by assuming the earth to be a stack of thin horizontal layers and performing iterative ray tracing (figure 7.1). Ray tracing yields angle of incidence as a function of offset and zero-offset two-way time. The angle of incidence $\theta_{1}$ can be calculated from the formula:

$$
\tan \theta=\frac{\frac{S R}{2}}{O C}
$$

where SR is the distance between the source and receiver, OC is the depth to the reflector.

Snell's law equates the ratio of material velocities $V_{1}$ and $V_{2}$ to the ratio of the sine's of incident $\left(\theta_{1}\right)$ and refracted $\left(\phi_{1}\right)$ angles, as shown in the following equation.

$$
\frac{\sin \theta_{1}}{V_{1}}=\frac{\sin \phi_{1}}{V_{2}}
$$

where $\mathrm{V} 1$ is the velocity of layer 1 and $\mathrm{V}_{2}$ is the velocity of layer 2 . Once the refraction angle $\phi_{1}$, has been found from the above equation, $\phi_{1}=\theta_{2}$ as they are interior opposite angles. Here $\theta_{2}$ denotes angle of incidence on layer 2 . 


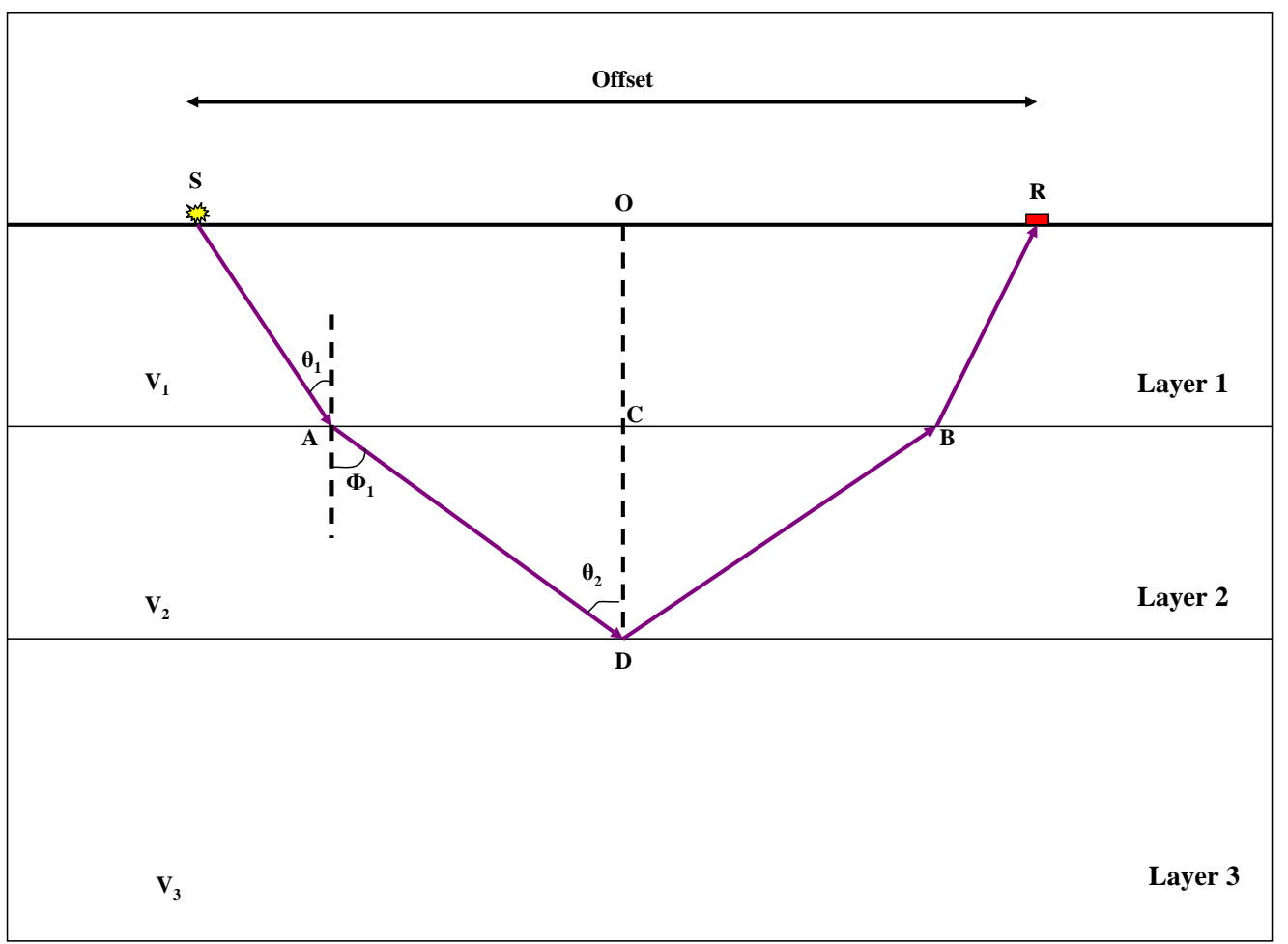

Figure 7.1: Multilayer geometry-complex relationship with $\theta$ and offset

The calculated angle of incidence for CDP 7600 from the offset parameters is shown in table 7.1. The Amplitude Versus Angle of incidence (AVA) for this CDP is displayed in figure 4.16. Here the velocity to the seafloor of $1500 \mathrm{~m} / \mathrm{s}\left(\mathrm{V}_{1}\right)$ and velocity to the BSR of $1900 \mathrm{~m} / \mathrm{s}\left(\mathrm{V}_{2}\right)$ are used, which are calculated from the velocity model. 


\begin{tabular}{|c|c|c|c|c|}
\hline Receivers & Offset & Offset/2 & $\theta_{1}$ & $\theta_{2}$ \\
\hline 1 & -185 & -92.5 & 3.528771219 & 4.474179236 \\
\hline 2 & -260 & -130 & 4.953257478 & 6.282658601 \\
\hline 3 & -335 & -167.5 & 6.371632631 & 8.085757746 \\
\hline 4 & -410 & -205 & 7.782210724 & 9.882006217 \\
\hline 5 & -485 & -242.5 & 9.183362002 & 11.66999336 \\
\hline 6 & -560 & -280 & 10.57352342 & 13.4483797 \\
\hline 7 & -635 & -317.5 & 11.95120799 & 15.21590722 \\
\hline 8 & -710 & -355 & 13.3150129 & 16.97140845 \\
\hline 9 & -785 & -392.5 & 14.66362622 & 18.71381425 \\
\hline 10 & -860 & -430 & 15.99583231 & 20.44216031 \\
\hline 11 & -935 & -467.5 & 17.31051575 & 22.15559231 \\
\hline 12 & -1010 & -505 & 18.60666393 & 23.85336994 \\
\hline 13 & -1085 & -542.5 & 19.88336839 & 25.53486954 \\
\hline 14 & -1160 & -580 & 21.13982481 & 27.19958592 \\
\hline 15 & -1235 & -617.5 & 22.37533199 & 28.847133 \\
\hline 16 & -1310 & -655 & 23.58928973 & 30.47724382 \\
\hline 17 & -1385 & -692.5 & 24.78119592 & 32.08976985 \\
\hline 18 & -1460 & -730 & 25.95064278 & 33.68467986 \\
\hline 19 & -1535 & -767.5 & 27.09731252 & 35.2620585 \\
\hline 20 & -1610 & -805 & 28.22097256 & 36.82210489 \\
\hline 21 & -1685 & -842.5 & 29.3214703 & 38.36513127 \\
\hline 22 & -1760 & -880 & 30.39872771 & 39.89156197 \\
\hline 23 & -1835 & -917.5 & 31.45273571 & 41.40193308 \\
\hline 24 & -1910 & -955 & 32.48354851 & 42.89689283 \\
\hline 25 & -1985 & -992.5 & 33.49127803 & 44.3772031 \\
\hline 26 & -2060 & -1030 & 34.47608836 & 45.84374236 \\
\hline 27 & -2135 & -1067.5 & 35.43819035 & 47.29751035 \\
\hline 28 & -2210 & -1105 & 36.37783649 & 48.739635 \\
\hline 29 & -2285 & -1142.5 & 37.29531593 & 50.17138218 \\
\hline 30 & -2360 & -1180 & 38.19094982 & 51.59416885 \\
\hline
\end{tabular}

Table 7.1: Angle of incidence calculation from offset for CDP 7600 


\subsection{Directivity corrections data for CDP 7600}

Directivity corrections are calculated as described in section 4.5.3 after applying the spherical divergence corrections to the data. The characteristic frequency of the BSR is $50 \mathrm{~Hz}$ and hence the corresponding wavelength $\lambda$ of $30 \mathrm{~m}$ is used. Each group of channel is made of $\mathrm{n}=$ 16 hydrophones separated by $\Delta x=0.781 \mathrm{~m}$. Data shown in table 7.2 is used to plot the graph as shown in figures 4.16 .

\begin{tabular}{|c|c|c|c|c|}
\hline Receivers & $\begin{array}{l}\text { Angle of } \\
\text { incidence }\end{array}$ & $\begin{array}{l}\text { Directivity } \\
\text { correction }\end{array}$ & $\begin{array}{l}\text { BSR amplitude } \\
\text { (picked) } \\
\text { multiplied by }-1\end{array}$ & $\begin{array}{l}\text { BSR amplitude } \\
\text { (corrected) } \\
\text { multiplied by }-1\end{array}$ \\
\hline 1 & 4.474179236 & 0.998924474 & 26.94 & 26.96900587 \\
\hline 2 & 6.282658601 & 0.997884136 & 31.594 & 31.66099034 \\
\hline 3 & 8.085757746 & 0.996506026 & 41.05 & 41.19393051 \\
\hline 4 & 9.882006217 & 0.994800983 & 50.674 & 50.93883186 \\
\hline 5 & 11.66999336 & 0.992782177 & 51.415 & 51.78880241 \\
\hline 6 & 13.4483797 & 0.990464866 & 46.987 & 47.43934048 \\
\hline 7 & 15.21590722 & 0.987866115 & 45.669 & 46.22994891 \\
\hline 8 & 16.97140845 & 0.985004499 & 48.328 & 49.06373528 \\
\hline 9 & 18.71381425 & 0.981899797 & 48.615 & 49.5111621 \\
\hline 10 & 20.44216031 & 0.978572672 & 45.453 & 46.44826217 \\
\hline 11 & 22.15559231 & 0.975044369 & 46.074 & 47.25323427 \\
\hline 12 & 23.85336994 & 0.97133642 & 55.269 & 56.89995643 \\
\hline 13 & 25.53486954 & 0.967470366 & 61.306 & 63.36731557 \\
\hline 14 & 27.19958592 & 0.963467505 & 64.12 & 66.55128444 \\
\hline 15 & 28.847133 & 0.959348669 & 65.372 & 68.14206565 \\
\hline 16 & 30.47724382 & 0.955134027 & 67.538 & 70.71049514 \\
\hline 17 & 32.08976985 & 0.950842923 & 69.096 & 72.66815407 \\
\hline 18 & 33.68467986 & 0.946493738 & 72.011 & 76.08185568 \\
\hline 19 & 35.2620585 & 0.942103794 & 56.909 & 60.40629535 \\
\hline 20 & 36.82210489 & 0.937689269 & 67.743 & 72.24461475 \\
\hline 21 & 38.36513127 & 0.933265157 & 72.852 & 78.06141633 \\
\hline 22 & 39.89156197 & 0.928845238 & 74.452 & 80.15544137 \\
\hline 23 & 41.40193308 & 0.924442071 & 74.192 & 80.2559753 \\
\hline
\end{tabular}




\begin{tabular}{|l|c|c|c|c|}
\hline 24 & 42.89689283 & 0.920067012 & 87.758 & 95.38218292 \\
25 & 44.3772031 & 0.915730238 & 78.886 & 86.14545718 \\
26 & 45.84374236 & 0.91144079 & 71.268 & 78.19268213 \\
27 & 47.29751035 & 0.907206622 & 54.539 & 60.1175065 \\
28 & 48.739635 & 0.903034656 & 60.731 & 67.25212551 \\
29 & 50.17138218 & 0.898930845 & 54.767 & 60.92459757 \\
30 & 51.59416885 & 0.894900242 & 52.97 & 59.19095502 \\
\hline
\end{tabular}

Table 7.2: Directivity corrections for CDP 7600 
7.3. Seafloor reflection coefficients as a function of angle of incidence for CDP 7600

\begin{tabular}{|c|c|c|}
\hline Receivers & Angle of incidence & Amplitude of seafloor \\
\hline 1 & 3.052882515 & 270.36 \\
\hline 2 & 4.479023077 & 261.68 \\
\hline 3 & 5.899625047 & 251.21 \\
\hline 4 & 7.312986245 & 249.13 \\
\hline 5 & 8.717456965 & 241.95 \\
\hline 6 & 10.11145082 & 225.95 \\
\hline 7 & 11.49345452 & 247.6 \\
\hline 8 & 12.86203637 & 234.03 \\
\hline 9 & 14.21585347 & 234.78 \\
\hline 10 & 15.55365759 & 214.04 \\
\hline 11 & 16.87429954 & 238.1 \\
\hline 12 & 18.17673224 & 217.74 \\
\hline 13 & 19.46001244 & 220.7 \\
\hline 14 & 20.72330117 & 224.02 \\
\hline 15 & 21.96586305 & 205.81 \\
\hline 16 & 23.18706451 & 190.11 \\
\hline 17 & 24.3863711 & 206.78 \\
\hline 18 & 25.56334406 & 196.13 \\
\hline 19 & 26.71763611 & 168.74 \\
\hline 20 & 27.84898685 & 161.24 \\
\hline 21 & 28.9572176 & 193.71 \\
\hline 22 & 30.04222609 & 172.45 \\
\hline 23 & 31.10398087 & 174.92 \\
\hline 24 & 32.1425157 & 144.32 \\
\hline 25 & 33.15792388 & 146.12 \\
\hline 26 & 34.15035272 & 135.05 \\
\hline 27 & 35.11999805 & 141.26 \\
\hline 28 & 36.06709906 & 129.42 \\
\hline 29 & 36.9919332 & 112.52 \\
\hline 30 & 37.89481147 & 100.45 \\
\hline
\end{tabular}




\begin{tabular}{|l|c|c|}
\hline 31 & 38.77607388 & 107.28 \\
32 & 39.6360853 & 83.136 \\
33 & 40.47523153 & 82.979 \\
34 & 41.29391567 & 66.381 \\
35 & 42.09255487 & 52.981 \\
36 & 42.87157725 & 63.021 \\
\hline
\end{tabular}

Table 7.3: Seafloor reflection coefficients calculated as a function of angle of incidence for CDP 7600. 


\subsection{Reflection coefficient data for CDP 7600}

The Reflection coefficient of the BSR is calculated as described in section 4.5.3. The following table gives the data used to plot the reflection coefficient of CDP 7600 as a function of angle of incidence as shown in figure 4.18.

\begin{tabular}{|c|c|c|c|c|c|}
\hline Receivers & $\begin{array}{l}\text { Seafloor } \\
\text { Amplitude }\end{array}$ & $\begin{array}{l}\text { Multiple } \\
\text { Amplitude }\end{array}$ & $\begin{array}{c}\text { BSR } \\
\text { Amplitude }\end{array}$ & $\begin{array}{l}\text { Reflection } \\
\text { coefficient } \\
\text { of seafloor }\end{array}$ & $\begin{array}{c}\text { Reflection } \\
\text { coefficient of } \\
\text { BSR }\end{array}$ \\
\hline 1 & 270.5779012 & $-2.66 \mathrm{E}+01$ & -26.96900587 & 0.09831919 & -0.009799658 \\
\hline 2 & 262.1337773 & $-2.57 \mathrm{E}+01$ & -31.66099034 & 0.098064432 & -0.011504572 \\
\hline 3 & 251.9653145 & $-3.60 \mathrm{E}+01$ & -41.19393051 & 0.142841089 & -0.014968532 \\
\hline 4 & 250.2800647 & $-3.03 E+01$ & -50.93883186 & 0.120880582 & -0.018509511 \\
\hline 5 & 243.5356428 & $-2.47 \mathrm{E}+01$ & -51.78880241 & 0.101356827 & -0.018818363 \\
\hline 6 & 227.9400418 & $-2.09 \mathrm{E}+01$ & -47.43934048 & 0.091760973 & -0.01723791 \\
\hline 7 & 250.4140233 & $-2.06 \mathrm{E}+01$ & -46.22994891 & 0.082267757 & -0.016798457 \\
\hline 8 & 237.3562202 & $-1.48 \mathrm{E}+01$ & -49.06373528 & 0.062252424 & -0.017828162 \\
\hline 9 & 238.8498956 & $-1.68 \mathrm{E}+01$ & -49.5111621 & 0.070458478 & -0.017990742 \\
\hline 10 & 218.4739007 & $-2.10 \mathrm{E}+01$ & -46.44826217 & 0.096020623 & -0.016877784 \\
\hline 11 & 243.89457 & $-2.26 \mathrm{E}+01$ & -47.25323427 & 0.09268349 & -0.017170285 \\
\hline 12 & 223.8762161 & $-3.04 \mathrm{E}+01$ & -56.89995643 & 0.135673188 & -0.020675589 \\
\hline 13 & 227.8134062 & $-3.16 \mathrm{E}+01$ & -63.36731557 & 0.13881097 & -0.023025617 \\
\hline 14 & 232.1894234 & $-2.55 E+01$ & -66.55128444 & 0.110022238 & -0.024182568 \\
\hline 15 & 214.2217958 & $-1.51 \mathrm{E}+01$ & -68.14206565 & 0.070501696 & -0.024760606 \\
\hline 16 & 198.7458364 & $-1.39 \mathrm{E}+01$ & -70.71049514 & 0.070129771 & -0.025693889 \\
\hline 17 & 217.1418732 & $-2.62 \mathrm{E}+01$ & -72.66815407 & 0.120483441 & -0.026405239 \\
\hline 18 & 206.8993539 & $-2.52 \mathrm{E}+01$ & -76.08185568 & 0.121629186 & -0.027645666 \\
\hline 19 & 178.8313428 & $-3.55 \mathrm{E}+01$ & -60.40629535 & 0.198779473 & -0.021949679 \\
\hline 20 & 171.6848682 & $-5.07 \mathrm{E}+01$ & -72.24461475 & 0.29554148 & -0.026251338 \\
\hline 21 & 207.2340859 & $-6.27 \mathrm{E}+01$ & -78.06141633 & 0.302522627 & -0.028364974 \\
\hline 22 & 185.3668679 & $-6.08 \mathrm{E}+01$ & -80.15544137 & 0.328176231 & -0.029125875 \\
\hline 23 & 188.9174194 & $-6.40 \mathrm{E}+01$ & -80.2559753 & 0.338571214 & -0.029162405 \\
\hline 24 & 156.6105468 & $-4.50 \mathrm{E}+01$ & -95.38218292 & 0.287170953 & -0.034658776 \\
\hline 25 & 159.3159846 & $-3.70 \mathrm{E}+01$ & -86.14545718 & 0.231972957 & -0.031302451 \\
\hline
\end{tabular}




\begin{tabular}{|l|c|c|c|c|c|}
\hline 26 & 147.9408504 & $-4.30 \mathrm{E}+01$ & -78.19268213 & 0.290791893 & -0.028412672 \\
27 & 155.4679995 & $-3.68 \mathrm{E}+01$ & -60.1175065 & 0.236511695 & -0.021844742 \\
28 & 143.097548 & $-3.53 \mathrm{E}+01$ & -67.25212551 & 0.246454258 & -0.02443723 \\
29 & 124.9818282 & $-3.07 \mathrm{E}+01$ & -60.92459757 & 0.245795732 & -0.022138013 \\
30 & 112.0799333 & $-2.65 \mathrm{E}+01$ & -59.19095502 & 0.236420555 & -0.021508064 \\
\hline
\end{tabular}

Table 7.4: Reflection coefficient calculation for CDP 7600 


\subsection{Zero-offset reflection coefficient data}

Zero-offset or near-vertical reflection coefficients for 25 CDP's shown in table 5 are used to plot the graph shown as figure 4.18.

\begin{tabular}{|c|c|}
\hline CDP & Zero-offset reflection coefficient \\
\hline 7595 & -0.004259849 \\
\hline 7596 & -0.00856809 \\
\hline 7597 & -0.015688165 \\
\hline 7598 & -0.013932656 \\
\hline 7599 & -0.013212652 \\
\hline 7600 & -0.009799658 \\
\hline 7601 & -0.010222237 \\
\hline 7602 & -0.012334322 \\
\hline 7603 & -0.019795717 \\
\hline 7604 & -0.012191501 \\
\hline 7605 & -0.010896427 \\
\hline 7606 & -0.016979826 \\
\hline 7607 & -0.020172498 \\
\hline 7608 & -0.017546499 \\
\hline 7609 & -0.012972958 \\
\hline 7610 & -0.020444539 \\
\hline 7611 & -0.014047801 \\
\hline 7612 & -0.020175559 \\
\hline 7613 & -0.019514641 \\
\hline 7614 & -0.023484079 \\
\hline 7615 & -0.011696989 \\
\hline 7616 & -0.018397836 \\
\hline 7617 & -0.019962042 \\
\hline 7618 & -0.023279089 \\
\hline 7619 & -0.020493653 \\
\hline 7620 & -0.017010597 \\
\hline
\end{tabular}

Table 7.5: Zero-offset reflection coefficients for 25 CDP's (7595-7620) 


\subsection{Intercept and Gradient data}

\begin{tabular}{|c|c|c|c|}
\hline CDP & Intercept & Gradient & $\begin{array}{l}\text { Zero-offset } \\
\text { reflection } \\
\text { coefficient }\end{array}$ \\
\hline 7595 & -0.007946529 & -0.030968384 & -0.004259849 \\
\hline 7596 & -0.011646831 & -0.0358418 & -0.00856809 \\
\hline 7597 & -0.016101796 & -0.029105923 & -0.015688165 \\
\hline 7598 & -0.014445162 & -0.022776901 & -0.013932656 \\
\hline 7599 & -0.017027255 & -0.02648378 & -0.013212652 \\
\hline 7600 & -0.015136489 & -0.030738782 & -0.009799658 \\
\hline 7601 & -0.015447308 & -0.030398105 & -0.010222237 \\
\hline 7602 & -0.015614863 & -0.031205328 & -0.012334322 \\
\hline 7603 & -0.020871627 & -0.039675969 & -0.019795717 \\
\hline 7604 & -0.01534133 & -0.032470101 & -0.012191501 \\
\hline 7605 & -0.012229806 & -0.029180574 & -0.010896427 \\
\hline 7606 & -0.016386758 & -0.040771963 & -0.016979826 \\
\hline 7607 & -0.016482156 & -0.046977422 & -0.020172498 \\
\hline 7608 & -0.017157353 & -0.046874548 & -0.017546499 \\
\hline 7609 & -0.017214519 & -0.041570879 & -0.012972958 \\
\hline 7610 & -0.02206074 & -0.048419562 & -0.020444539 \\
\hline 7611 & -0.014541445 & -0.027622276 & -0.014047801 \\
\hline 7612 & -0.018958781 & -0.037047648 & -0.020175559 \\
\hline 7613 & -0.017155018 & -0.034720325 & -0.019514641 \\
\hline 7614 & -0.02073101 & -0.03943498 & -0.023484079 \\
\hline 7615 & -0.019085186 & -0.018254469 & -0.011696989 \\
\hline 7616 & -0.021496616 & -0.013007092 & -0.018397836 \\
\hline 7617 & -0.020968386 & -0.016467493 & -0.019962042 \\
\hline 7618 & -0.021587964 & -0.036087715 & -0.023279089 \\
\hline 7619 & -0.018727917 & -0.032572794 & -0.020493653 \\
\hline 7620 & -0.018924435 & -0.018040079 & -0.017010597 \\
\hline
\end{tabular}

Table 7.6: Intercept, Gradient and Zero-offset reflection coefficients for 25 CDP's (7595-7620) 



\section{References}

Alexander, C. R., J. P. Walsh, A. R. Orpin, B. W. Sumners, and S. A. Kuehl, 2006, Modern Sedimentation on the Continental Slope Seaward of the Waipaoa River, New Zealand EOS, Transactions, American Geophysical Union [EOS Trans. Am. Geophys. Union]. , v. 87.

Barnes, P. M., G. Lamarche, J. Bialas, S. Henrys, I. Pecher, G. L. Netzeband, J. Greinert, J. J. Mountjoy, K. Pedley, and G. Crutchley, 2010, Tectonic and geological framework for gas hydrates and cold seeps on the Hikurangi subduction margin, New Zealand: Marine Geology, v. 272 , p. $26-48$.

Berryman, K., M. Marden, D. Eden, C. Mazengarb, Y. Ota, and I. Moriya, 2000, Tectonic and paleoclimatic significance of Quaternary river terraces of the Waipaoa river, east coast, North Island, New Zealand: New Zealand Journal of Geology and Geophysics, v. 43, p. 229 245.

Blunier, T., J. Chapellaz, J. Schwander, B. Stauffer, and D. Raynaud, 1995, Variations in methane concentration during the Holocene epoch: Nature v. 374, p. 46-49.

Borowski, W. S., 2004, A review of methane and gas hydrates in the dynamic, stratified system of the Blake Ridge region, offshore southeastern North America.: Chemical Geology, v. 205 , p. 311.

Boswell, R., and T. Collett, 2006, DOE-NETL Fire in the Ice. Methane Hydrate Newsletter, p. 5 .

Brackley, H. L., 2006, Land to ocean transfer of erosion-related organic carbon, Waipaoa sedimentary system, East Coast, New Zealand: Dissertation thesis, Victoria University of Wellington, $129 \mathrm{pp}$ plus appendices $\mathrm{p}$.

Brook, E. J., T. Sowers, and J. Orchardo, 1996, Rapid variations in atmospheric methane concentrations during the past 110,000 years: Science, v. 273, p. 1087-1091. 
Buffett, B. A., and O. Y. Zatsepina, 1999, metastability of gas hydrate: Geophys. Res. Lett., v. 26, p. 2981-2984.

C. Pearson, J. Murphy, and R. Hermes, 1986, Acoustic and resistivity measurements on rock samples containing tetrahydrofuran hydrates: laboratory analogues to natural gas hydrate deposits: Journal of Geophysical Research, v. 91, p. 14132-14138.

Carter, L., A. R. Orpin, and S. A. Kuehl, 2010, From mountain source to ocean sink - the passage of sediment across an active margin, Waipaoa Sedimentary System, New Zealand: Marine Geology, v. 270, p. 1-10.

Chapellaz, J., T. Blunier, D. Raynaud, J. M. Barnola, J. Schwander, and B. Stauffer, 1993, Synchronous changes in atmospheric $\mathrm{CH} 4$ and Greenland climate between 40 and 8 kyr ago: Nature, v. 366, p. 443-445.

Collett, T. S., 2007, Arctic Gas Hydrate Energy Assessment Studies: The Arctic Energy Summit.

Collett, T. S., 2009, Unconventional Fuels II: The Promise of Methane Hydrates

p. Statement of Dr. Timothy S.Collet, Research Geologist in U.S Geological Survey before the Subcommittee on Energy and Mineral Resources on Unconventional Fuels II: The Promise of Methane Hydrates

Collett, T. S., and V. A. Kuuskraa, 1998, Hydrates contain vast store of world gas resources: Oil and Gas Journal, v. 96, p. 90-95.

Collett, T. S., A. H. Johnson, C.C.Knapp, and R.Boswell, eds., 2009 Natural Gas Hydrates: A Review: Natural gas hydrates - Energy resource potential and associated geologic hazards, v. 89, AAPG Memoir 146-219 p.

Collot, J.-Y., B. Davy, and G. Lamarche, 1996, Forearc structures and tectonic regimes at the oblique collision zone between the Hikurangi Plateau and the southern Kermadec arc: Eos, Transactions,American Geophysical Union v. 77, p. 121. 
Collot, J.-Y., K. Lewis, G. Lamarche, and S. Lallemand, 2001, The giant Ruatoria debris avalanche on the northern Hikurangi margin, New Zealand: Result of oblique seamount subduction: Journal of Geophysical Research, v. 106, p. 19271-19297.

Crutchley, G. 2009. Gas Hydrates on New Zealand's Hikurangi Margin: the importance of focused fluid flow for highly-concentrated deposits, methane seepage, and seafloor erosion. Dunedin, University of Otago. PhD thesis.

Crutchley GJ, Pecher IA, Gorman AR, Henrys S, Greinert J 2010, Seismic imaging of gas conduits beneath seafloor vent sites in a shallow marine gas hydrate province, Hikurangi Margin, New Zealand. Mar. Geol. 272(1-4): 114-126.

Dai, J., H. Xu, F. Snyder, and N. Dutta, 2004, Detection and estimation of gas hydrates using rock physics and seismic inversion: Examples from the northern deepwater Gulf of Mexico: The Leading Edge, v. 23, p. 60-66.

Davey, F. J., M. Hampton, J. Childs, M. A. Fisher, K. Lewis, and J. R. Pettinga, 1986, Structure of a growing accretionary prism, Hikurangi margin, New Zealand: Geology, v. 14, p. 663-666.

Davy, B., and R. Wood, 1994, Gravity and magnetic modelling of the Hikurangi Plateau: Marine Geology, v. 118, p. 139-151.

Dillon, W. P., M. W. Lee, D. R. Hutchinson, R. M. Drury, M. H. Taylor, and J. S. Booth, eds., 1998, Evidence for faulting related to dissociation of gas hydrate and release of methane off the southeastern United States: Gas hydrates: Relevance to world margin margin stability and climate change, v. Special publications: London, Geological Society of London, 137 p.

Dvorkin, J., A. Nur, and H. Yin, 1994, Effective properties of cemented granular materials: Mechanics of Materials, v. 18, p. 351-366. 
Ellis, S., Pecher, I.A, Kukowski, N., Xu W., Henrys, S. A., Greinert, J., 2009. Testing proposed mechanisms for seafloor weakening at the top of gas hydrate stability on an uplifted ridge (Rock garden), New Zealand. Marine Geology (in press).

Faure, K., J. Greinert, J. S. von Deimling, D. F. McGinnis, R. Kipfer, and P. Linke, 2010, Methane seepage along the Hikurangi Margin of New Zealand: Geochemical and physical data from the water column, sea surface and atmosphere: Marine Geology, v. 272, p. 170188.

Fischer, P. A., 1999, Gas hydrate research heats up, World Oil, Gulf Publishing Co.

Foster, G., and L. Carter, 1997, Mud sedimentation on the continental shelf at an accretionary margin - Poverty Bay, New Zealand: New Zealand Journal of Geology and Geophysics, v. 40, p. 157-173.

Fujii, T., T. Saeki, T. Kobayashi, T. Inamori, M. Hayashi, O. Takano, Takayama, T. Kawasaki, S. Nagakubo, M. Nakamizu, and K. Yokoi, 2008, Resource Assessment of Methane Hydrate in the Eastern Nankai Trough, Japan, in Proc. 38th Offshore Technology Conference, edited, pp. 19310-MS.

Gerber, T. P., L. F. Pratson, S. Kuehl, J. P. Walsh, C. Alexander, and A. Palmer, 2010, The influence of sea level and tectonics on Late Pleistocene through Holocene sediment storage along the high-sediment supply Waipaoa continental shelf: Marine Geology, v. 270, p. 139159.

Ghosh, R., and K. Sain, 2008, Effective medium modeling to assess gas hydrate and free-gas evident from the velocity structure in the Makran accretionary prism, offshore Pakistan: Marine Geophysical Researches, v. 29, p. 267-274.

Greinert, J., K. B. Lewis, J. Bialas, I. A. Pecher, A. Rowden, D. A. Bowden, M. De Batist, and P. Linke, 2010, Methane seepage along the Hikurangi Margin, New Zealand: Overview of studies in 2006 and 2007 and new evidence from visual, bathymetric and hydroacoustic investigations: Marine Geology, v. 272, p. 6-25. 
Guerin, G., D. Goldberg, and A. Meltser, 1999, Characterization of in situ elastic properties of gas hydrate-bearing sediments on the Blake Ridge: J. Geophys. Res., v. 104, p. 1778117795.

Haq, B. U., 1998, Natural gas hydrates: searching for the long-term climatic and slopestability records: Geological Society special publications, v. 137, p. 303-318.

Hashin, Z., and S. Shtrikman, 1963, A variational approach to the elastc behaviour of multiphase materials: Journal of Mechanics and Physics of Solids, v. 11, p. 127-140.

Helgerud, M., 2001, Wave speeds in gas hydrate and sediments containing gas hydrate: a laboratory and modeling study, Stanford University

Helgerud, M. B., J. Dvorkin, A. Nur, A. Sakai, and T. Collett, 1999, Elastic wave velocity in marine sediments with gas hydrates: Effective medium modeling: Geophys. Res. Lett., v. 26, p. 2021-2024.

Henrys, S. A., D. J. Woodward, and I. A. Pecher, eds., 2009, Variation of bottom-simulatingreflection strength in a high-flux methane province, Hikurangi margin, New Zealand: Natural gas hydrates-Energy resource potential and associated geologic hazards, v. 89, AAPG Memoir, 481-489 p.

Hesse, R., 2003, Pore water anomalies of submarine gas-hydrate zones as tool to assess hydrate abundance and distribution in the subsurface: What have we learned in the past decade?: Earth-Science Reviews, v. 61, p. 149-179.

Hicks, D. M., B. Gomez, and N. A. Trustrum, 2000, Erosion thresholds and suspended sediment yields, Waipaoa River Basin, New Zealand.: Water Resources Research v. 36, p. $1129-1142$.

Hicks, D. M., and U. Shankar, 2003, Sediment from New Zealand Rivers, in N. C. M. Series, ed., Wellington, National Institute of Water \& Atmospheric Research Ltd. . 
Holt, W. E., and A. J. Haines, 1995, The kinematics of northern South Island, New Zealand, determined from geologic strain rates: Journal of Geophysical Research, v. 100, p. 1799118010.

Holbrook, W. S., A. R. Gorman, et al. (2002). Seismic detection of marine methane hydrate. The Leading Edge 21(7): 686-689.

Hunt, J. M., 1979, Petroleum geochemistry and geology: Petroleum geochemistry and geology: San Fransisco, California, W. H. Freeman, 617 p.

Hyndman, R. D., K. Moran, and T. Yuan, 1999, The concentration of deep sea gas hydrates from downhole resistivity logs and laboratory data: Earth Planet Science Letters, v. 172, p. 167-177.

Hyndman, R. D., and G. D. Spence, 1992, A Seismic Study of Methane Hydrate Marine Bottom Simulating Reflectors: J. Geophys. Res., v. 97, p. 6683-6698.

Jean-Yves Collot, Jean Delteil, Keith B. Lewis, Bryan Davy, Geoffroy Lamarche, JeanChristophe Audru, Phil Barnes, Franck Chanier, Eric Chaumillon, Serge Lallemand, Bernard Mercier Lepinay, Alan Orpin, Bernard Pelletier, Marc Sosson, B. Toussaint, and C. Uruski, 1996, From oblique subduction to intra-continental transpression: Structures of the southern Kermadec-Hikurangi margin from multibeam bathymetry, side-scan sonar and seismic reflection: Marine Geophysical Researches, v. 18, p. 357-381.

Julien Bailleul, Cécile Robin, Frank Chanier, François Guillocheau, B. Field, and J. Ferrière, 2007, Turbidite Systems in the Inner Forearc Domain of the Hikurangi Convergent Margin (New Zealand): New Constraints on the Development of Trench-Slope Basins: Journal of Sedimentary Research, v. 77, p. 263-283.

Katz, H. R., 1975, Ariel Bank off Gisborne-an offshore late Cenozoic structure, and the problem of acoustic basement on the east coast, North Island, New Zealand: New Zealand Journal of Geology and Geophysics, v. 18, p. 95-107. 
Katz, H. R., 1982, Plate margin transition from oceanic arc-trench to continental system: The Kermadec-New Zealand example: Tectonophysics, v. 87, p. 49-64.

Kearey, P., M. Brooks, and I. Hill, eds., 2002, An introduction to geophysical exploration, Blackwell Publishing Company.

Kennett J.P, Cannariato K.G, Hendy I.L, and B. R.J., 2002, Methane hydrates in Quaternary climate change: the clathrate gun hypothesis: Washington, American Geophysical Union, 360 p.

Krason, J., 2000, Messoyakh Gas Field (W. Siberia): A Model for Development of the Methane Hydrate Deposits of Mackenzie Delta: Annals of the New York Academy of Sciences, v. 912, p. 173-188.

Kvenvolden, K. A., 1993, Gas hydrates - geological perspective and global change: Reviews of Geophysics, v. 31, p. 173-187.

Kvenvolden, K. A., ed., 1998, A primer on the geological occurrence of gas hydrate: Gas Hydrates: relevance to world margin stability and climate change., v. 137: London, The Geological Society, 338 p.

Kvenvolden, K. A., 1999, Potential effects of gas hydrate on human welfare: Proceedings of the National Academy of Sciences of the United States of America, v. 96, p. 3420-3426.

Kvenvolden, K. A., and L. A. Barnard, eds., 1983, Hydrates in natural gas in contental margins: Studies in contental margin geology, v. 34, AAPG Memoir, 631-640 p.

Kvenvolden, K. A., and G. E. Claypool, 1988, Gas hydrate in oceanic sediment, USGS Open file report, p. 88-216.

Kvenvolden, K. A., and T. D. Lorenson, 2008, A Global Inventory of Natural Gas Hydrate Occurrence, United States Geological Survey. 
Lee, M., 2002, Biot-Gassmann theory for velocities of gas hydrate bearing sediments: Geophysics v. 67, p. 1711-1719.

Lee, M., and T. Collett, eds., 2001 Comparison of elastic velocity models for gas hydratebearing sediments: Natural gas hydrates: occurrence, distribution and detection, v. 124, American Geophysical Union 179-188 p.

Lee, M. W., D. R. Hutchinson, T. S. Collett, and W. P. Dillon, 1996, Seismic velocities for hydrate-bearing sediments using weighted equation: J. Geophys. Res., v. 101, p. 2034720358.

Lewis, K. B., 1973, Erosion and deposition on a tilting continental shelf during Quaternary oscillations of sea level: New Zealand Journal of Geology and Geophysics, v. 16, p. 281-301.

Lewis, K. B., 1997, The succession of seamount impacts and giant avalanches on the Hikurangi margin., in D. N. B. Skinner, ed., Geological Society of New Zealand 1997 annual conference, p. 99.

Lewis, K. B., 2001, Voyage Report TAN0106, Wellington, National Institution of Water and Atmospheric Research.

Lewis, K. B., and P. M. Barnes, 1999, Kaikoura Canyon, New Zealand: active conduit from near-shore sediment zones to trench-axis channel: Marine Geology, v. 162, p. 39-69.

Lewis, K. B., C. Jean-Yves, and E. L. Serge, 1998, The dammed Hikurangi Trough: a channel-fed trench blocked by subducting seamounts and their wake avalanches Basin Research, v. 10, p. 441-468.

Lewis, K. B., and B. A. Marshall, 1996, Seep faunas and other indicators of methane-rich dewatering on New Zealand convergent margins: New Zealand Journal of Geology and Geophysics, v. 39, p. 181 - 200. 
Lewis, K. B., and H. M. Pantin, 2002, Channel-axis, overbank and drift sediment waves in the southern Hikurangi Trough, New Zealand: Marine Geology, v. 192, p. 123-151.

Lewis, K. B., and J. R. Pettinga, 1993, The emerging, imbricate frontal wedge of the Hikurangi Margin.: Sedimentary Basins of the World, v. 2, p. 225-250.

Liu, X., and P. B. Flemings (2007), Dynamic multiphase flow model of hydrate formation in marine sediments, Journal of Geophysical Research., 112.

MacDonald, G. T., 1990b, Role of methane clathrates in past and future climates: Climate Change, v. 16, p. 247-281.

Maslin, M., M. Owen, R. Betts, S. Day, T. D. Jones, and A. Ridgwell, 2010, Gas hydrates: Past and future geohazard?: Philosophical Transactions of the Royal Society A, v. 368, p. 2369-2393.

Mazengarb, C., and I. G. Speden, 2000, Geology of the Raukumara area: Institute of Geological and Nuclear Sciences.

Middleton, G. V., 2003, Encyclopedia of sediments and sedimentary rocks, v. 23, Springer, $821 \mathrm{p}$.

Milkov, A. V., 2004, Global estimates of hydrate-bound gas in marine sediments: how much is really out there?: Earth-Science Reviews, v. 66, p. 183-197.

Miller, J. J., M. W. Lee, and R. von Huene, 1991, An analysis of a seismic reflection from the base of a gas hydrate zone, offshore Peru: AAPG Bulletin, v. 75, p. 910-924.

Milliman, J. D., and J. P. M. Syvitski, 1992, Geomorphic/Tectonic Control of Sediment Discharge to the Ocean: The Importance of Small Mountainous Rivers: The Journal of Geology, v. 100, p. 525-544. 
Minshull, T. A., S. C. Singh, and G. K. Westbrook, 1994, Seismic velocity structure at a gas hydrate reflector, offshore western Colombia, from full waveform inversion: J. Geophys. Res., v. 99, p. 4715-4734.

Moridis, G. J., and M. B. Kowalsky, 2006, Geomechanical implications of thermal stresses on hydrate-bearing sediments, Fire in the Ice, Methane Hydrate R\&D Program Newsletter.

Moridis, G. J., and E. D. Sloan, 2007, Gas Production Potential of Disperse Low-Saturation Hydrate Accumulations in Oceanic Sediments: Journal of Energy Conversion and Management, v. 48, p. 1834-1849.

Nisbet, E. G., 1990, The end of the ice age: Canadian Journal of Earth Sciences, v. 27, p. $148-157$.

Orpin, A. R., 2004, Holocene sediment deposition on the Poverty-slope margin by the muddy Waipaoa River, East Coast New Zealand: Marine Geology, v. 209, p. 69-90.

Orpin, A. R., C. Alexander, L. Carter, S. Kuehl, and J. P. Walsh, 2006, Temporal and spatial complexity in post-glacial sedimentation on the tectonically active, Poverty Bay continental margin of New Zealand: Continental Shelf Research, v. 26, p. 2205-2224.

Page, M. J., N. A. Trustrum, and R. C. DeRose, 1994a, A high resolution record of storm induced erosion from lake sediments, New Zealand: Journal of Paleolimnology v. 11, p. 333348.

Park, K. P., 2008, Gas hydrate exploration activities in Korea: Proceedings of the 6th International Conference on Gas Hydrates, p. 10.

Park, K. P., J.J. Bahk, Y. Kwon, G.Y. Kim, M. Riedel, M.Holland, P. Schultheiss, K. Rose, and UBGH-1 Scientific Party, 2008, Korean national program expedition confirm rich gas hydrate deposits in the Ulleung Basin, East Sea, Fire in the Ice Methane Hydrate Newsletter, p. 6-9. 
Paull, C. K., W. Ussler, III, and W. P. Dillon, 1991, Is the extent of glaciation limited by marine gas hydrates?: Geophysical Research Letters, v. 18, p. 432-434.

Paull, C., R. Matsumoto, and P. J. Wallace, 1996, Initial reports - Gas Hydrate sampling on the Blake Ridge and Carolina Rise: Proceedings of the Ocean Drilling Program, p. 623.

Pearson, C., Murphy, J. and Hermes, R. (1986). "Acoustic and resistivity measurements on rock samples containing tetrahydrofuran hydrates: laboratory analogues to natural gas hydrate deposits." Journal of Geophysical Research 91(14): 14132-14138.

Pecher, I. A., and S. A. Henrys, 2003, Potential gas reserves in gas hydrate sweet spots on the Hikurangi margin, New Zealand, Institute of Geological and Nuclear Sciences science report, Institute of Geological and Nuclear Sciences, p. 36.

Pecher, I. A., S. A. Henrys, S. Ellis, S. M. Chiswell, and N. Kukowski, 2005, Erosion of the seafloor at the top of the gas hydrate stability zone on the Hikurangi Margin, New Zealand: Geophys. Res. Lett., v. 32, p. L24603.

Pecher, I.A., and the GHR Working Group, Gas Hydrates in New Zealand - A Large Resource for a Small Country? Fire in the Ice newsletter, U.S. Dept. of Energy, 2011.

Pedley, K. L., P. M. Barnes, J. R. Pettinga, and K. B. Lewis, 2010, Seafloor structural geomorphic evolution of the accretionary frontal wedge in response to seamount subduction, Poverty Indentation, New Zealand: Marine Geology, v. 270, p. 119-138.

Peter G. Brewer, J. Franklin M. Orr, Gernot Friederich, Keith A. Kvenvolden, Daniel L. Orange, James McFarlane, and W. Kirkwood, 1997, Deep-ocean field test of methane hydrate formation from a remotely operated vehicle: Geology, v. 25, p. 407 - 410.

Petersen, C., C. Papenberg, and D. Klaeschen, 2007, Local seismic quantification of gas hydrates and BSR characterization from multi-frequency OBS data at northern Hydrate Ridge: Earth planet sceince letters, v. 255, p. 414-431. 
Raynaud, D., J. Chapellaz, and T. Blunier, 1998, Ice-core record of atmospheric methane changes: relevance to climatic changes and possible gas hydrate sources.: Geological Society special publications, v. 137, p. 327-331.

Reid, C., 1999, Waipaoa River at Kanakanaia: a review of flood data, Gisborne District Council, p. 52.

Reyners, M., and P. McGinty, 1999, Shallow subduction tectonics in the Raukumara Peninsula, New Zealand, as illuminated by earthquake focal mechanisms: Journal of Geophysical Research, v. 104, p. 3025-3034.

Riedel, M., E. Willoughby, M. Chen, T. He, I. Novosel, K. Schwalenberg, R. Hyndman, G. Spence, N. Chapman, and R. Edwards, eds., 2006, Gas hydrate on the northern Cascadia margin: regional geophysics and structural frame work. : The Expedition 311 Scientists (eds) Proceedings of the Integrated Ocean Drilling Program, v. 311.

Ruppel, C., Boswell, R., and Jones, E., 2008, Scientific results from Gulf of Mexico Gas Hydrates Joint Industry Project Leg 1 drilling; introduction and overview: Marine and Petroleum Geology, November 2008, v. 25, no. 9.

Sassen, R., and MacDonald, I.R., 1994, Evidence of structure H hydrate, Gulf of Mexico continental slope: Organic Geochemistry, v. 23p. 1029-1032.

Shedd, W., M. Frye, P. Godfriaux, R. Boswell, and D. R. Hutchinson, 2009, Occurrence and variety in expression of the base of gas hydrate stability in the Gulf of Mexico, USA: Fire in the Ice, v. Winter 2009, p. 11-14.

Sheriff, R. E., and L. P. Geldart, eds., 1995, Exploration Seismology, Cambridge university press, $592 \mathrm{p}$.

Shine, K. P., 1991, Climatic effects of carbon dioxide and methane releases: Teaching Earth Science, v. 16, p. 17-20. 
Shipley, T. H., M. H. Houston, R. T. Buffler, F. J. Shaub, K. J. McMillen, J. W. Ladd, and J. L. Worzel, 1979, Seismic evidence for widespread possible gas hydrate horizons on continental slopes and rises: AAPG Bulletin, v. 63, p. 2204-2213.

Sloan, E. D., ed., 1998a, Clathrate Hydrates of Natural Gas, CRC Press, 705 p.

Sloan, E. D., ed., 1998b, Physical/Chemical properties of gas hydrates and application to world margin stability and climate change. : Gas Hydrates: relevance to world margin stability and climate change., v. 137 London, The Geological Society, 338 p.

Smith, W. H. F., and D. T. Sandwell, 1997, Global Sea Floor Topography from Satellite Altimetry and Ship Depth Soundings: Science, v. 277, p. 1956-1962.

Stoll, R. D., and G. M. Bryan, 1979, Physical Properties of Sediments Containing Gas Hydrates: J. Geophys. Res., v. 84, p. 1629-1634.

Suess, I., G. Bohrmann, G. J., and L. E., 1999, Methane hydrates: Flammable ice: Scientific American, v. 281, p. 76-83.

Townend, J., 1997, Estimates of conductive heat flow through bottom-simulating reflectors on the Hikurangi and southwest Fiordland continental margins, New Zealand: Marine Geology, v. 141, p. 209-220.

Tréhu AM, C Ruppel, M Holland, GR Dickens, ME Torres, TS Collett, D Goldberg, M Riedel, and P. Schultheiss., 2006, Gas hydrates in marine sediments: lessons from scientific ocean drilling.: Oceanography, v. 19, p. 124-143.

Trofimuk, A. A., N. V. Cherskiy, and V. P. Tsarev, 1973, Accumulation of natural gases in zones of hydrate - formation in the hydrosphere: Dokl. Akad. Nauk SSSR v. 212, p. 931934.

Tsuji, Y., Ishida, H., Nakamizu, M., Matsumoto, R. and Shimizu, S., 2004. Overview of the MITI Nankai Trough wells: a milestone in the evaluation of methane hydrate resources. 
Resource Geology, 54, 3-10.

Walcott, R. I., 1978, Present tectonics and Late Cenozoic evolution of New Zealand: Geophysical Journal of the Royal Astronomical Society, v. 52, p. 137-164.

Wallace, L. M., J. Beavan, R. McCaffrey, and D. Darby, 2004, Subduction zone coupling and tectonic block rotations in the North Island, New Zealand: J. Geophys. Res., v. 109, p. B12406.

Walsh, J. P., C. R. Alexander, T. Gerber, A. R. Orpin, and B. W. Sumners, 2007, Demise of a submarine canyon? Evidence for highstand infilling on the Waipaoa River continental margin, New Zealand: Geophysical Research Letters, v. 34, p. L20606.

Warner, M., 1990, Absolute reflection coefficients from deep Seismic reflections: Tectonophysics, v. 173, p. 15-23.

Winters W. J., Pecher I. A., Waite W. F., and M. D. H, 2004, Physical properties and rock physics models of sediment containing natural and laboratory-formed methane gas hydrate.: American Minerologist, v. 89, p. 1221-1227.

Wood, W. T., P. L. Stoffa, and T. H. Shipley, 1994, Quantitative detection of methane hydrate through high-resolution seismic velocity analysis: J. Geophys. Res., v. 99, p. 96819695.

Wu, N., S. Yang, H. Zhang, J. Liang, H. Wang, X. Su, and S. Fu, 2008, Preliminary discussion on gas hydrate reservoir system of Shenhu area, North Slope of South China Sea: Proceedings of the 6th International Conference on Gas Hydrates, p. 10.

Xu, W., and C. Ruppel, 1999, Predicting the occurrence, distribution, and evolution of methane gas hydrate in porous marine sediments: J. Geophys. Res., v. 104, p. 5081-5095.

Yang, S., H. Zhang, N. Wu, X. Su, P. Schultheiss, M.Holland, G. Zhang, J. Liang, J. Lu, and K. Rose, 2008, High concentration hydrate in disseminated forms obtained in Shenhu area, 
North Slope of South China Sea: Proceedings of the 6th International Conference on Gas Hydrates, p. 10.

Yilmaz, O., ed., 2001, Seismic Data Analysis, Society of Exploration Geophysicists, 2027 p.

Zhang, H. and Brown, R.J. 2001, A review of AVO analysis, CREWES Research Report, Volume 13.

Zhang, H., S. Yang, N. Wu, and P. Schultheiss, 2007a, China's first gas hydrate drilling expedition: Fire in the Ice Methane Hydrate Newsletter.

Zhang, H., S. Yang, N. Wu, X. Su, M. Holland, and P. Schultheiss, 2007b, Successful and surprising results for China's first gas hydrate drilling expedition: Fire in the Ice Methane Hydrate Newsletter. 